VLADIMIR EMILIANO MOREIRA ROCHA

\title{
Uma Arquitetura Escalável para Recuperação e Atualização de Informações com Relação de Ordem Total
}


VLADIMIR EMILIANO MOREIRA ROCHA

\section{Uma Arquitetura Escalável para Recuperação e Atualização de Informações com Relação de Ordem Total}

Tese apresentada à Escola Politécnica da Universidade de São Paulo para obtenção do título de Doutor em Ciências. 
VLADIMIR EMILIANO MOREIRA ROCHA

\section{Uma Arquitetura Escalável para Recuperação e Atualização de Informações com Relação de Ordem Total}

Tese apresentada à Escola Politécnica da Universidade de São Paulo para obtenção do título de Doutor em Ciências.

Área de concentração:

Engenharia da Computação

Orientador:

Profa. Dra. Anarosa Alves Franco Brandão 
Este exemplar foi revisado e corrigido em relação à versão original, sob responsabilidade única do autor e com a anuência de seu orientador.

São Paulo, de de

Assinatura do autor:

Assinatura do orientador:

Catalogação-na-publicação

Rocha, Vladimir Emiliano Moreira

Uma Arquitetura Escalável para Recuperação e Atualização de Informações com Relação de Ordem Total / V. E. M. Rocha -- versão corr. -- São Paulo, 2017. $153 \mathrm{p}$.

Tese (Doutorado) - Escola Politécnica da Universidade de São Paulo. Departamento de Engenharia de Computação e Sistemas Digitais.

1.Sistemas Multiagentes 2.Tabela de Hash Distribuída 3.Arquitetura de Software 4.Arquitetura e Organização de Computadores I.Universidade de São Paulo. Escola Politécnica. Departamento de Engenharia de Computação e Sistemas Digitais II.t. 


\section{AGRADECIMENTOS}

Primeiro agradeço a Deus pela vida e pela saúde. Tanto a minha quanto a dos que me rodeiam.

Agradeço aos meus pais por todo o carinho e apoio que sempre recebi deles, esse apoio e carinho incondicional. Obrigado papis por estarem sempre junto de mi, não importando quão difícil fosse a situação.

Agradeço à minha orientadora. Obrigado professora Anarosa porque você me fez sentir o mesmo carinho de uma mãe e de uma amiga. Para ser sincero, você foi essa força e essa fonte de luz que me permitiu concluir esse ciclo na minha vida. Faço extensivo também o agradecimento ao seu esposo o professor Leônidas pelas gratas conversas nas horas do café.

Agradeço também aos professores do LTI, professora Anna e professor Jaime. Agradeço porque conseguiram criar uma família no laboratório. E não somente por isso, mas pelo carinho acolhedor que sempre senti de vocês ao longo do doutorado.

Dos meus antigos amigos, imagino que passaria o dia todo escrevendo a quantidade de momentos felizes que tive com vocês. Mesmo assim, não poderia deixar de mencionar o Edu, Thiaguin, Christian, Jesús Mena, Arlindo, Marcos e Carola (hoje todos longe de casa). Obrigado por tudo mesmo.

Dos meus novos amigos, obrigado João, Leandro, Arthur, Silvia, Igor, Felipe, Ruben e tantos outros. Levarei todas as boas lembranças comigo. 


\section{RESUMO}

Desde o início do século XXI, vivenciamos uma explosão na produção de informações de diversos tipos, tais como fotos, áudios, vídeos, entre outros. Dentre essas informações, existem aquelas em que a informação pode ser dividida em partes menores, mas que devem ser relacionadas seguindo uma ordem total. Um exemplo deste tipo de informação é um arquivo de vídeo que foi dividido em dez segmentos identificados com números de 1 a 10 . Para reproduzir o vídeo original a partir dos segmentos é necessário que seus identificadores estejam ordenados. A estrutura denominada tabela de hash distribuída (DHT) tem sido amplamente utilizada para armazenar, atualizar e recuperar esse tipo de informação de forma eficiente em diversos cenários, como monitoramento de sensores e vídeo sob demanda. Entretanto, a DHT apresenta problemas de escalabilidade quando um membro da estrutura não consegue atender as requisições recebidas, trazendo como consequência a inacessibilidade da informação. Este trabalho apresenta uma arquitetura em camadas denominada MATe, que trata o problema da escalabilidade em dois níveis: estendendo a DHT com a introdução de agentes baseados na utilidade e organizando a quantidade de requisições solicitadas. A primeira camada trata a escalabilidade ao permitir a criação de novos agentes com o objetivo de distribuir as requisições evitando que um deles tenha a escalabilidade comprometida. A segunda camada é composta por grupos de dispositivos organizados de tal forma que somente alguns deles serão escolhidos para fazer requisições. A arquitetura foi implementada para dois cenários onde os problemas de escalabilidade acontecem: (i) monitoramento de sensores; e (ii) vídeo sob demanda. Para ambos cenários, os resultados experimentais mostraram que MATe melhora a escalabilidade quando comparada com as implementações originais da DHT.

Palavras-chave: Sistemas multiagentes. Tabela de Hash Distribuída, Agregação de Dados. 


\begin{abstract}
Since the beginning of the 21st century, we have experienced an explosive growth in the generation of information, such as photos, audios, videos, among others. Within this information, there are some in which the information can be divided and related following a total order. For example, a video file can be divided into ten segments identified with numbers from 1 to 10 . To play the original video from these segments, their identifiers must be fully ordered. A structure called Distributed Hash Table (DHT) has been widely used to efficiently store, update, and retrieve this kind of information in several application domains, such as video on demand and sensor monitoring. However, DHT encounters scalability issues when one of its members fails to answer the requests, resulting in information loss. This work presents MATe, a layered architecture that addresses the problem of scalability on two levels: extending the DHT with the introduction of utility-based agents and organizing the volume of requests. The first layer manages the scalability by allowing the creation of new agents to distribute the requests when one of them has compromised its scalability. The second layer is composed of groups of devices, organized in such a way that only a few of them will be chosen to perform requests. The architecture was implemented in two application scenarios where scalability problems arise: (i) sensor monitoring; and (ii) video on demand. For both scenarios, the experimental results show that MATe improves scalability when compared to original DHT implementations.
\end{abstract}

Keywords: Multiagent systems. Distributed Hash Table. Data Aggregation. 


\section{LISTA DE FIGURAS}

1 Classificações do Tempo. . . . . . . . . . . . . . . . . . . . . . . . . . . 10

2 Curva de Hilbert. . . . . . . . . . . . . . . . . . . . . . . . . 12

3 Arquitetura cliente/servidor. . . . . . . . . . . . . . . . . . . . . 15

4 Arquitetura P2P. . . . . . . . . . . . . . . . . . . . . . 16

5 Propagação controlada nas arquiteturas P2P. . . . . . . . . . . . . . . . . 18

6 Transformação da tabela de hash normal a uma distribuída. . . . . . . . . 20

$7 \quad$ Tabela de roteamento do nó com identificador $25 \ldots \ldots 22$

8 Busca na estrutura de anel com oito nós. . . . . . . . . . . . . . . . . . 22

9 Rede de sensores baseadas em grupos. . . . . . . . . . . . . . . . . . 23

10 Sistema distribuído de três camadas, inspirado de Abdelwahab (ABDELWAHAB et al., 2015). . . . . . . . . . . . . . . . . . . . . 30

11 Arquitetura de duas camadas da ADHT, inspirado de (HARJULA et al., 2014).

12 Arquitetura de duas DHT do C2WSN, inspirado de (YU; LIU; SONG,

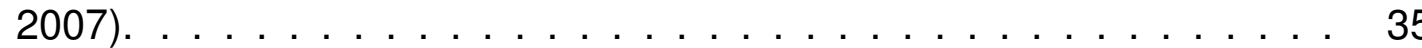

13 Camada de Agentes e Dispositivos. . . . . . . . . . . . . . . . . . 46

14 Camada de Dispositivos. . . . . . . . . . . . . . . . . . . . . . . 49

15 Arquitetura Interna do Dispositivo, traduzida de (ROCHA; BRANDãO, 2015). . . . . . . . . . . . . . . . . . . . 52

16 Atividade de Divisão, traduzida de (ROCHA; BRANDãO, 2016). . . . . . 55

17 Arquitetura interna de três agentes traduzida de (ROCHA; BRANDãO, 2015). . . . . . . . . . . . . . . . 56

18 Relacionamentos de Salto do Agente. . . . . . . . . . . . . . . . . . 58 
19 Relacionamentos de saltos modificados. . . . . . . . . . . . . . . 61

20 Processo de Modelagem das Camadas. . . . . . . . . . . . . . . 67

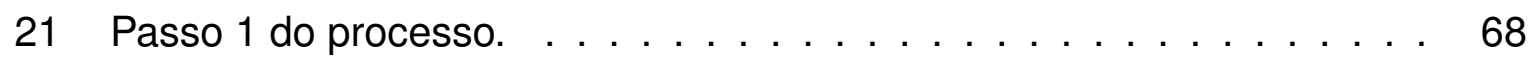

22 Passo 2 do processo. . . . . . . . . . . . . . . . . . 69

23 Passo 3 do processo. . . . . . . . . . . . . . . . . . 70



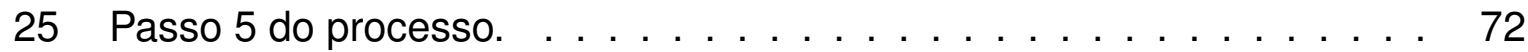

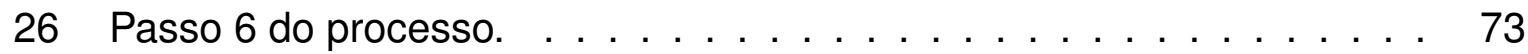

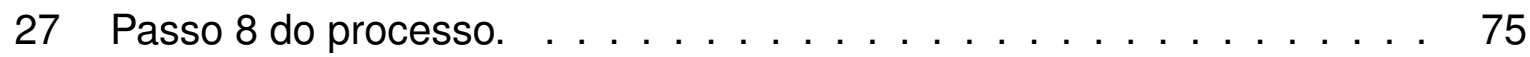

28 Cenário de Vídeo sob Demanda. . . . . . . . . . . . . . . . . . . . . 80

29 Fronteira de uma borda. . . . . . . . . . . . . . . . . . . . . . 83

30 Testes de eficiência sem modificação nos agentes da estrutura. . . . . 89

31 Testes de eficiência com saída de 10\% de agentes da estrutura. . . . . 90

32 Teste de eficiência na modificação dos relacionamentos de saltos. . . . 91

33 Teste de escalabilidade nas requisições enviadas e atendidas. . . . . . 93

34 Teste de escalabilidade no tempo para responder as requisições. . . . . 94

35 Teste de escalabilidade na recepção de requisições por agente. . . . . 96

36 Bordas em biodiversidade . . . . . . . . . . . . . . . . . . . 99

37 Bordas em mobilidade humana . . . . . . . . . . . . . . . . . . . 101

38 Percentual de dispositivos na borda em mobilidade humana. . . . . . 102

39 Percentual de dispositivos na borda em mobilidade de veículos. . . . . 104



41 Métrica do tempo de espera . . . . . . . . . . . . . . . . . . 107

42 Métrica do estresse do servidor. . . . . . . . . . . . . . . . . . . . . 108

43 Métrica do tempo de inicialização. . . . . . . . . . . . . . . . . . 109 
44 Algoritmo de atualização da fronteira. . . . . . . . . . . . . . 125

45 Algoritmo de divisão da borda. . . . . . . . . . . . . . . . . . 125

46 Algoritmo de atualização de conexões. . . . . . . . . . . . . . . 126

47 Algoritmo de agentificação. . . . . . . . . . . . . . . . . . . 127

48 Algoritmo de busca por uma localização. . . . . . . . . . . . . . . . 128

49 Algoritmo de monitoramento do grupo. . . . . . . . . . . . . 128

50 Algoritmo de atualização da fronteira. . . . . . . . . . . . . . . . . . 129

51 Algoritmo de junção de grupos. . . . . . . . . . . . . . . . . . . . 129

52 Algoritmo de separação do grupo (verificação). . . . . . . . . . . . 130

53 Algoritmo de divisão do grupo. . . . . . . . . . . . . . . . . . . 131

54 Algoritmo de separação do grupo. . . . . . . . . . . . . . . . . 134

55 Divisão do grupo. . . . . . . . . . . . . . . . . . . . . . 135

56 Casos a-d na divisão do grupo. . . . . . . . . . . . . . . . . . 135

57 Algoritmo de separação do grupo. . . . . . . . . . . . . . . 136

58 Divisão do grupo. . . . . . . . . . . . . . . . . . . . . . . . . 137 


\section{LISTA DE TABELAS}

1 Definição da tabela de roteamento de um nó $p \ldots \ldots$. . . . . . . . . 21 


\section{LISTA DE ABREVIAÇÕES}

$\begin{array}{ll}\text { CPU } & \text { Central Processing Unit } \\ \text { DHT } & \text { Distributed Hash Table } \\ \text { GM } & \text { Group Master } \\ \text { GPS } & \text { Global Positioning System } \\ \text { IP } & \text { Internet Protocol } \\ \text { P2P } & \text { Peer-to-Peer } \\ \text { RAM } & \text { Random Access Memory } \\ \text { TTL } & \text { Time-To-Live } \\ \text { VoD } & \text { Video on Demand }\end{array}$




\section{SUMÁRIO}

1 Introdução 1

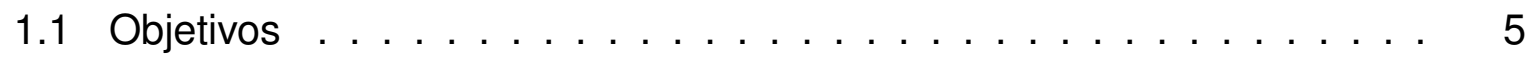

1.2 Método .............................. 6

1.3 Estrutura do documento . . . . . . . . . . . . . . . . . . . . . 7

2 Conceitos e cenários de aplicação $\quad 8$

2.1 Escalabilidade e Eficiência . . . . . . . . . . . . . . . . . . . 8

2.2 Informação com relação de ordem total . . . . . . . . . . . . . . . . 8

2.2.1 Informações dependentes do tempo . . . . . . . . . . . . . . . 9

2.2.2 Informações dependentes do espaço euclidiano . . . . . . . . . 9

2.3 Cenários utilizados no trabalho . . . . . . . . . . . . . . . . 11

2.3.1 Monitoramento de sensores . . . . . . . . . . . . . . . . . . . . 11

2.3.2 Video sob demanda . . . . . . . . . . . . . . . . . . . . . 13

3 Referencial Teórico $\quad 15$

3.1 Arquitetura Cliente/Servidor . . . . . . . . . . . . . . . . . . . 15

3.2 Arquitetura Peer-to-Peer . . . . . . . . . . . . . . . . . . . . 16

3.3 Tabela de Hash Distribuída . . . . . . . . . . . . . . . . . . . . . . . . . 18

3.4 Agregação de Dados . . . . . . . . . . . . . . . . . . . . . . 23

3.5 Sistemas Multiagentes . . . . . . . . . . . . . . . . . . . . . . . . . . . . 24

4 Trabalhos Relacionados $\quad 27$

4.1 Monitoramento de sensores . . . . . . . . . . . . . . . . . . . . 27

4.1 .1 Sistemas multiagentes . . . . . . . . . . . . . . . . 27 
4.1 .2 Agregação de dados . . . . . . . . . . . . . . . . 32

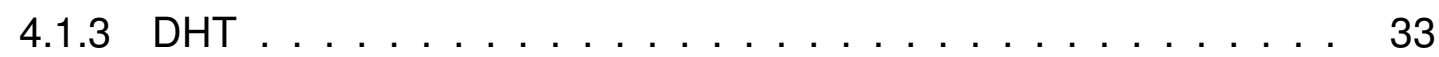

4.2 Vídeo sob demanda . . . . . . . . . . . . . . . 37

4.2.1 Sistemas multiagentes . . . . . . . . . . . . . 37

$4.2 .2 \mathrm{DHT} \ldots \ldots \ldots \ldots \ldots \ldots \ldots \ldots \ldots \ldots \ldots \ldots$

5 Arquitetura $\quad 45$

5.1 Visão geral . . . . . . . . . . . . . . . . . 45

5.2 Conceitos relacionados aos dispositivos . . . . . . . . . 47

5.3 Conceitos relacionados aos agentes $\ldots \ldots \ldots \ldots \ldots \ldots$

5.4 Camada de dispositivos . . . . . . . . . . . . . . . . . 51

5.4.1 Arquitetura interna do dispositivo . . . . . . . . . 51

5.4 .2 Caracterizando dispositivos da fronteira . . . . . . . . . 53

5.4.3 Responsabilidades dos dispositivos da fronteira $\ldots \ldots \ldots$

5.5 Camada multiagentes . . . . . . . . . . . . . 55

5.5 .1 Arquitetura interna do agente $\ldots \ldots \ldots \ldots 6$

5.5 .2 Buscando um agente $\ldots \ldots \ldots \ldots \ldots \ldots$

5.5 .3 Responsabilidades do agente . . . . . . . . . . . . . . 59

5.6 Análise da arquitetura $\ldots \ldots \ldots \ldots \ldots \ldots \ldots \ldots$

5.6.1 Análise da camada de dispositivos . . . . . . . . . 63

5.6.2 Análise da camada de agentes . . . . . . . . . . . 64

6 Ciclo de Vida da Arquitetura 66

$\begin{array}{lll}7 & \text { Instanciando a Arquitetura } & 76\end{array}$

7.1 Arquitetura para o cenário de monitoramento de sensores . . . . . . 76 
7.1 .1 Visão geral . . . . . . . . . . . . . . . . 76

7.1 .2 Conceitos . . . . . . . . . . . . . . . 77

7.1 .3 Camada de dispositivos . . . . . . . . . . . . 77

7.1 .4 Camada de agentes . . . . . . . . . . . . . 78

7.2 Arquitetura para o cenário de vídeo sob demanda . . . . . . . . . 79

7.2 .1 Visão geral . . . . . . . . . . . . . . . . . 79

7.2 .2 Conceitos . . . . . . . . . . . . . . . . 80

7.2.3 Camada de dispositivos . . . . . . . . . . . . . 82

7.2 .4 Camada de agentes . . . . . . . . . . . . . . 83

7.3 Análise da instanciação da arquitetura . . . . . . . . . . . . . 84

8 Resultados Experimentais $\quad 85$

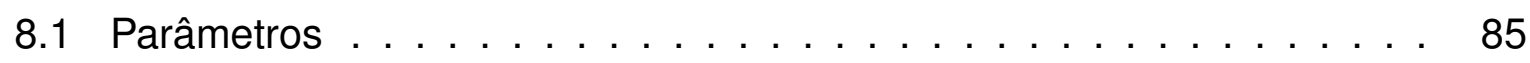

8.2 Testes relativos à eficiência $\ldots \ldots \ldots \ldots \ldots \ldots$

8.3 Testes relativos à escalabilidade $\ldots \ldots \ldots \ldots \ldots \ldots$

8.4 Monitoramento de sensores . . . . . . . . . . . . . . 96

8.5 Vídeo sob demanda . . . . . . . . . . . . . . . . . 103

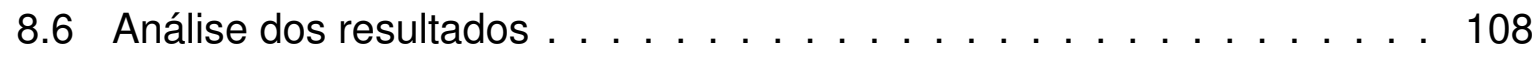

9 Conclusão e trabalhos futuros $\quad 111$

9.1 Contribuições . . . . . . . . . . . . . . . . . . . . . 112

9.2 Publicações . . . . . . . . . . . . . . . . . . . . . . . . 112

9.3 Trabalhos futuros $\ldots \ldots \ldots \ldots \ldots \ldots \ldots \ldots \ldots$

$\begin{array}{ll}\text { Referências } & 115\end{array}$

Apêndice A - Construção da Arquitetura $\quad 124$ 
A.1 Construção das responsabilidades do dispositivo . . . . . . . . . . . . . 124

A.2 Construção das responsabilidades do agente . . . . . . . . . . . . . 126

Apêndice B - Construção da separação de um grupo 132

B.1 Cenário de monitoramento de sensores . . . . . . . . . . . . . . . . 132

B.2 Cenário de vídeo sob demanda . . . . . . . . . . . . . . . . . . . 133 


\section{INTRODUÇÃO}

$\mathrm{Na}$ denominada era da informação, estamos vivenciando uma explosão na produção de informação. Diariamente são produzidos milhares de Petabytes de informação em fotos, áudios, vídeos, documentos, entre outros (CISCO, 2015).

Em se tratando das informações, existem algumas delas cuja particularidade é a possibilidade de dividi-las em partes menores e ordená-las de acordo com algum critério (TANENBAUM; STEEN, 2006). Tome por exemplo um arquivo de vídeo que foi dividido em dez segmentos identificados com números do 1 a 10. Note que para reproduzir o vídeo original, a partir dos segmentos, é necessário que estes estejam ordenados de acordo com o identificador do segmento. Essas informações, quando é possível dividi-las e ordená-las totalmente de acordo com uma relação ${ }^{1}$, são denominadas de informações com relação de ordem total.

Dado que essas informações podem influenciar decisões ou gerar conhecimentos que afetem o mundo como um todo, faz-se necessário desenvolver sistemas computacionais que facilitem o acesso a elas (PAL, 2008).

Para facilitar o acesso, diversos aspectos foram considerados na criação desses sistemas, dentre eles, onde armazenar a informação e como localizá-la. Uma das primeiras alternativas para atender os aspectos de localização e armazenamento da informação foi a utilização da arquitetura cliente/servidor (SINHA, 1992). Nesta arquitetura, um computador poderoso em termos de capacidade de armazenamento, processamento e largura de banda (denominado servidor) é dedicado a servir como provedor dos serviços de localização e armazenamento de informações para os demais computadores menos poderosos (denominados clientes). Nesse contexto, toda informação produzida pelos clientes é enviada ao servidor para ser armazenada. Por sua vez, o servidor é encarregado de receber e armazenar as informações e responder às requisições de busca e atualização dessas informações realizadas pelos clientes.

Desde sua criação, a arquitetura cliente/servidor tornou-se muito eficiente para localizar uma informação, visto que todas as informações estão centralizadas no ser-

\footnotetext{
${ }^{1}$ No caso, utilizando a relação "maior que" para identificadores numéricos.
} 
vidor. Por outro lado, percebeu-se que a arquitetura atendia um número limitado de requisições. A partir desse limite, as requisições de novos clientes diminuíam o desempenho do servidor até o ponto de deixá-lo inacessível para atender qualquer requisição. Para resolver este problema, foi necessário desenvolver arquiteturas capazes de se adaptar a uma demanda crescente de clientes sem diminuir seu desempenho. Nascia assim o conceito de arquitetura escalável (BONDI, 2000).

Com o aumento da demanda originada pelos clientes, cresceu a necessidade de arquiteturas mais escaláveis que a cliente/servidor. Tais arquiteturas não deveriam depender somente de um servidor para armazenar e localizar todas as informações.

Dentre as várias arquiteturas propostas, as arquiteturas P2P (ORAM, 2001) (Peerto-Peer) têm como principal característica a possibilidade de qualquer peer (também denominado nó) atuar como cliente e como servidor. Nesse contexto, o nó pode tanto armazenar as informações quanto realizar e receber requisições dessas informações.

Nas arquiteturas P2P, cada nó é responsável por gerenciar um conjunto de toda a informação produzida, o que as torna mais escaláveis que a arquitetura cliente/servidor. Entretanto, como a informação está distribuída nos nós, a localização eficiente de uma determinada informação passou a ser uma questão importante a ser considerada (LEUF, 2002).

Uma das estruturas mais utilizadas para localizar uma informação nas arquiteturas P2P é a tabela de hash distribuída (CASTRO et al., 2003) (DHT - Distributed Hash Table). A tabela de hash distribuída é uma estrutura que permite a realização das funções de uma tabela de hash normal, ou seja, nela pode-se armazenar um valor, dada uma chave, e procurar por esse valor utilizando a chave. Na DHT, os nós se organizam para serem responsáveis por um conjunto disjunto de chave/valor (por disjunto entenda-se que uma chave/valor só será gerenciada por um nó) o que torna a estrutura mais escalável que uma arquitetura cliente/servidor. Por outro lado, a eficiência na localização é reduzida pois a busca deve ser realizada em uma coleção de nós e não só em um, como no caso da arquitetura cliente/servidor (TANENBAUM; WETHERALL, 2010).

Pela sua escalabilidade e relativa eficiência, diversos domínios de aplicação utilizam a DHT para gerenciar as informações distribuídas nos nós (YIU; JIN; CHAN, 2007; 
ALI; UZMI, 2004). Um dos cenários desses domínios é o de vídeo sob demanda, que permite aos usuários assistirem um vídeo. Nesse cenário, o vídeo é particionado em segmentos, onde cada um é identificado com um número, que representa um intervalo de tempo. Por exemplo, o segmento com identificador 1 representa o intervalo do segundo 1 ao 10 . Já o segmento com identificador 2 representa o intervalo do segundo 11 ao 20. Nesse contexto, os sistemas desse cenário armazenam na DHT o identificador do segmento (como chave), associado a uma lista de endereços IP dos usuários que baixaram o segmento (como valor).

Entretanto, no cenário de vídeo sob demanda, a DHT sofre de um sério problema de escalabilidade. O problema surge quando todos os usuários buscam por um segmento específico (e.g., o primeiro segmento ou um segmento popular) e o nó, responsável pelo segmento, não consegue atender todas as requisições de busca. Assim, a estrutura deixa de ser escalável, pois o nó passa a ter o mesmo comportamento do servidor da arquitetura cliente/servidor.

Para endereçar o problema da escalabilidade, nossa primeira pesquisa (ROCHA; BRANDãO, 2015) resolveu o problema permitindo que os nós da estrutura pudessem distribuir as requisições. Para isso, os nós da DHT foram estendidos com a introdução de agentes reativos simples, onde cada um seria responsável pelo gerenciamento de um conjunto de segmentos (não necessariamente disjunto, como na DHT). Assim, quando um usuário solicitasse um segmento, este seria obtido de qualquer agente responsável por gerenciá-lo.

A seguir, como questionamento de pesquisa nos perguntamos: qual é a característica comum das informações que são gerenciadas nos domínios de aplicação que utilizam a DHT? A característica comum encontrada nesses domínios é que as informações gerenciadas possuem uma relação de ordem total entre elas, seja considerando a dependência do tempo ou do espaço.

No caso da dependência do tempo, mencionamos anteriormente que as informações (segmentos que representam intervalos de tempo) estão ordenadas de acordo com um identificador que representa esse intervalo, que permite encontrar de forma eficiente o próximo segmento a ser assistido pelo usuário. Além dos cenários de vídeo sob demanda, podemos citar como exemplo os de voz sobre IP (SINGH; SCHULZ- 
RINNE, 2005), de streaming de vídeo (YIU; JIN; CHAN, 2007), de compartilhamento de arquivos (WANG; KANGASHARJU, 2013), entre outros.

No caso da dependência do espaço, os cenários têm como objetivo monitorar os dispositivos móveis localizados em determinadas regiões do espaço (e.g., sensores de posição dos telefones celulares das pessoas nos arredores de um estádio). Por dispositivos nos referimos aos objetos reais ou virtuais, como sensores, atuadores, computadores, telefones celulares, entre outros, que se movimentam no tempo e no espaço e podem sentir, calcular e se comunicar com outros dispositivos, como definido em (BORGIA, 2014). Como cada região possui uma identificação única que a representa, os sistemas desses cenários armazenam na DHT o identificador da região (como chave), associado a uma lista de informações dos dispositivos localizados nessa região (como valor).

Cabe destacar que, assim como as informações dependentes do tempo, as informações dependentes do espaço também possuem uma ordenação. Nesse sentido, a ordenação vem dada pelo identificador da região, que permite encontrar de forma eficiente os setores adjacentes à localização do dispositivo quando o mesmo se movimenta entre eles. Como exemplo desses cenários podemos citar os de localização de biodiversidade (DRESSLER et al., 2016), de rastreamento de objetos (WU et al., 2012), de monitoramento do ecossistema (IANCU; STEGARU; TUDOSE, 2016), entre outros.

Nos cenários de monitoramento, a DHT sofre do mesmo problema de escalabilidade mencionado no vídeo sob demanda. Isso acontece quando todos os dispositivos de uma determinada região atualizam suas informações e o nó encarregado pela região não consegue atender às requisições de atualização. Entretanto, no cenário de monitoramento, faz-se necessário organizar as requisições dado que a quantidade de dispositivos que podem atualizar suas informações é muito maior que a de usuários de vídeo. Segundo a CISCO (CISCO, 2015), existem aproximadamente 15 bilhões de dispositivos conectados a Internet enquanto que segundo Van der Sar (Ernesto Van der Sar, 2016), existem aproximadamente 30 milhões de usuários baixando vídeos.

Para endereçar o problema da escalabilidade nos cenários de monitoramento, nossa segunda pesquisa (ROCHA; BRANDãO, 2016) estendeu a pesquisa anterior 
em dois níveis: transformando dispositivos em agentes baseados na utilidade, para que pudessem fazer parte da DHT, e organizando a quantidade de requisições solicitadas.

No nível dos agentes, um agente cria novos agentes (também denominado de agentificação, na qual transforma-se dispositivos em agentes) para distribuir as requisições quando sua escalabilidade está comprometida. Com a transformação, tanto o dispositivo transformado em agente quanto o agente que o transformou serão responsáveis por gerenciar as requisições por uma determinada informação, tarefa antes realizada somente por um agente. No nível dos dispositivos, estes são agrupados e organizados de tal forma que somente alguns deles serão encarregados por agregar as informações de outros dispositivos e enviá-las ao agente. Com isso, o agente recebe uma menor quantidade de requisições, consequentemente aumentando sua escalabilidade.

\subsection{Objetivos}

O principal objetivo da pesquisa é definir uma arquitetura que aumente a escalabilidade em domínios que utilizam a DHT para buscar e atualizar constantemente as informações armazenadas na estrutura. O objetivo é guiado pelas seguintes questões de pesquisa (QP) abordadas nesse trabalho:

QP1 É possível aumentar a escalabilidade da DHT, quando uma grande quantidade de nós realizam requisições nela, sem alterar seu desempenho? Como?

QP2 É possível criar uma arquitetura que possa ser reutilizada em diversos domínios de aplicação? Como?

Esta arquitetura é composta por duas camadas de software que permitem a atualização escalável de informações com relação de ordem total, mantendo a eficiência da DHT na localização das mesmas.

Uma camada, denominada multiagentes, é composta por agentes de software baseados na utilidade (RUSSELL; NORVIG, 2009) encarregados de gerenciar tanto uma 
informação quanto os grupos de dispositivos que realizam requisições por essa informação. Nessa camada, cada agente, além de servir de repositório da chave/valor de informações (como os nós da DHT), será responsável por monitorar o comportamento do grupo e atuar sobre ele. Esta ação passa pela adição, transformação e remoção de dispositivos, para aumentar a escalabilidade da arquitetura. Além disso, os agentes são capazes de se relacionarem para gerenciar junções e separações que surjam entre os grupos.

A outra camada, denominada de dispositivos, é composta por grupos de dispositivos que realizam requisições (e.g., de busca e atualização) em uma determinada informação. Nessa camada, cada grupo é organizado de tal forma que somente alguns dos dispositivos serão responsáveis por agregar as informações de outros dispositivos e por enviar as requisições de atualização de informações ao agente responsável pelo grupo, evitando o problema da escalabilidade surgido quando todos os membros do grupo realizam essas requisições.

\subsection{Método}

O método adotado para responder à questão de pesquisa QP1, abordada no Capítulo 8, consistiu no seguinte:

- Determinar qual é o valor limite de requisições que um nó da DHT pode atender antes de diminuir o desempenho no tempo de resposta, afetando a escalabilidade da arquitetura.

- Analisar como a criação de novos agentes aumenta a escalabilidade da arquitetura quando o valor limite de requisições é atingido e as novas requisições serão distribuídas entre eles.

- Analisar como a criação de novos agentes diminui o desempenho no tempo de resposta quando é e quando não é atingindo o valor limite de requisições.

- Determinar qual é a quantidade de requisições enviada pelos membros de um grupo e compará-la com a quantidade enviada quando somente alguns deles realizam essa ação. Uma diminuição influencia na carga exercida no agente para responder essas requisições, aumentando sua escalabilidade. 
O método adotado para responder à questão de pesquisa QP2, abordada nos Capítulos 5 e 7, consistiu no seguinte:

- Analisar as similaridades e diferenças nas atividades realizadas pelos membros de diferentes domínios de aplicação.

- Determinar se uma arquitetura conceitual pode generalizar as atividades realizadas pelos membros de diferentes domínios de aplicação, promovendo sua reutilização.

- Determinar quais atividades devem ser definidas especificamente para o domínio de aplicação, evitando sua reutilização em outros domínios.

\subsection{Estrutura do documento}

O presente texto está estruturado em 9 capítulos. No capítulo 2 detalham-se os conceitos de escalabilidade, eficiência e ordem total, assim como os cenários de vídeo sob demanda e de monitoramento de sensores utilizados na tese. O capítulo 3 é dedicado a apresentar as arquiteturas a serem utilizadas na comparação com a nossa prosposta. Já o capítulo 4 aborda os trabalhos relacionados a esta tese. O capítulo 5 especifica a arquitetura proposta, apresentando a visão geral junto com as camadas que a compõem. No capítulo 6 mostram-se os passos necessários para a construção da arquitetura. O capítulo 7 detalha como é realizada a instanciação da arquitetura para os cenários de monitoramento de sensores e de vídeo sob demanda. Já no capítulo 8 analiza-se os resultados alcançados da instanciação da arquitetura nos cenários mencionados anteriormente. O capítulo 9 é dedicado a mostrar as conclusões, contribuições e possíveis caminhos de investigação que podem ser seguidos para a continuação deste trabalho. Por fim, nos apêndices A e B mostram-se os algoritmos que implementam a arquitetura. 


\section{CONCEITOS E CENÁRIOS DE APLICAÇÃO}

Neste capítulo serão apresentados os conceitos e cenários a serem utilizados neste trabalho. Assim, primeiro são descritos os conceitos de escalabilidade, eficiência e a informação com relação de ordem total, para depois apresentar os cenários de aplicação.

\subsection{Escalabilidade e Eficiência}

A escalabilidade no gerenciamento de requisições e a eficiência na busca de informações servirá para analisar e comparar as arquiteturas.

- Escalabilidade: quantidade de requisições que uma arquitetura, composta por um ou mais nós, pode gerenciar sem perda do desempenho nas respostas às requisições (SCHROEDER; HARCHOL-BALTER, 2006). Assim, quanto maior for a quantidade de requisições atendidas, maior será a escalabilidade da arquitetura.

- Eficiência: quantidade de nós que devem ser contatados até encontrar o responsável por gerenciar a informação requisitada (STOICA et al., 2001). Assim, quanto menor for a quantidade de nós contatados, maior será a eficiência da arquitetura.

\subsection{Informação com relação de ordem total}

No contexto deste trabalho, as informações a serem gerenciadas formam um conjunto $A$ no qual pares de elementos são comparáveis sob uma relação de ordem total. Nesse sentido, dado uma relação binária $\leq$ sobre $A$ tal que $\leq \subseteq A \mathrm{X} A$, $\leq$ é uma relação de ordem total se satisfaz as seguintes propriedades:

- $\leq$ é Reflexiva. $\forall x \in A, x \leq x$.

- $\leq$ é Antissimetrica. $\forall x, y \in A$ se, $x \leq y \wedge y \leq x$ então $x=y$.

- $\leq$ é Transitiva. $\forall x, y, z \in A$, se $x \leq y \wedge y \leq z$ então $x \leq z$. 
- $\leq$ é Total. $\forall x, y \in A, x \leq y \vee y \leq x$.

\subsubsection{Informações dependentes do tempo}

Para o contexto desse trabalho, informações dependentes do tempo são aquelas nas quais a temporização é o fator fundamental para interpretar corretamente seu significado (TANENBAUM; STEEN, 2006). Quanto à ordem, o tempo pode ser classificado em consecutivo, ramificado e circular (EDELWEISS; OLIVEIRA, 1994).

Como mostra a Figura 1(a), o tempo consecutivo possui uma ordenação entre quaisquer dois pontos diferentes $t_{1}$ e $t_{2} \in R$ tal que $t_{1} \leq t_{2}$. O tempo ramificado permite a existência de diversas situações para um determinado momento $t$. Como mostra a Figura 1(b), no tempo $t$ existem duas situações, ramificadas em um determinado tempo $t_{r}$. O tempo circular permite que haja uma periodicidade na ocorrência das situações. Na Figura 1(c) pode-se observar o ciclo das estações do ano.

As informações dependentes do tempo consideradas nesse trabalho são aquelas com representação discreta que possuem um atributo tempo com ordem consecutiva e total. Exemplos característicos desse tipo de informação são áudios e vídeos.

No caso do áudio, considere que foi construído como uma sequência de amostras de 16 bits, cada uma representando a amplitude de uma onda sonora. Para reproduzir o som original, as amostras devem ser tocadas na ordem em que foram construídas ou ter-se-á uma versão diferente.

No caso do vídeo, considere que foi construído como uma sequência de imagens em formato JPG que representa partes de um movimento. Para reproduzir o vídeo original, as imagens devem ser apresentadas na ordem em que foram construídas.

\subsubsection{Informações dependentes do espaço euclidiano}

Para o contexto desse trabalho, informações dependentes do espaço Euclidiano são aquelas nas quais o ponto (definido como uma $n$-tupla ordenada, com $n=2$ ou $n=3$ ) e os postulados da geometria Euclidiana (por exemplo, o cálculo da distância entre dois pontos) são os fatores fundamentais para interpretar corretamente seu significado. Nesse sentido, as informações dependentes do espaço consideradas nesse 
Figura 1: Classificações do Tempo.

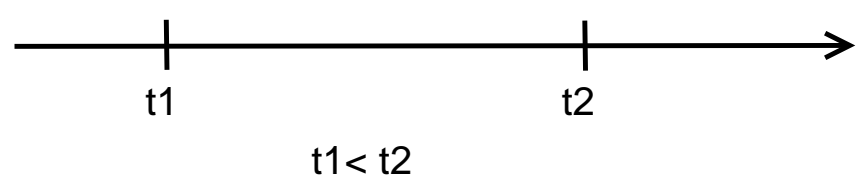

(a) Tempo consecutivo.

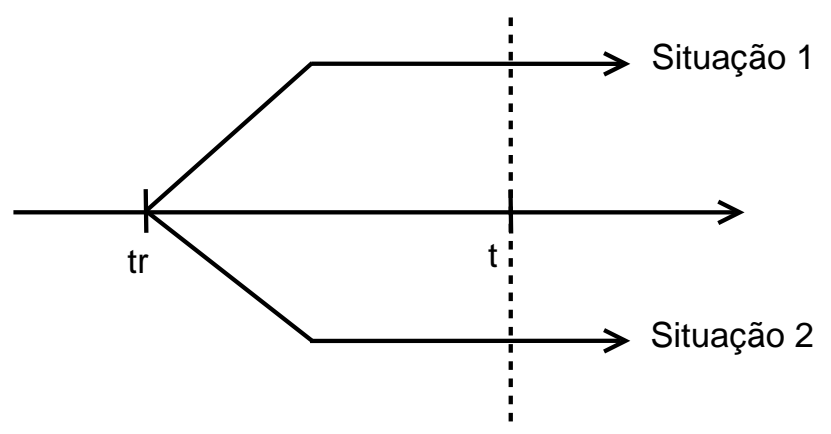

(b) Tempo ramificado.

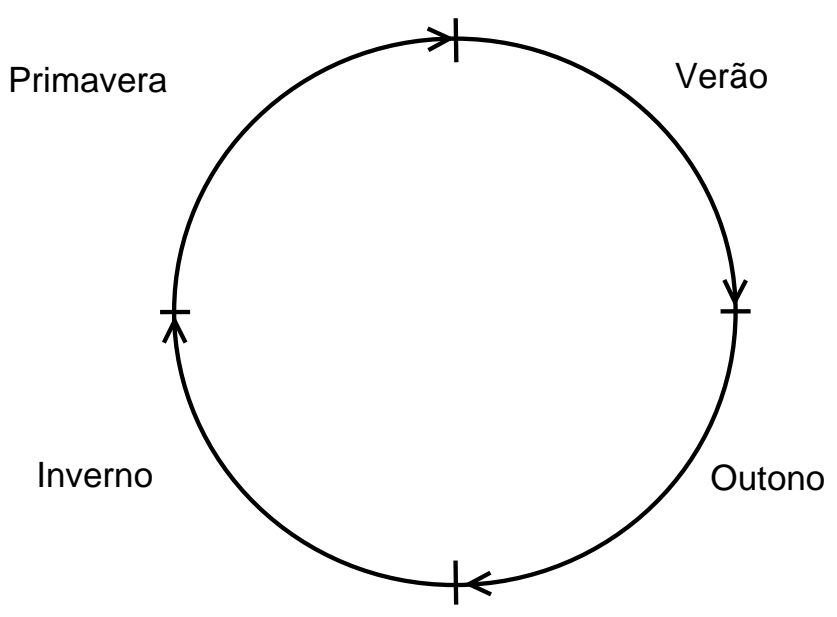

(c) Tempo circular.

Fonte: (EDELWEISS; OLIVEIRA, 1994).

trabalho possuem um atributo que representa um ponto.

Em se tratando do espaço $S$, subconjunto de $\mathbb{R}^{2}$, este será dividido em quadrados, cada um deles denominado de setor. Quanto à ordem desses setores, faz-se necessário aplicar alguma transformação que permita dar uma representação monodimensional a um espaço multidimensional. Assim, será possível gerar uma ordem total nessa representação.

Diversas alternativas podem ser utilizadas para realizar a transformação, entre elas a curva de Peano e a curva de Hilbert (BADER, 2013). A curva de Hilbert de ordem $p \in \mathbb{N}, p>0$, define uma partição de $S$ composta por $2^{2 p}$ quadrados. 
A curva de Hilbert de ordem 1 une os centros dos 4 quadrados que formam a partição de $S$, como apresentado na Figura 2(a). Já a curva de ordem 2 une os centros dos 16 quadrados que formam a partição de $S$, como apresentado na Figura 2(b). Já a curva de ordem 3 une os centros dos 64 quadrados que formam a partição de $S$, como apresentado na Figura 2(c). Para uma ordem $n$, a curva é construída utilizando o processo mencionado anteriormente, dividindo cada quadrado em quatro e seguindo o padrão da curva da ordem $n-1$ (WIRTH, 1985). Note que cada quadrado pelo qual passa a curva possui um identificador único, o que permite gerar a ordem total no conjunto de identificadores.

\subsection{Cenários utilizados no trabalho}

A arquitetura proposta resolve o problema de escalabilidade conforme descrito na introdução para os domínios que gerenciam informações com relação de ordem total. Nesses domínios, escolhemos dois cenários para serem utilizados ao longo do texto: monitoramento de sensores e de vídeo sob demanda.

\subsubsection{Monitoramento de sensores}

Os cenários de monitoramento espacial de sensores permitem monitorar de forma contínua a localização dos mesmos em determinados setores de interesse. Um sistema utilizado para esse tipo de cenários é o Waze (Waze, 2017), que permite a visualização das rotas viárias menos congestionadas entre dois lugares, utilizando a geo-localização dos sensores de posição instalados nos dispositivos móveis (como telefones celulares) próximos a esses lugares.

Para comportar a visualização, uma solução possível consiste em utilizar um servidor que será responsável por coletar as atualizações de localização de todos os sensores. Entretanto, como o servidor possui um certo limite (seja computacional, de largura de banda, etc.), uma quantidade de sensores que se aproxime desse limite fará com que o servidor diminua seu desempenho na coleta de informações, comprometendo a escalabilidade da arquitetura.

Para aumentar a escalabilidade da arquitetura, uma solução possível consiste em 
Figura 2: Curva de Hilbert.

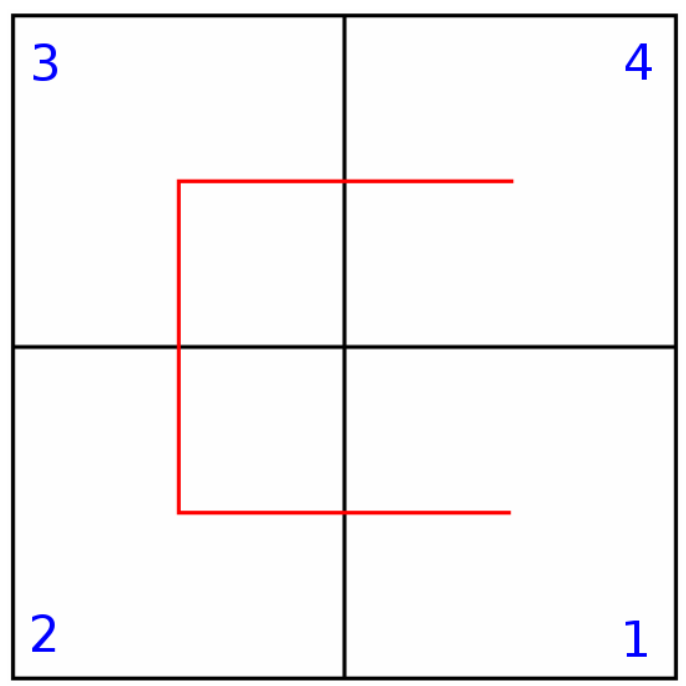

(a) Ordem 1.

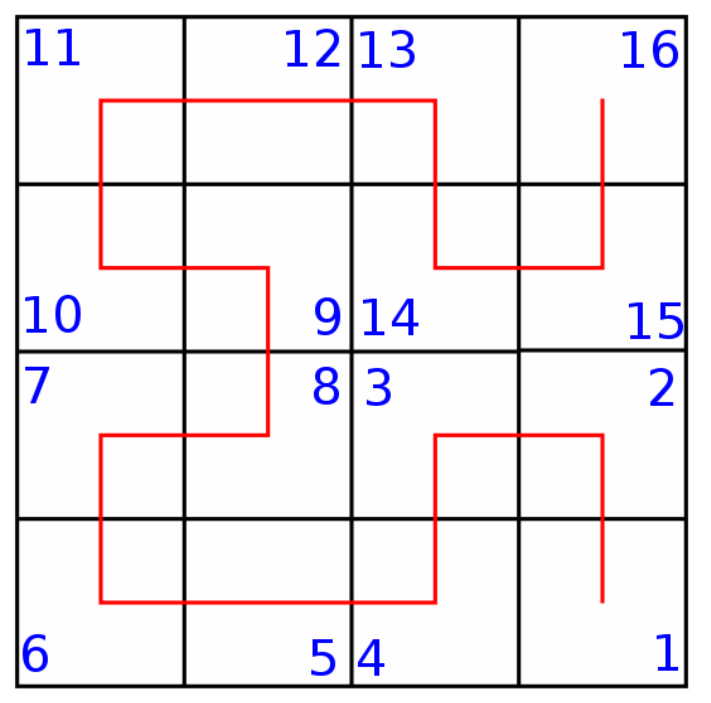

(b) Ordem 2.

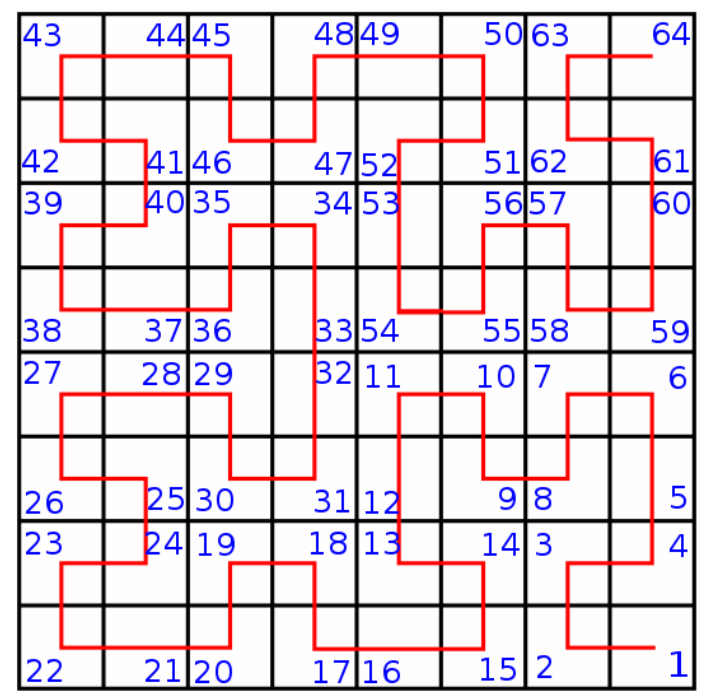

(c) Ordem 3.

Fonte: Autor.

dividir o espaço geográfico a ser monitorado em setores e distribuir, nos dispositivos móveis, a responsabilidade por agregar a localização dos sensores posicionados nesses setores. Nesse sentido, cada sensor atualizará sua localização no dispositivo responsável por gerenciar o setor onde ele está localizado. Entretanto, a escolha desse dispositivo deve ser realizada com cuidado, pois cada dispositivo possui uma quantidade limitada tanto de memória e processamento quanto de energia. Esta última é consumida (em cada coleta) até ser esvaziada, deixando-o inutilizável. 
Com a divisão do espaço, cada setor pode ser caracterizado como uma informação com relação de ordem total dependente do espaço Euclidiano, desde que seja aplicada alguma das transformações mencionadas na seção anterior.

Considerando a solução descrita, o cenário de monitoramento de sensores a ser tratado nesta tese pode ser resumido da seguinte maneira:

- O espaço é dividido em setores, cujos gerenciamentos são distribuídos nos dispositivos.

- Cada setor é caracterizado com um identificador único, incremental e discreto, que corresponde a uma região do espaço.

- Um sensor atualiza sua posição no dispositivo responsável pelo setor onde está localizado o sensor.

- Um dispositivo possui uma quantidade de energia que é consumida em cada requisição, até deixá-lo inutilizável.

- Um dispositivo possui uma capacidade limitada de memória e processamento, que evita executar algoritmos complexos.

\subsubsection{Video sob demanda}

Os sistemas de Video sob Demanda (Video-on-Demand ou VoD) têm se tornado muito populares, pois permitem ao usuário reproduzir e interagir com um vídeo enquanto está sendo baixado (denominado streaming). Nesses sistemas, a interação com um vídeo ocorre quando o usuário deseja assisti-lo a partir de uma posição qualquer, onde a posição é determinada pelos segundos transcorridos do começo do vídeo. Um exemplo desses sistemas é o YouTube (GOOGLE, 2017a), que alcançou a marca de 1.3 bilhão de usuários com bilhões de visualizações por dia (GOOGLE, 2017b).

Para comportar o streaming, uma solução possível consiste em utilizar uma arquitetura cliente/servidor, onde um servidor de streaming será o encarregado de prover o vídeo. Entretanto, como o servidor possui um limite (seja computacional, de largura de banda, etc.), uma quantidade de requisições de usuários que se aproxime desse limite 
fará com que o servidor diminua seu desempenho em prover o vídeo, comprometendo a escalabilidade da arquitetura.

Para aumentar a escalabilidade da arquitetura, uma solução possível consiste em dividir o vídeo em segmentos e distribuí-los nos usuários. Desta forma, cada usuário pode baixar um ou mais segmentos e passa a servir como provedor dos mesmos para outros usuários. Nesse contexto, o servidor de streaming somente será utilizado (como provedor de segmentos) caso um segmento procurado não seja encontrado nos usuários que o baixaram.

Com a divisão do vídeo, cada segmento, que corresponde a um intervalo disjunto do tempo total do vídeo, pode ser caracterizado como uma informação com relação de ordem total dependente do tempo.

De acordo com o exposto, o cenário de VoD pode ser resumido da seguinte maneira:

- O vídeo é particionado em segmentos e distribuídos nos usuários que os assistem.

- Cada segmento é caracterizado com um identificador único, incremental e discreto, que corresponde a um intervalo de tempo do vídeo.

- Um usuário que assiste um segmento passa a ser provedor do mesmo para outros usuários.

- Um servidor de streaming proverá os segmentos que não forem encontrados nos usuários que o baixaram. 


\section{REFERENCIAL TEÓRICO}

Neste capítulo será apresentado o referencial teórico necessário para entender a arquitetura proposta.

\subsection{Arquitetura Cliente/Servidor}

A arquitetura cliente/servidor é uma das mais utilizadas atualmente pela simplicidade do seu funcionamento e pela facilidade na sua implantação e manutenção em um ambiente de produção (COULOURIS et al., 2011). A Figura 3 mostra a arquitetura, composta por um servidor e vários clientes.

Figura 3: Arquitetura cliente/servidor.

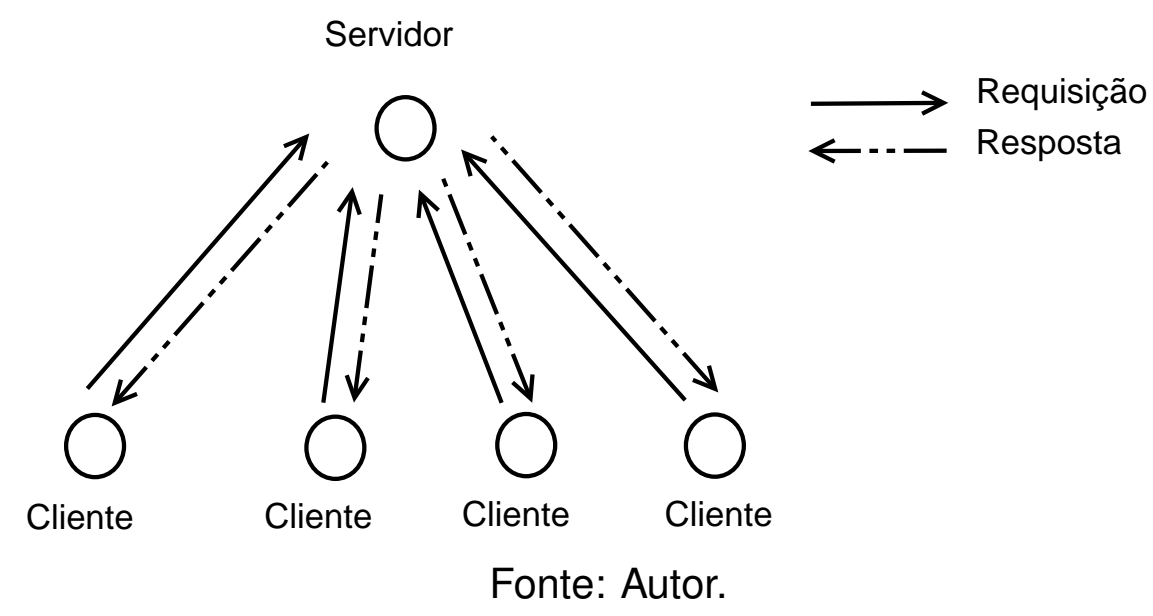

Nessa arquitetura, o servidor é um computador poderoso em termos de capacidade de armazenamento, processamento e largura de banda, responsável por gerenciar todas as informações gerada pelos computadores menos poderosos (denominados clientes) e por atendê-los nas requisições (respondendo as solicitações de busca ou atualização) dessas informações. Os clientes, por sua vez, se conectam ao servidor tanto para obter as informações quanto para armazená-las (SINHA, 1992).

Do ponto de vista da eficiência na busca, esta arquitetura apresenta os melhores resultados, visto que o cliente somente precisa conhecer um endereço IP (do servidor) para obter a resposta. Do ponto de vista da escalabilidade, a arquitetura está 
limitada pelo poder computacional e de largura de banda do servidor em atender um número máximo de clientes, a partir da qual diminuirá seu desempenho até tornar-se inacessível.

\subsection{Arquitetura Peer-to-Peer}

As arquiteturas Peer-to-Peer, ou P2P, surgiram para resolver o problema da escalabilidade do servidor centralizado da arquitetura cliente/servidor. Assim, para evitar que um único servidor gerencie todas as informações, nas arquiteturas P2P cada computador (denominado peer ou nó) atua como cliente e como servidor, sendo responsável por gerenciar somente um conjunto de informações (LEUF, 2002).

Nesse contexto, como cada nó pode atuar como um servidor para alguns clientes, e esses clientes podem atuar como servidores para outros clientes, a arquitetura P2P pode ser representada como um grafo não direcionado de conexões aleatórias entre nós, onde cada conexão corresponde ao canal de comunicação criado entre dois nós para requisitar e obter uma informação, como mostrado na Figura 4.

Figura 4: Arquitetura P2P.



Fonte: Autor.

Nas arquiteturas P2P, dado que os nós são responsáveis somente por um conjunto de informações, a escalabilidade é maior que a da arquitetura cliente/servidor. De fato, tanto as informações quanto as requisições (de busca e atualização) dessas informações podem ser distribuídas entre todos os nós, evitando centralizá-las em um único servidor, como no caso da arquitetura cliente/servidor.

Por outro lado, dado que a informação está distribuída, a eficiência na busca de 
uma informação é menor que a da arquitetura cliente/servidor, visto que um conjunto de nós será consultado para encontrar a informação (e não apenas um como na arquitetura cliente/servidor). Para buscar a informação, diversas propostas foram desenvolvidas, dentre elas a propagação completa e controlada (RIPEANU; IAMNITCHI; FOSTER, 2002) e as estruturas distribuídas (BUFORD; YU; LUA, 2008).

A propagação completa (chamada de flooding (TANENBAUM; WETHERALL, 2010)) consiste no envio de uma requisição de busca para todos os nós conectados ao nó emissor. Caso a informação não seja encontrada, cada um dos nós reenvia a requisição de busca a todas suas conexões, até encontrar a informação. Do ponto de vista da eficiência, supondo que a rede possua $N$ nós, no pior caso deverão ser contatados os $N$ nós (isto é, todos os nós da rede). A desvantagem dessa alternativa é que a quantidade de requisições aumenta exponencialmente (cada nó reenvia a requisição a todos seus contatos e estes aos seus contatos, etc.), o que sobrecarrega a rede ao ponto de inutilizá-la. Uma alternativa para evitar esse aumento é restringir a quantidade de reenvios que um nó pode realizar. Nesse sentido, os algoritmos epidêmicos (gossip) permitem encontrar a informação usando a propagação completa, mas contatando de forma aleatória uma pequena quantidade de nós (geralmente um ou dois) (DEMERS et al., 1987).

A propagação controlada consiste no envio da requisição de busca a todos os nós conectados ao nó emissor, porém com um determinado tempo de vida (TTL - TimeTo-Live). O valor do TTL diminui cada vez que a requisição atinge um nó, até chegar a zero, quando a requisição deixa de ser propagada. Em outras palavras, quando a requisição atinge um nó, este verifica se o tempo de vida ainda é maior que zero, reenviando a mensagem para suas conexões, com um tempo de vida decrementado, repetindo o processo. Do ponto de vista da eficiência, supondo que a rede possua $N$ nós, e que na propagação com o tempo de vida sejam contatados no máximo $K$ nós, com $K \ll N$, podemos considerar que é mais eficiente que a propagação completa. Entretanto, a grande desvantagem dessa alternativa é a impossibilidade de garantir que a informação exista em algum dos $N$ - $K$ nós da rede, caso não tenha sido encontrada nos $K$ nós. Por exemplo, vamos supor que a requisição de busca de uma informação, armazenada no nó $n_{5}$, é inicialmente solicitada pelo nó emissor $n_{1}$ (Figura 5). Na figura é possível observar que a requisição em $n_{1}$ (com um TTL com valor 2) 
é propagada nos seus contatos (i.e., nos nós $n_{2}, n_{3}$ e $n_{4}$ ). Quando recebida pelos contatos, estes diminuem o valor da TTL (o valor agora é 1) e propagam a busca nos seus contatos (o nó $n_{2}$ a propagará para $n_{5} \mathrm{e} n_{4}$, mesmo que este já a tenha recebido anteriormente via $n_{1}$ ). Finalmente, o nó $n_{5}$ recebe a busca, diminui o valor da TTL (o valor agora é 0) e devolve a informação ao nó $n_{1}$. Cabe destacar que, se a informação estivesse armazenada somente em $n_{6}$, a propagação controlada não a encontraria, dado que o valor da TTL no nó $n_{5}$ e zero.

Figura 5: Propagação controlada nas arquiteturas P2P.

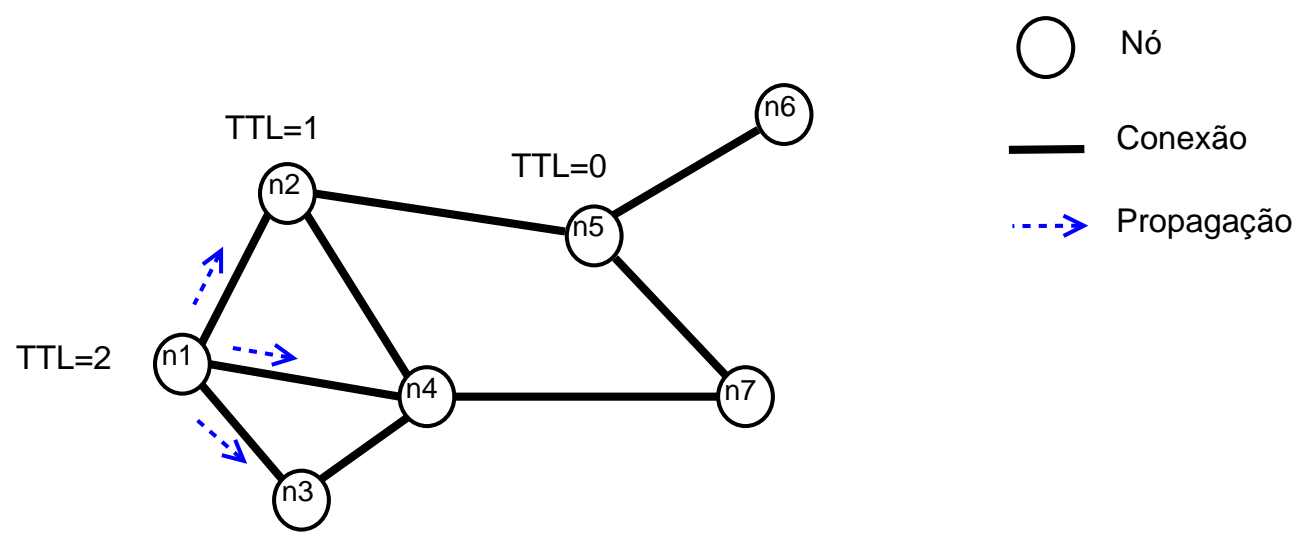

Fonte: Autor.

As estruturas distribuídas surgem com o intuito de melhorar o desempenho das alternativas anteriores na busca de uma informação. Para isso, as conexões entre os nós deixam de ser aleatórias, o que permite encaminhar as requisições por caminhos gerados de forma determinística ou probabilística (VU; LUPU; OOI, 2010). Existem diversas estruturas criadas para esse fim, tais como: listas distribuídas (ASPNES; SHAH, 2007), árvores distribuídas (AGUILERA; GOLAB; SHAH, 2008) e tabelas de hash distribuídas(TANENBAUM; WETHERALL, 2010).

\subsection{Tabela de Hash Distribuída}

A tabela de hash distribuída é uma arquitetura P2P que permite a implementação das funções de uma tabela de hash normal (podendo armazenar um valor dada uma chave, e procurar pelo valor utilizando a chave) porém de forma distribuída (TANENBAUM; WETHERALL, 2010). 
A transformação de uma tabela de hash normal para uma distribuída pode ser observada no exemplo da Figura 6. Na Figura 6(a), mostra-se a representação da tabela de hash normal em um vetor de 200 posições. Nesse sentido, na tabela poderão ser inseridas 200 chaves de acordo com uma função de hash que mapeia cada chave a um índice do vetor. Na Figura 6(b), o vetor é transformado a uma lista duplamente ligada, onde cada célula armazena o identificador $i$ (que representa o índice do vetor) e apontadores para endereços de memória da célula com identificador $i-1$ (denominado de predecessor) e identificador $i+1$ (denominado de sucessor). Além disso, é possível observar que a última célula (que representa a última posição do vetor) foi unida com a primeira célula da lista (que representa a primeira posição do vetor). $\mathrm{Na}$ Figura 6(c), cada célula é distribuída e gerenciada por um nó. Nesse sentido, algumas mudanças na célula deverão ser realizadas, entre elas: os apontadores predecessor e sucessor apontarão a endereços IP (e não a endereços de memória como na lista ligada) dos nós responsáveis pelos respectivos identificadores. Finalmente, na Figura 6(d), é realizada uma redução da quantidade de nós (mas sem reduzir a quantidade de chaves a serem armazenadas). Para isso, cada nó será responsável por um intervalo de identificadores, cujo menor identificador será o do predecessor mais 1 e cujo maior identificador será o do próprio nó. Por exemplo, na figura é possível observar que o nó com identificador 25 será responsável pelos identificadores entre 9 e 25 .

A redução mostrada na Figura 6(d) é importante, pois geralmente é possível armazenar trilhões de identificadores em uma tabela de hash distribuída, embora não seja viável ter a mesma quantidade de nós.

A busca eficiente de uma informação, por outro lado, precisa mais do que simplesmente os apontadores ao predecessor e sucessor de um nó (se somente usarmos esses apontadores, no pior caso precisariam ser contatados os $N$ nós que compõem a rede). Por exemplo, na Figura 6(d), caso o nó com identificador 25 recebesse uma requisição de busca pelo identificador 136 (i.e., uma chave $X$ foi mapeada para o identificador 136), o nó 25 teria que encaminhar a requisição para seu sucessor, e este para seu sucessor, etc., contatando 6 dos 8 nós da estrutura.

Para evitar isso, cada nó possui uma estrutura adicional, denominada de tabela de roteamento, composta por apontadores que permitem conhecer os nós cujos identificadores têm valores maiores que o do seu sucessor. Dentre as alternativas para 
Figura 6: Transformação da tabela de hash normal a uma distribuída.

\begin{tabular}{|l|l|l|l|l|l|l|l|}
0 & 1 & 2 & 3 \\
& & & & & 197 & 198 & 199 \\
\hline & & & & & & & \\
\hline
\end{tabular}

(a) Vetor de 200 posições.

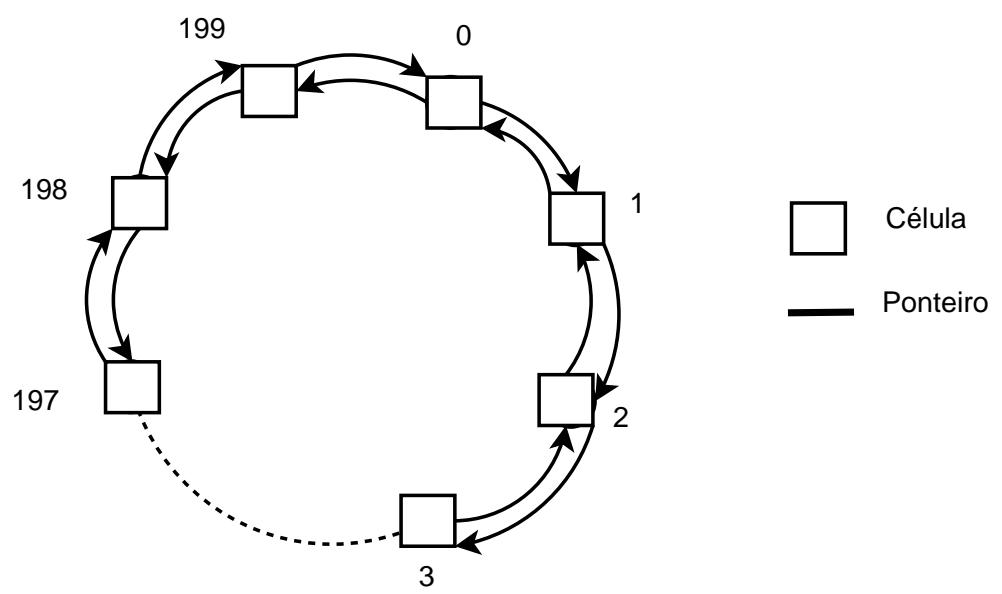

(b) Lista ligada com 200 células.

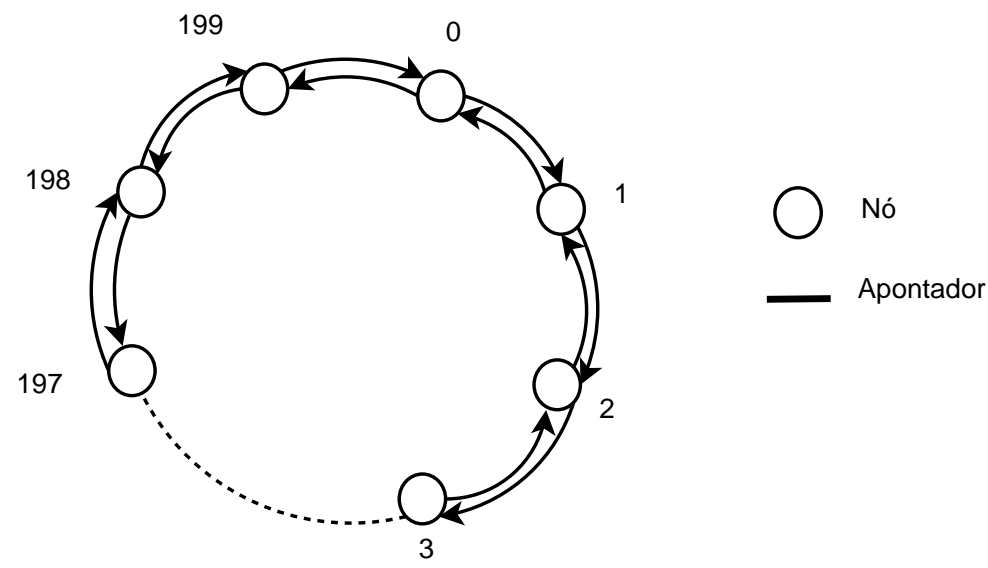

(c) Lista distribuída nos nós.

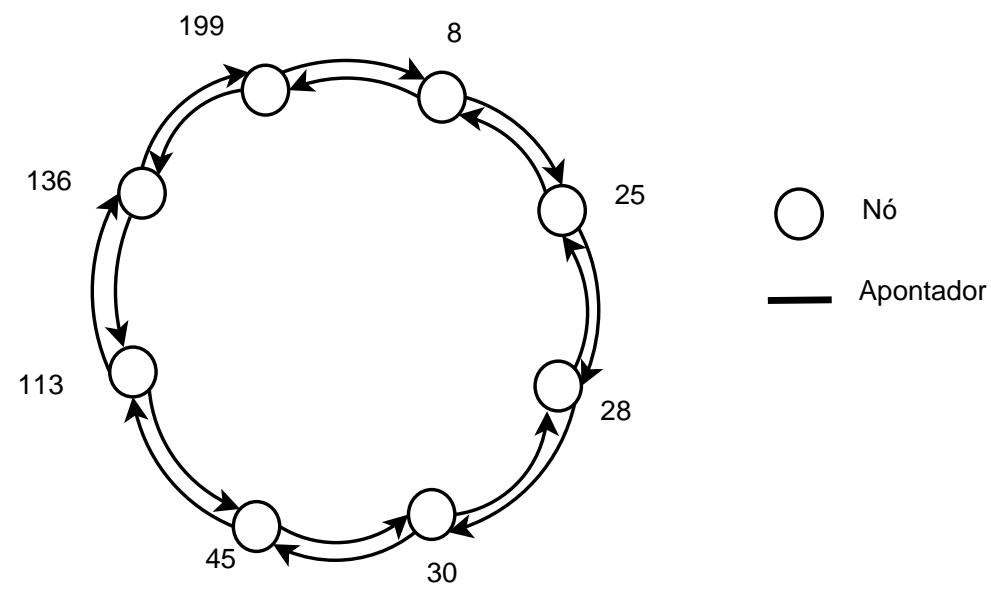

(d) Redução dos nós.

Fonte: Autor. 
preencher os registros da tabela de roteamento, tem-se o uso de uma fórmula matemática, onde cada registro $i$ contém $o$ identificador do nó $p$ ( $p$ será o identificador desse nó) cujo valor é maior ou igual a $p+2^{i}$ (STOICA et al., 2001), mostrada na Tabela 1. Por exemplo, na Figura 7 é possível observar os quatro primeiros registros do nó $p$ com identificador 25 (para simplificar, a conexão na figura estabelece o relacionamento sucessor e predecessor entre dois nós). Pela fórmula, o primeiro registro deve apontar para o nó responsável pelo identificador $26\left(25+2^{0}\right)$, que no caso é o nó com identificador 28 (lembrando que esse nó é responsável pelo intervalo de identificadores [26,28]). Já o segundo registro aponta para o mesmo nó do primeiro registro, pois a fórmula $25+2^{1}=27$ corresponde ao intervalo gerenciado pelo nó com identificador 28. O quarto registro deve apontar para o nó responsável pelo identificador $33\left(25+2^{3}\right)$, que no caso é o nó com identificador 45, responsável pelo intervalo de identificadores $[31,45]$. Além disso, na tabela de roteamento é necessário manter também um mapeamento entre o identificador e o endereço IP do nó. Cabe destacar que a quantidade de registros mantidos na tabela, ou seja o valor máximo de $i$, geralmente está relacionada com a quantidade de valores armazenados pela estrutura. Normalmente, a quantidade de registros é 160 (STOICA et al., 2001).

Tabela 1: Definição da tabela de roteamento de um nó $p$

\begin{tabular}{l|l}
\hline Registro & Definição \\
\hline 0 & apontador para o sucessor de $p$ \\
\hline $\mathrm{i}$ & $\begin{array}{l}\text { apontador para o nó } s \text { no anel : } \\
s \text { é responsável pelo intervalo }\left[p+2^{i}, p+2^{i+1}\right)\end{array}$ \\
\hline
\end{tabular}

Com o uso dessa tabela será possível buscar uma informação utilizando $O(\log N)$ requisições, de forma análoga ao método de busca binária, porque a cada passo da busca o intervalo de valores é dividido pela metade.

A Figura 8 apresenta os passos necessários para buscar o nó responsável pela chave "segmento-1", quando a requisição atinge o nó com identificador 25. No passo 1, transforma-se a chave "segmento-1" em um número identificador utilizando alguma função de hash. Vamos supor que esse identificador seja 122. No passo 2, o nó 25 procura na sua tabela de roteamento o nó com identificador mais próximo ao identificador procurado, que neste exemplo é o nó 45 . No passo 3 , a requisição será repassada ao nó 45 , que por sua vez, no passo 3 , encontrará na sua tabela de roteamento 0 
Figura 7: Tabela de roteamento do nó com identificador 25.


Fonte: Autor.

nó 113 ao qual repasará a requisição. Finalmente, a requisição chegará ao nó 136, responsável por gerenciar o intervalo de identificadores [114,136].

Figura 8: Busca na estrutura de anel com oito nós.

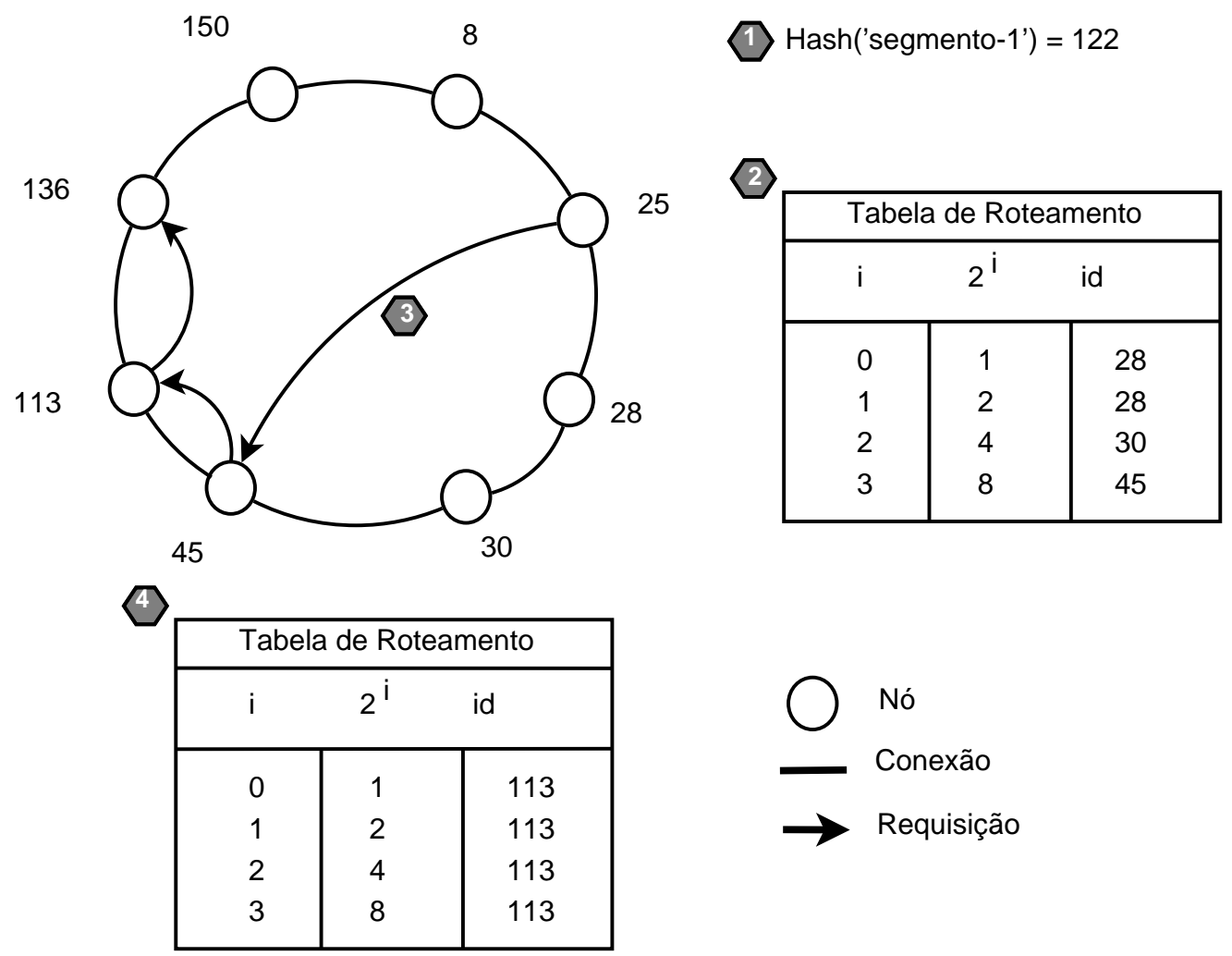

Fonte: Autor. 


\subsection{Agregação de Dados}

O processo de agregação de dados consiste na coleta de informações advindas de diversas fontes e no processamento das mesmas, com o objetivo de eliminar as informações com valores redundantes, com erros, ou abaixo de um determinado valor, entre outras (KRISHNAMACHARI; ESTRIN; WICKER, 2002).

Por exemplo, no contexto das redes de sensores sem fio, o processo é utilizado para evitar que todos os sensores enviem diretamente as informações à estação base, com o objetivo de diminuir o consumo de energia produzido pelas transmissões (RAJAGOPALAN; VARSHNEY, 2006). Para isso, como mostra a Figura 9, os sensores enviam suas informações a um nó intermediário, encarregado pela execução da agregação de dados, denominado Cluster head. O nó intermediário, ao estar localizado mais próximo de um grupo de nós que a estação base (em termos de distância euclideana), permite que o consumo de energia gerado pela transmissão do nó até o Cluster head seja menor que a do nó até a estação base, pois quanto menor a distância, menor o consumo. Finalmente, de posse das informações, o Cluster head executa o processo de agregação e envia essa informação à estação base.

Figura 9: Rede de sensores baseadas em grupos.

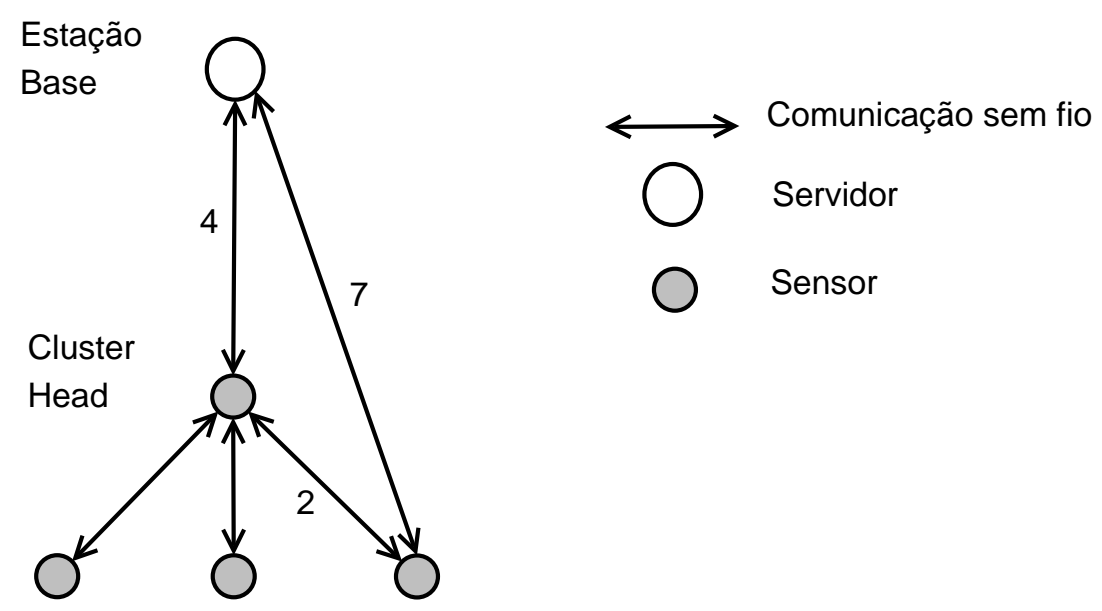

Fonte: Autor.

Para entender como essa abordagem diminui o consumo total de energia, vamos supor que, como mostra a figura, o consumo para transmitir uma informação entre o nó e a estação base, entre o nó e o Cluster head e entre o Cluster head e a estação base seja de 7,2 e 4 unidades de energia, respectivamente. 
Se contabilizamos as unidades de energia consumidas caso não existisse o Cluster head, o total seria de 21 unidades ( 3 transmissões realizadas pelos 3 nós do grupo até a estação base). Por outro lado, com a utilização do Cluster head, o total seria de 10 unidades ( 6 unidades pelas 3 transmissões dos nós até o Cluster head, mais 4 unidades pela transmissão do Cluster head até a estação base).

\subsection{Sistemas Multiagentes}

Um sistema multiagentes consiste de um conjunto de agentes que interagem, em um determinado ambiente, para cooperar ou negociar o cumprimento de objetivos próprios e comuns (WOOLDRIDGE, 2009).

Cada agente desse sistema é um programa de computador capaz de realizar ações autônomas que Ihe permitem cumprir seus objetivos no ambiente onde está situado. Para tornar o agente inteligente, este deve possuir algumas características, como reatividade, proatividade e habilidade social. A primeira característica permite ao agente perceber as mudanças no ambiente que foram captadas pelos seus sensores. A segunda permite ao agente exibir um comportamento como se estivesse tomando a iniciativa para alcançar seus objetivos. A terceira permite ao agente interagir com o ambiente e com outros agentes para satisfazer seus objetivos, utilizando para isso técnicas de cooperação, negociação, entre outras (WOOLDRIDGE, 2009).

Segundo (RUSSELL; NORVIG, 2009), foram descritos diversos tipos de agentes que especificam as bases que apoiam o processo de raciocínio do agente para executar uma ação. Em outras palavras, o tipo de agente define como a informação e o conhecimento são representados internamente e quais ações este deve realizar, baseado em mecanismos de raciocínio e interpretação. A seguir, serão descritos brevemente quatro tipos de agentes: agentes reativos simples, agentes reativos baseados em modelo, agentes baseados em objetivos e agentes baseados na utilidade.

O agente reativo simples baseia-se em um mapeamento direto de percepçãoação. Nesse sentido, o agente percebe 0 ambiente utilizando seus sensores e responde diretamente às mudanças percebidas utilizando seus atuadores. Em outras palavras, o agente realiza sua próxima ação de acordo com o estado atual percebido do ambiente e de uma estrutura hierárquica de regras que podem ser aplicadas nesse 
estado.

O agente reativo baseado em modelos utiliza o conhecimento de como o mundo funciona (denominado de modelo do mundo) para realizar sua próxima ação. Para isso, o agente possui estados internos que permitem analisar tanto como o mundo evolui independente das suas ações, quanto como suas ações afetam o mundo. Assim, a busca pela próxima ação do agente é realizada em dois passos: (1) utilizar o modelo do mundo para encontrar um possível estado do ambiente; e (2) como no agente reativo simples, obter a ação de acordo com uma estrutura hierárquica de regras. Cabe destacar que a representação do mundo pode ser modelada de diversas maneiras, por exemplo, utilizando a lógica proposicional de primeira ordem.

O agente baseado em objetivo é orientado nas sua ações pelo objetivo que deseja alcançar. Assim, a busca pela próxima ação do agente é realizada em dois passos: (1) como no agente reativo baseado em modelos, utilizar o modelo do mundo para encontrar um possível estado do ambiente; e (2) obter a ação considerando se o objetivo pode ser alcançado através dela ou através de uma sequência de ações onde ela aparece. Cabe destacar que existem diversas áreas da inteligência artificial, como planejamento e busca, dedicadas a encontrar essas ações.

O agente baseado na utilidade é orientado nas sua ações por uma função de utilidade. Nesse sentido, a função possibilita atribuir uma pontuação para qualquer sequência de estados do ambiente. Dessa forma, o agente poderá comparar as ações a serem tomadas, dado que estas geram diversos estados no ambiente. Assim, a busca pela próxima ação do agente é realizada em dois passos: (1) obter os possíveis estados do ambiente considerando se o objetivo, isto é a maximização da função de utilidade, pode ser alcançado através deles; (2) aplicar a função de utilidade para cada estado obtido do passo 1 e escolher a ação que leva ao estado que devolver a maior pontuação.

Em se tratando da interação entre dois ou mais agentes, a coordenação, como uma das propriedades dos sistemas multiagentes, permite aos agentes trabalharem em conjunto para realizarem alguma atividade no ambiente (WEISS, 2000). Segundo Weiss, a coordenação pode ser dividida em cooperativa ou competitiva. Na cooperativa, os agentes são benevolentes e não competem entre si, permitindo que a tarefa 
possa ser realizada sem que haja uma oposição por parte deles. Nessa abordagem, os agentes utilizam ténicas para sincronizar suas ações dado um plano de ação conjunto, gerado de forma centralizada ou distribuída. Na competitiva, os agentes competem entre si visando apenas seus próprios objetivos. Nessa abordagem, os agentes devem utilizar diversas técnicas, tais como negociação, votação, argumentação, entre outras, que permitam tomar decisões em conjunto para alcançar seus objetivos. No caso mais extremo, os agentes não só competem entre si, mas tentam se opor aos objetivos dos demais. Cabe destacar que a cooperação pode ser alcançada utilizando concomitantemente agentes cooperativos e competitivos (CASTRO; SICHMAN, 2013).

Nessa tese, os agentes utilizados são do tipo baseado na utilidade que se coordenam de forma cooperativa. 


\section{TRABALHOS RELACIONADOS}

Considerando o problema tratado nesta tese e a solução proposta, neste capítulo são apresentados os trabalhos relacionados aos cenários de monitoramento de sensores e vídeo sob demanda. Em ambos cenários são detalhados os trabalhos que utilizam sistemas multiagentes e a DHT.

\subsection{Monitoramento de sensores}

No cenário do monitoramento de sensores, a arquitetura proposta combina o uso de agentes, com o processo de agregação de dados e da DHT para lidar com o problema de escalabilidade no monitoramento contínuo das informações dos sensores. Assim, nesta seção apresentamos primeiro os trabalhos que utilizam agentes, seguido dos que utilizam o processo de agregação de dados. Finalmente apresentaremos os que utilizam a DHT para a recuperação e atualização das informações.

\subsubsection{Sistemas multiagentes}

As pesquisas na área focam seus esforços em como utilizar os agentes para descobrir, de forma escalável e eficiente, os serviços que um dispositivo disponibiliza (por exemplo, sua localização).

Wang et al. (WANG; ZHU; MA, 2013) propõe uma arquitetura conceitual que provê a coordenação entre os agentes através de interfaces. Entre essas interfaces, aquelas que estão relacionadas com a descoberta são: o agente de descoberta de serviços (service discovery agent), o agente intermediário (broker agent) e o repositório de serviços (service repository). O repositório de serviços é um repositório centralizado que armazena as informações dos serviços disponibilizados pelos dispositivos. O agente de descoberta de serviços permite que o dispositivo se conecte com o repositório de serviços para registrar e atualizar as informações e para anunciá-las a outros dispositivos de forma ativa (i.e., utilizando notificações no modo push). Já o agente intermediário permite que o dispositivo possa descobrir serviços de outros dispositivos de forma passiva (i.e., utilizando mensagens no modo pull). 
Fortino et al. (FORTINO et al., 2013) propõe um arcabouço de descoberta de serviços que permite a um dispositivo registrar seus serviços para que outros possam descobri-los. Para isso, o arcabouço é composto por dois módulos: um centralizado e um distribuído. No módulo centralizado, um registro central é encarregado de armazenar tanto a informação dos dispositivos quanto os serviços que este disponibiliza. Já no módulo distribuído, cada dispositivo é modelado como um agente (i.e., existe uma associação um-a-um com um dispositivo). Nesse módulo, o dispositivo cadastra e atualiza seus serviços no registro central. Para descobrir um serviço, o agente se comunica com o Jade Directory Facilitator (CAMPO, 2002), que é encarregado de intermediar o processo de descoberta com o registro central. Embora a utilização do módulo distribuído permita aumentar a escalabilidade do arcabouço, os problemas dessa solução consistem no ponto único de falha, tendo em vista o servidor centralizado, e na quantidade de agentes que devem ser criados pela associação um-a-um.

Huang (HUANG, 2013) propõe um sistema multiagentes no qual os agentes formam grupos virtuais de acordo com os seus interesses e seus comportamentos. Assim como em Fortino et al., cada dispositivo também é modelado como um agente, mas Huang estende esse modelo adicionando ao agente um identificador do domínio (similar ao nome de dominio do DNS, mas com um significado semântico). Para tirar vantagem desses identificadores, a arquitetura foi construida como uma estrutura de árvore distribuída, similar à estrutura hierárquica do DNS. Nessa árvore distribuída, cada nó tem um prefixo do domínio (obtido do identificador de domínio do agente) que Ihe permite comunicar-se com outros nós do mesmo nível da árvore. Para descobrir os serviços que um certo grupo oferece, a árvore provê uma busca recursiva. Nesse sentido, dado um certo domínio dom a ser procurado, a busca inicializa na raiz da árvore (que representa o domínio mais geral) e segue pelos nós até que a condição da busca dom corresponda a um dos identificadores de domínio dos nós, ou se chegue às folhas (que representam o domínio mais específico).

Abdelwahab et al. (ABDELWAHAB et al., 2015) evita o uso das estruturas centralizadas, propondo um sistema distribuído de três camadas. Como mostra a Figura 10, a camada inferior é composta pelos dispositivos (loT devices). A camada do meio é composta por agentes da nuvem (cloud agents i.e., computadores ou dispositivos com características especiais, tais como conectividade constante ou alto poder com- 
putacional). Nessa camada, cada agente é responsável por gerenciar as informações de vários dispositivos da camada inferior (i.e., existe uma associação um-a-muitos). Além do gerenciamento das informações (e.g., a localização destes e os sensores que carregam) o agente é encarregado por enviá-las à camada superior. A camada superior é composta por nós de uma nuvem computacional (cloud) que armazenam e processam as informações enviadas pelos agentes da camada do meio. Para descobrir as informações de um determinado dispositivo ou informações de um grupo de sensores, um usuário do sistema contata um nó da nuvem (do cloud da camada superior) que redireciona o pedido para alguns cloud agents da camada do meio. Cada agente que recebe o pedido inicializa a disseminação do pedido entre os $10 T$ devices da camada inferior, utilizando um protocolo de disseminação de informação (gossip protocol). Nesse protocolo, o agente primeiro envia o pedido para um dos dispositivos que ele gerencia (escolhido aleatoriamente). Se o dispositivo não possui a informação, o mesmo repete o processo, reenviando o pedido para um dos dispositivos localizado geograficamente próximo a ele (escolhido também de forma aleatória). Finalmente, quando um dos dispositivos possui a informação, entrega ao agente que fez o pedido. A utilização de uma nuvem computacional permite aumentar a escalabilidade do sistema, no entanto, a escalabilidade pode ser afetada caso um agente da nuvem (e.g., um dispositivo) da camada do meio tenha que gerenciar uma grande quantidade de dispositivos, que o sobrecarregue até o ponto de deixá-lo inacessível.

Hernández et al. (HERNáNDEZ; REIFF-MARGANIEC, 2015) adota uma abordagem similar a de Abdelwahab et al., mas mapeia cada dispositivo a um agente e utiliza somente duas camadas. A camada inferior é composta por agentes que podem comunicar-se diretamente, inclusive se estão geograficamente separados além da área de cobertura da antena. A camada superior consiste de um repositório distribuído (CouchDB (Apache CouchDB, 2017)) que armazena as informações recebidas por todos os dispositivos pertencentes à camada inferior. Para descobrir um serviço, o sistema utiliza o protocolo Gnutella (CHAWATHE et al., 2003). No protocolo, o agente $a$ envia a requisição, com um certo valor inicial de TTL para outro agente $b$ escoIhido aleatoriamente. Se o agente $b$ não possui a informação requisitada, $b$ repete o processo, reenviando o pedido para outro agente escolhido de forma aleatória, mas diminuindo o valor do TTL em um. O processo de busca finaliza quando o agente que 
Figura 10: Sistema distribuído de três camadas, inspirado de Abdelwahab (ABDELWAHAB et al., 2015).

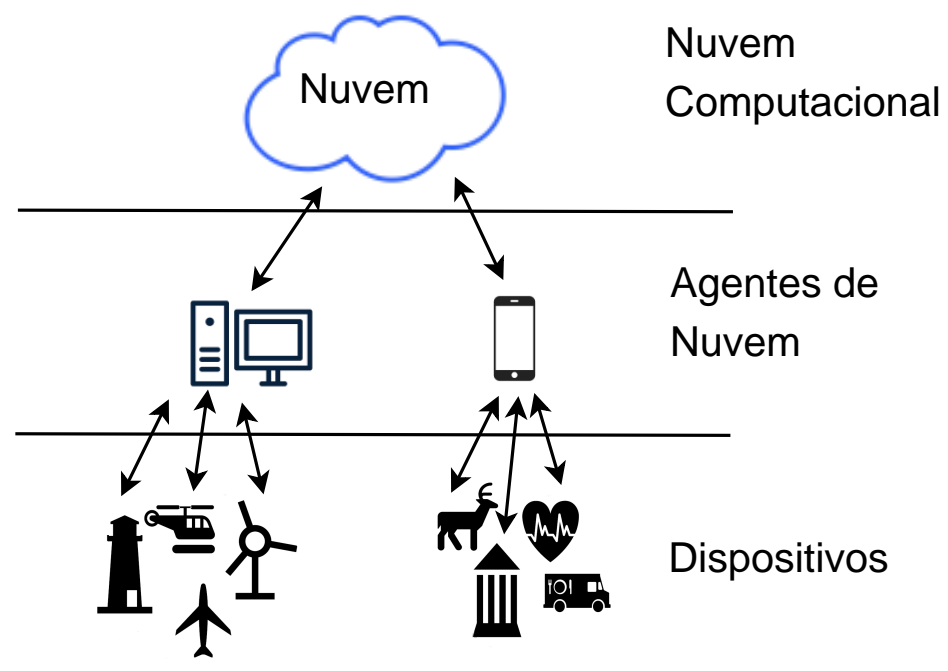

Fonte: Autor.

recebe a requisição possui a informação pedida por $a$, ou quando o TTL da mensagem enviada atinge o valor zero.

Harjula et al. (HARJULA et al., 2014), o trabalho mais próximo do nosso em termos da utilização de agentes em combinação com a DHT, propõe uma arquitetura com duas camadas, denominada ADHT. Como mostra a Figura 11, nessa arquitetura, a camada inferior é composta por dispositivos, agrupados de acordo com um prefixo de IP criado virtualmente (grupo denominado de subnet). A camada superior é a DHT, onde a chave está associada ao IP virtual do dispositivo que atua como agente (peer-agent), responsável por gerenciar a informação dos dispositivos da subnet. Para evitar que um grupo fique indisponível quando o peer-agent consome toda sua energia, a responsabilidade de atuar como agente é rotacionada entre os dispositivos da subnet, utilizando o mecanismo de agentes móveis (COULOURIS et al., 2011) para manter persistente os estados ao realizar a rotação. Para descobrir um dispositivo, o sistema ADHT provê um algoritmo eficiente para encontrá-lo: inicialmente, um usuário envia um pedido ao peer-agent $a$, dado o endereço de IP virtual do dispositivo como chave. A seguir, o peer-agent $a$ extrai o prefixo do IP e encontra, através da $\mathrm{DHT}$, o peer-agent $b$ associado a esse prefixo, encaminhando-Ihe o pedido. Assim que o peer-agent $b$ receber o pedido, o reencaminha aos dispositivos da sua subnet. 
Finalmente o dispositivo que possui o endereço de IP virtual procurado entrega a informação para o usuário. Embora a arquitetura permita a escalabilidade da camada superior, ao dividir os dispositivos em grupos (i.e. subnets), o problema reside no fato de que o grupo pode conter uma grande quantidade de dispositivos, cujas atualizações sobrecarregarão o peer-agent ao ponto de deixá-lo inacessível. Nesse sentido, mesmo que haja uma rotação, o novo peer-agent desse grupo sofrerá novamente a mesma sobrecarga.

Figura 11: Arquitetura de duas camadas da ADHT, inspirado de (HARJULA et al., 2014).

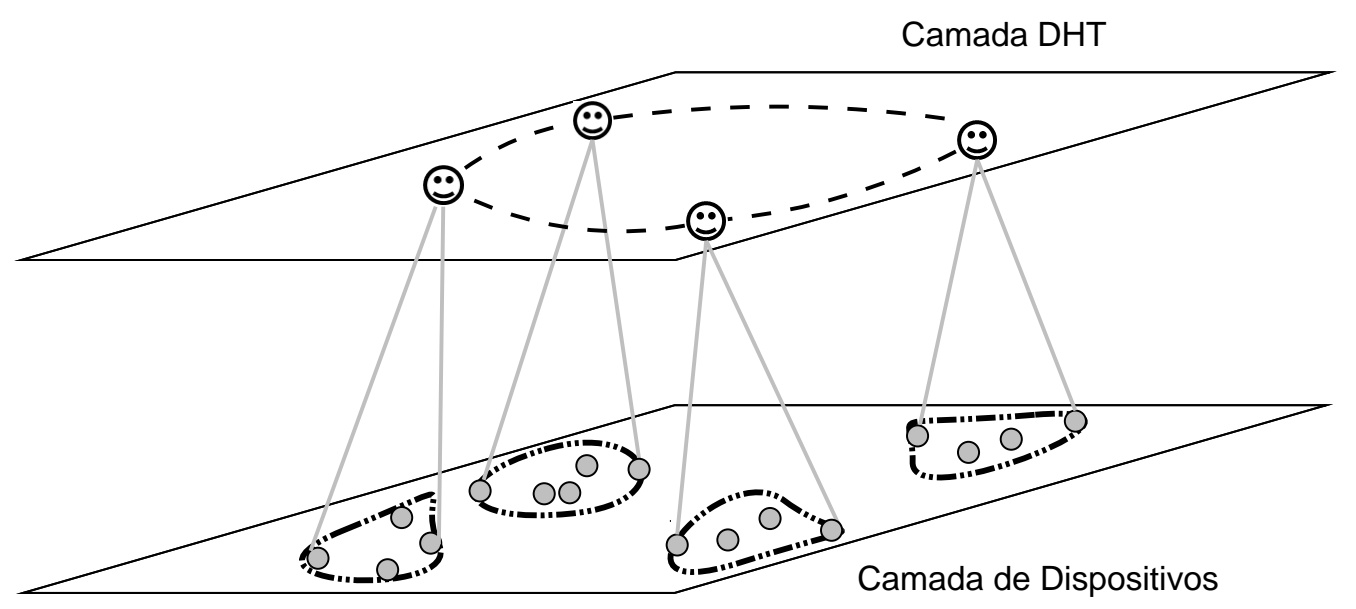
(-) Peer-Agent
Subnet
Dispositivo
Gerencia
- - - Relacionamento

Fonte: Autor.

Apesar de a maioria das soluções propostas utilizarem agentes para gerenciar um grupo de dispositivos de capacidade limitada, nenhuma delas permite que os grupos se unam ou se dividam. Nesse sentido, a união pode representar um problema na escalabilidade do agente que gerenciará o grupo resultante da união. Por outro lado, a separação permitiria que um agente possa distribuir a carga exercida pelo grupo com um novo agente, aumentando a escalabilidade das soluções. 


\subsubsection{Agregação de dados}

As pesquisas no cenário de sensores também têm focado seus esforços em como explorar a agregação de dados para melhorar a escalabilidade na descoberta e atualização de informações de um grupo de dispositivos.

Galluccio et al. (GALLUCCIO et al., 2011) propõe que um dispositivo móvel (Group Master ou GM) seja o responsável por agregar e enviar as informações de todos os dispositivos (slaves) que estão localizados dentro da área de cobertura da antena. Essa abordagem foi avaliada em (D'ORO et al., 2015), onde uma grande quantidade de simulações foram realizadas quando o GM é um veículo que carrega itens de usuário (cenário de logística) e quando o GM é um humano que carrega os denominados objetos inteligentes, tais como smartphones (cenário humano). O sistema proposto permite que os deslocamentos dos dispositivos não precisem ser atualizados se os mesmos continuam dentro da área de cobertura do GM (nesse sentido, somente a posição do GM precisa ser atualizada). Além disso, quando um dispositivo quer se unir a um grupo, somente é necessário encontrar o GM e se conectar com ele (como encontrar o GM será analisado na Seção 4.1.3). A desvantagem dessa abordagem é que a área do grupo fica limitada pela cobertura do GM, deixando os dispositivos fora dessa área como pertencentes a outro grupo (mesmo que façam parte do primeiro). Além disso, o GM pode ficar sobrecarregado se muitos dispositivos se unem ao grupo, afetando sua escalabilidade.

Para lidar com as desvantagens antes citadas, Tang et al. (TANG et al., 2014) propõem dividir o espaço geográfico a ser monitorado em setores retangulares, agrupando os dispositivos localizados em cada um deles utilizando uma estrutura em árvore distribuída (Index Tree Structure (ZHANG et al., 2011)) denominada ECH-tree. Nesse sistema, cada setor tem um dispositivo (Head Node) com a mesma responsabilidade do GM, mas que é rotacionado entre todos os dispositivos do setor, tentando evitar consumir toda a energia de um dispositivo. Além disso, os dispositivos que estão próximos da fronteira do setor estendem a área de cobertura do grupo ao se conectar com dispositivos localizados em setores adjacentes. Por outro lado, o sistema não lida com deslocamentos que os dispositivos possam sofrer, obrigando a reindexação frequente da árvore. 
Kaur e Sood (KAUR; SOOD, 2015) adotam uma abordagem diferente das mencionadas, propondo que os GMs (denominados no trabalho de gateway node, ou eGN) realizem ações pró-ativas, trocando o estado dos dispositivos que gerencia entre o modo de repouso (sleep mode) e o modo ativo (active mode). Para realizar a troca, - GM analisa tanto a bateria remanescente quanto o histórico de uso do dispositivo. A vantagem do sistema é o aumento na escalabilidade, dado que a quantidade de informações recebidas pelo GM diminui (os nós em modo de repouso não enviam informações). Por outro lado, o GM ainda sofre de sobrecarga caso uma grande quantidade de nós entre no setor.

Apesar de que as alternativas utilizam a agregação de dados, específicamente - GM, para agregar as informações de um grupo e enviá-las ao nó responsável por ele, o problema da escalabilidade mencionado na seção anterior aplica-se também ao GM. Além disso, nas alternativas mencionadas, a responsabilidade do envio de informações é realizada por todos os nós que integram um grupo, sendo que poderia ser realizada por somente alguns nós, diminuindo a quantidade de informação recebida pelo GM, aumentando sua escalabilidade.

\subsubsection{DHT}

No cenário de monitoramento de sensores, o uso da DHT para encontrar o GM surgiu como uma alternativa de implementação promissora às soluções com servidores centralizados (MANZANARES-LOPEZ et al., 2011; ZHAO et al., 2011), que recebem informações de todos os dispositivos. Nesse cenário, a DHT é utilizada para armazenar, como chave, o identificador da região (na Seção 2.3.1 foi referenciado como setor) e como valor o GM responsável por gerenciar (i.e., agregar e processar) as informações de todos os dispositivos localizados nessa região. Entretanto, como o gerenciamento esgota a energia do dispositivo, as pesquisas têm focado seus esforços em como escolher o GM (que faz parte da DHT) para evitar ter que substituí-lo constantemente. Nesse sentido, evitar a substituição de um membro da DHT é crítico, dado que esse comportamento leva à perda de energia dos dispostivos enquanto a estrutura é reorganizada.

Uma das alternativas na seleção do GM foi dada pelo sistema Chord for Sensor 
Networks (CSN) (ALI; UZMI, 2004) que, aleatoriamente, escolhe um dispositivo dentre os existentes na região para ser o responsável em coletar as informações. Assim que o dispositivo estiver próximo de consumir sua energia, o sistema seleciona um outro dispositivo de forma aleatória (método chamado de rotação) para ser o GM. O sistema CSN se caracteriza por criar níveis de aglomerados (clusters) dentro de cada região, onde o aglomerado de um determinado nível (composto por nós da região) contém informações dos agregados de um nível inferior. Para permitir a comunicação entre os nós de um nível, o CSN usa a DHT com dois modos de operação, o modo robusto, que utiliza a tabela de roteamento da DHT para comunicar dois nós, e o modo eficiente (energy-efficient) que comunica os nós utilizando somente os vizinhos mais próximos. A abordagem eficiente permite economizar energia na transferência ao evitar utilizar a tabela de roteamento (onde os nós podem estar mais distantes, o que significa um maior consumo de energia para realizar a comunicação). Entretanto, a busca por um dispositivo, começando no nível superior e finalizando no inferior, é realizada em $O(m * \log N)$, sendo $m$ a quantidade de aglomerados em cada região e $N$ a quantidade total de nós na DHT.

O sistema Tiered Chord (TChord) (ALI; LANGENDOEN, 2007), estende o trabalho anterior ao analisar na seleção do dispositivo $\mathrm{GM}$, além da capacidade de energia, outras características como estabilidade na comunicação, latência entre os nós, entre outras. Por outro lado, o TChord determina que a DHT somente seja composta por GMs poderosos (baseados nas características mencionadas anteriormente) e não por todos os nós como no CSN (onde todos possuem as mesmas características). O TChord, diferente de CSN, não utiliza a hierarquia de aglomerados dentro de uma região, o que simplifica a sua implementação. Além disso, também evita que os nós que não são GMs (slaves) possam agregar informações de outros nós da região, diferentemente do CSN onde todos os nós podem armazenar as informações dos vizinhos. Entretanto, no sistema TChord não se analisa a rotação do GM, o que traz como consequência a inacessibilidade da região quando consome toda sua energia.

O sistema Two-Tiered Chord System (C2WSN) (YU; LIU; SONG, 2007) também analisa a seleção dos dispositivos usando as características levantadas em TChord, porém quando o GM está no limite de consumo de energia, o sistema faz a rotação do GM com outros dispositivos com características similares, evitando que a região fique 
inacessível como no TChord. Como mostra a Figura 12, o sistema C2WSN utiliza duas DHT para criar uma hierarquia entre seus nós. A primeira DHT é formada por todos os nós que não são GM e a segunda DHT é formada somente pelos GMs. Para conectar as duas DHTs, cada GM da segunda é responsável por um intervalo disjunto de valores da primeira, correspondendo assim a todos os nós cujos identificadores estejam contidos nesse intervalo. Na busca por informações de um determinado nó, é necessário encontrar, na segunda DHT, o GM responsável pelo intervalo onde se encontra localizado o nó. A seguir, esse GM deve encaminhar para a primeira DHT a busca pela informação sobre o nó. Entretanto, a busca por um dispositivo é realizada em $O(\log m)+O\left(\log m_{i}\right)$, sendo $m$ a quantidade de intervalos e $m_{i}$ a quantidade de nós no intervalo.

Figura 12: Arquitetura de duas DHT do C2WSN, inspirado de (YU; LIU; SONG, 2007).

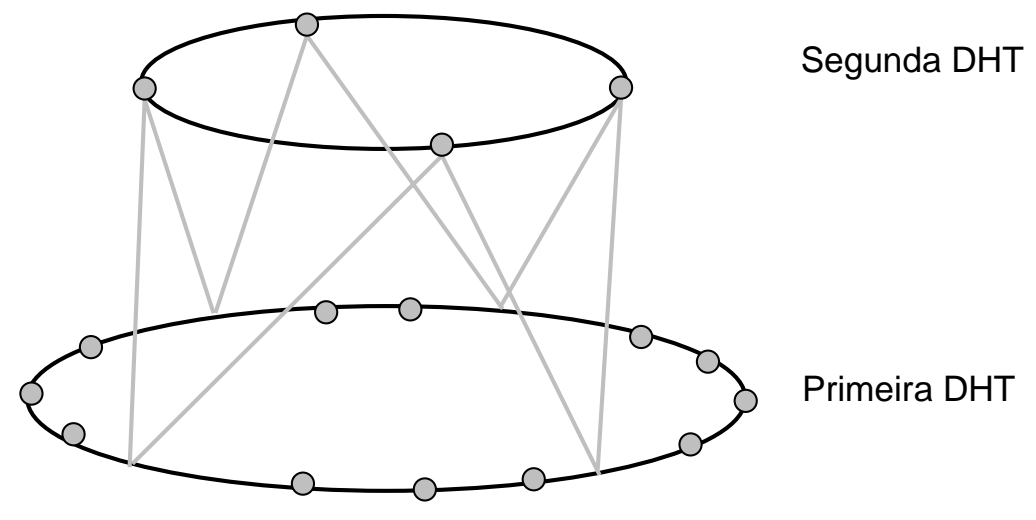

— Conexão $\bigcirc$ Dispositivo $\bigwedge$ Intervalo gerenciado

Fonte: Autor.

Diferente dos Chord anteriores, o sistema Enhanced Mobile Chord (EMC) (THAALBI et al., 2011) foca na modificação da tabela de roteamento para diminuir a latência no caminho entre dois nós dado que estes têm uma conexão intermitente. Para isso, ao invés de somente ter uma tabela com o identificador do sucessor (dado uma distância $i$ ), os autores adicionam dois parâmetros, sendo estes a estabilidade do nó e a latência esperada para um determinado tipo de aplicação que usa a DHT. Para obter essas duas novas informações, cada nó envia periodicamente mensagens para diversos nós da distância $i$ da sua tabela. Assim que recebida a mensagem de volta, 
o nó calcula a latência e atualiza sua tabela de roteamento, inserindo os nós com o menor valor. Nesse sentido, quando dois nós precisam se comunicar, o caminho entregue pela DHT será o de menor latência encontrado até esse momento. O EMC foi estendido pelos mesmos autores em (THAALBI et al., 2012), para encontrar sempre um caminho entre dois nós, mesmo que existam desconexões entre os nós que fazem parte do caminho. Para isso, utilizam o conceito de timeout e backtracking da seguinte maneira: quando um nó $p$ do caminho recebe a requisição por uma chave, busca na sua tabela de roteamento o nó mais próximo da chave solicitada (nó q) e envia a requisição para esse nó, inicializando um temporizador. Caso o nó $p$ não tenha recebido uma resposta e o temporizador sinalize que o tempo de espera foi atingido (i.e., significando que provavelmente o caminho sofreu uma desconexão), $p$ procura na tabela de roteamento pelo nó anterior a $q$, repetindo o processo.

O sistema Mobile Robust Chord (MR-Chord) (WOUNGANG et al., 2015) tem o mesmo objetivo do (THAALBI et al., 2012), mas modifica a tabela de roteamento com parâmetros que não dependem da latência. Assim, para cada nó $p$ da tabela, foram acrescentados os parâmetros succ, fail e weaknode. O parâmetro succ é utilizado para registrar o número de vezes que uma busca passou pelo nó $p$ e teve sucesso (o nó estava ativo). O parâmetro fail registra o número de vezes que a busca falhou em $p$ (i.e., o nó continua ativo, mas teve algum problema durante a execução da busca). O parâmetro weaknode é um valor booleano utilizado para registrar se vale a pena ou não repassar uma busca a esse nó (calculado pela quantidade de vezes que falhou e que teve sucesso). Quando uma busca em $p$ por uma determinada chave é realizada, o nó $p$ selecionará da tabela de roteamento o nó $q$ mais próximo da chave (sempre anterior a ela, de acordo com o protocolo de busca do Chord) cujo weaknode tenha o valor falso. Para atualizar os valores da tabela, MR-Chord pode realizar o procedimento Real-Time Fix Scheme, que modifica somente o registro na tabela associado ao nó ao qual será repassada a busca, e o procedimento By-Detect Fix Scheme, que modifica todos os registros da tabela, enviando mensagens para cada um dos nós associados a esses registros.

Embora as alternativas mencionadas acima possibilitam a escolha e rotação do dispositivo GM sem alterar a eficiência na busca da região gerenciada pelo dispositivo, o problema da escalabilidade ainda permanece em aberto. $O$ problema surge 
quando a quantidade de dispositivos que solicita ou atualiza informações sobre uma determinada região (correspondente à chave) é próxima ao limite de requisições que o GM dessa chave pode atender. Nesse sentido, a estrutura torna-se menos escalável, pois o GM experimenta o mesmo comportamento de um servidor centralizado da arquitetura cliente/servidor. Para tratar desse problema, os nós da DHT poderiam criar novos GM caso as requisições os estejam sobrecarregando, evitando comprometer a escalabilidade da arquitetura.

\subsection{Vídeo sob demanda}

No cenário de Vídeo sob Demanda, a arquitetura proposta combina agentes e arquiteturas Peer-to-Peer para lidar com o problema da escalabilidade e eficiência na recuperação de segmentos de vídeo. Assim, nesta seção apresentamos primeiro os trabalhos que utilizam agentes e peers e, a seguir, os que utilizam a DHT para a recuperação dos segmentos.

\subsubsection{Sistemas multiagentes}

A combinação de agentes e peers para streaming de vídeo é uma área de pesquisa que tem emergido recentemente (YANG et al., 2006; ORYńCZAK; KOTULSKI, 2011; TEKET; SAYIT; KARDAS, 2014). Nessa área, as pesquisas têm focado seus esforços em como um agente deveria agir para melhorar o desempenho dos peers que compartilham os segmentos de vídeo.

O sistema MPSS (YANG et al., 2006) é um dos primeiros trabalhos em fazer uso de agentes e da DHT para sistemas de Vídeo sob Demanda. Nesse sistema, a chave na DHT é o identificador do vídeo e o valor é o endereço do nó (denominado tracker) responsável por gerenciar os nós que compartilham os segmentos desse vídeo. A partir dai, tanto o tracker quanto os nós tem as mesmas atribuições que no protocolo Bittorrent (COHEN, 2008a), onde o primeiro é responsável por entregar a lista de nós que compartilham os segmentos do vídeo, e o segundo utiliza a lista para baixar os segmentos e disseminá-los entre outros nós. No MPSS, os agentes são executados em servidores especializados em armazenar os segmentos do vídeo, com o intuito de permitir que estes estejam sempre disponíveis caso os nós que os baixaram tenham 
saído do sistema. A busca por um segmento ocorre da seguinte maneira: quando um nó precisa de um segmento, primeiro o procura nos nós da lista que recebeu do tracker. Caso o segmento não tenha sido localizado, poderá obtê-lo de algum agente, que deverá procurá-lo em outros agentes caso não o tenha armazenado.

OryńCzak et Al. (ORYńCZAK; KOTULSKI, 2011) apresenta uma arquitetura, baseada na combinação de agentes e das arquiteturas P2P, geral o suficiente para ser utilizada em diversos tipos de aplicações de tempo real, entre elas videoconferência e vídeo sob demanda. Na arquitetura, os agentes são utilizados para encontrar o meIhor caminho (i.e., de menor latência) entre quaisquer pares de nós. Nesse sentido, o melhor caminho permitirá transferir de forma eficiente os segmentos do vídeo entre os nós da rede P2P. Para construir esse caminho (i.e., criar uma tabela de roteamento eficiente, composta pelos endereços dos nós por onde o segmento será transferido) cada agente é responsável por gerenciar as informações de um grupo de nós, dos quais analisa diferentes parâmetros, tais como o uso da largura de banda, número de mensagens perdidas, latência, entre outros. De posse dessas informações, o agente constrói a tabela de roteamento, utilizando para isso o algoritmo de Dijkstra (DIJKSTRA, 1959) (visando a minimização da latência total do caminho pelo qual o segmento deve atravessar) e a dissemina a outros agentes, para que possam modificar suas próprias tabelas.

Teket et Al. (TEKET; SAYIT; KARDAS, 2014) propõe utilizar agentes BDI (BeliefDesire-Intentions) em sistemas de live streaming, sistemas nos quais os mesmos segmentos consecutivos de um vídeo são disseminados a todos os nós. Nesse sistema, cada nó é modelado como um agente (i.e., existe uma associação um-a-um com um nó). O objetivo do agente é encontrar os melhores nós que possam diminuir o tempo para baixar os segmentos, melhorando a qualidade de serviço entregue ao usuário (ao evitar esperas por segmentos não baixados). Para isso, o agente recebe de um servidor centralizado (tracker) uma lista de nós que estão próximos em termos de distância geográfica (especificamente, dentro do mesmo provedor de serviços de Internet - ISP). Desses nós, o agente analisa quais podem prover os próximos segmentos a serem assistidos pelo usuário (calculando o tempo transcorrido desde a requisição pelo segmento até o que foi totalmente baixado) e escolhendo aqueles com os menores tempos. 
Yildirim et Al. (YILDIRIM; SAYIT; KARDAS, 2015) estende o trabalho anterior ao considerar, além da distância geográfica e da latência, mais dois parâmetros na seleção do melhor nó que melhorará o desempenho do streaming, sendo estes a largura de banda disponível para compartilhar o segmento e a quantidade de saltos (denominados de hops) entre o agente que requisita e o nó que disponibiliza o segmento. A escolha do nó, utilizando os novos parâmetros, é realizada da seguinte maneira: primeiro, o agente localiza os nós que estão próximos dele em termos de distância geográfica (utilizando a mesma estratégia do tracker do trabalho anterior). A seguir, o agente escolhe aqueles nós que tiverem uma largura de banda maior que um determinado valor inicial. Dos escolhidos, o melhor nó será aquele que tem menor latência e, caso hajam vários nós com latências iguais, escolhe-se o com menor quantidade de saltos.

O sistema Mobile Agent and Trust in Peer-to-Peer Streaming Media System (MATPS) (XU et al., 2013) é o trabalho mais próximo do nosso em termos da combinação de agentes com a DHT para sistemas de streaming de vídeos. No MATPS, a DHT é utilizada para encontrar o agente (MAMS) responsável por um determinado segmento, quem por sua vez, é responsável por gerenciar o grupo de nós que baixaram esse segmento. Para baixar um segmento, um nó (Search Agent) faz a requisição a um agente $a$ do sistema, quem por sua vez utiliza a DHT para localizar o agente $b$, responsável pelo segmento requisitado, e obter deste uma lista de nós que o baixaram. De posse dessa lista, o agente $a$ ordena os nós de acordo com certos critérios de seleção, utilizando métricas de confiança (e.g., tempo de conexão, quanta largura de banda destinaram para outros nós, etc.) e os entrega ao Search Agent. Essa abordagem de seleção tem o intuito de melhorar o tempo para baixar um vídeo, pois os nós mais confiáveis serão os escolhidos para compartilhar os segmentos. Embora a alternativa de utilizar a DHT para armazenar o MAMS responsável por um determinado segmento seja escalável, perde-se a oportunidade tanto de gerenciar os outros segmentos que foram baixados pelo grupo, quanto de criar relacionamentos entre diversos MAMS para permitir aos usuários assistirem o vídeo de forma não sequencial (pulando para um momento específico do vídeo).

As alternativas apresentadas focam principalmente na eficiência na busca por um determinado segmento. No entanto, em nenhuma delas trata-se o problema da esca- 
labilidade já citado nas seções anteriores. Nesse sentido, faz-se necessário dotar ao agente da capacidade de analisar a carga exercida nele (vinda tanto das requisições de busca quanto de atualização de quem baixou o segmento) para evitar que uma sobrecarga o deixe inacessível.

\subsubsection{DHT}

As pesquisas na área focam seu esforços na busca eficiente dos nós que baixaram um determinado segmento, utilizando para isso a DHT.

O sistema VMesh (YIU; JIN; CHAN, 2007) foi pioneiro no uso da DHT, onde a chave é o identificador do segmento e o valor corresponde a uma lista dos endereços IP de todos os nós (que representam os usuários) que baixaram esse segmento. No VMesh, como cada segmento está vinculado ao seguinte e ao anterior, cada nó que baixou um determinado segmento deve criar conexões com os nós que tenham baixado o segmento anterior e o seguinte. Com isso, melhora-se a eficiência na busca pelo segmento seguinte ao evitar ter que perguntar por essa informação à DHT. Por outro lado, quando o usuário deseja assistir um segmento qualquer (que não for o seguinte) é necessário usar o mecanismo de busca da DHT, apresentado na Seção 3.3 para encontrar o segmento. No caso de segmentos denominados populares (i.e., aqueles que são mais baixados), VMesh replica esses segmentos em diversos nós predecessores da estrutura, de forma proporcional à sua popularidade, permitindo que possam ser encontrados mais rapidamente. Para estimar a popularidade de um segmento, cada nó contabiliza a quantidade de vezes que o segmento foi disponibilizado para outros nós, disseminando esse valor com seus vizinhos.

O sistema Temporal-DHT (BHATTACHARYA et al., 2010) estende a ideia do VMesh, ao adicionar como chave na DHT a posição do vídeo que o usuário está assistindo atualmente (denominado de dynamic caching), junto com o tempo que essa chave permanecerá na estrutura (denominado TTL - Time-To-Live). Para evitar ter que atualizar a posição do vídeo a cada momento transcorrido, cada nó do sistema cria um buffer que armazena $k$ segmentos (que representa um intervalo de tempo de execução do vídeo), escolhendo somente um deles para ser adicionado na DHT. Com essa abordagem, o sistema possibilita agrupar os usuários que estão dentro do deter- 
minado intervalo de tempo do vídeo, melhorando a eficiência na busca dos nós que compartilham segmentos comuns nesse intervalo. Por outro lado, o Temporal-DHT também armazena a lista de segmentos baixados (assim como o VMesh), inserindo na DHT o identificador do segmento, junto com o segmento, e associando-os a um TTL com valor infinito (que evita ser removido da estrutura). No caso dos segmentos populares, o Temporal-DHT foi estendido em (BHATTACHARYA; YANG; PAN, 2011) que, igual ao VMesh, utiliza a mesma estratégia de contagem da quantidade de acessos. Por outro lado, a extensão do Temporal-DHT somente incrementa o valor do TTL do segmento, não replicando-o como faz o VMesh. Assim, o segmento, ao ter seu TTL incrementado, estará mais tempo na estrutura se comparado com um segmento que não é popular.

O sistema Time-Driven Mesh (TDM) (CHOI et al., 2011) também utiliza a posição do vídeo do Temporal-DHT, mas adicionando a localização geográfica do nó. Com isso, o nó prefere baixar os segmentos dos nós próximos a ele tanto em termos da posição quanto em termos da distância geográfica. O intuito dessa estratégia é melhorar o tempo para baixar um segmento, na qual assume-se que existe uma relação entre a distância geográfica e a latência (i.e., quanto menor a distância geográfica, menor a latência na comunicação).

O sistema DHT-Aided Chunk-Driven-Overlay (DCO) (SHEN et al., 2010) também utiliza a DHT, mas para encontrar os endereços IP dos coordenadores (i.e., nós responsáveis por um determinado segmento), diferenciando-se com os trabalhos anteriores que armazenam como valor na DHT uma lista de endereços IP do nós que baixaram o segmento. No DCO, o coordenador está encarregado por gerenciar um grupo de nós que compartilham esse segmento e por atender os pedidos por novos segmentos. Nesse contexto, o coordenador recebe as requisições advindas do grupo, contatando outros coordenadores (via DHT) para recuperar os endereços dos nós que possuem esses segmentos. De posse dos endereços, o coordenador é responsável por criar uma árvore de nós responsáveis por disseminar o segmento dentro do grupo, diminuindo a quantidade de mensagens trafegadas (se comparada com as técnicas de inundação - flooding (TANENBAUM; WETHERALL, 2010)). Para lidar com o problema da escalabilidade, caso a quantidade de requisições vindas do grupo estiverem sobrecarregando seu coordenador, este escolhe um dos nós do grupo (aquele mais 
estável em tempo de conexão) para ser coordenador de um novo grupo, eliminando-o do grupo atual, diminuindo assim os pedidos que possam vir dele.

O sistema HQMedia (ZHUO et al., 2013), assim como o DCO, também utiliza coordenadores (denominados Super Peers), onde cada um é responsável por um determinado segmento e encarregado por gerenciar um grupo de nós (denominados Common Peers). Além disso, HQMedia também oferece a promoção de um Common Peer a um Super Peer, de acordo com o tempo de conexão quando um Common Peer está sobrecarregado. A diferença com o DCO está na ordem em que um segmento deve ser obtido de outros peers. No HQMedia, cada nó possui um buffer (representando um intervalo de tempo do vídeo) onde armazena os segmentos a serem assistidos. Nesse buffer, cada segmento tem uma ordem de importância definida a priori (essa ordem não é necessáriamente sequencial). Assim, quando a posição do vídeo está próxima de atingir o tempo inicial do buffer, determinado pelo seu primeiro segmento, o nó baixa o segmento de acordo com a ordem de importância, pedindo para o coordenador uma lista de Common Peers que possuem o segmento, e escolhendo aquele que possui a maior largura de banda. Para que a busca por segmentos seja mais eficiente, HQMedia utiliza uma extensão da DHT (denominada SDHT - Streaming DHT) (ZHUO; GANG; YI, 2013) que permite localizar um segmento de forma mais eficiente que uma DHT, em troca de ter uma maior tabela de roteamento.

O sistema High Performance DHT (HP-DHT) (CIANCAGLINI, 2013), estende os trabalhos anteriores ao permitir que um coordenador (HP-Peer) armazene e disponibilize o segmento do vídeo. Essa abordagem permite que um nó, quando precisa de um determinado segmento que não foi baixado por alguém do seu grupo $g_{1}$, encontre (via DHT) o coordenador do segmento procurado e possa baixá-lo diretamente dele. Com isso, o coordenador não precisa devolver ao nó solicitante a lista de nós do grupo $g_{2}$ que baixaram o segmento, melhorando a eficiência na recuperação da informação. Quando o nó recebe o segmento, o sistema HP-DHT o replica de forma pró-ativa no grupo $g_{1}$, utilizando técnicas de disseminação (gossip (DEMERS et al., 1987)), mesmo que nenhum nó desse grupo o tenha solicitado. Cabe destacar que nos trabalhos anteriores a replicação é realizada de forma reativa, ou seja, somente quando um outro nó requisita o mesmo segmento.

Os três trabalhos mais próximos do nosso são arquiteturas que organizam os gru- 
pos de dispositivos com o objetivo de diminuir o tempo para baixar os segmentos do vídeo. Esses trabalhos estendem a ideia do sistema Waterfall (PARK et al., 2013), onde existe um servidor centralizado (tracker) responsável por organizar os nós que estão compartilhando os segmentos de uma cena do vídeo (o vídeo é dividido em cenas e cada cena consta de um conjunto de segmentos consecutivos definidos a priori). Nesse contexto, cada nó de um grupo que compartilha uma determinada cena é conectado com um nó do grupo que compartilha a cena seguinte. Assim, um nó pode baixar segmentos tanto dos nós do seu mesmo grupo quanto dos nós do grupo da cena seguinte. O primeiro trabalho (YUJI; FUJITA, 2014) evita o ponto único de falha do Waterfall (i.e., ter um único servidor centralizado), permitindo que cada cena fosse gerenciada por um Super Peer, criando assim uma estrutura hierárquica. Nessa estrutura, o Super Peer de uma cena é encarregado de se conectar com o Super Peer da cena seguinte, permitindo a melhor escalabilidade da arquitetura ao distribuir a funcionalidade do servidor centralizado. Entretanto, a arquitetura não comporta a busca por cenas além da seguinte. Quase ao mesmo tempo que o trabalho anterior, no segundo trabalho (ROCHA et al., 2016) foi apresentada uma arquitetura híbrida que também utiliza uma camada de Super Peers, mas que permite a estes se conectarem com cenas além da seguinte, utilizando para isso a estrutura da DHT. Na DHT da estrutura híbrida, a chave é o identificador da cena e o valor corresponde ao endereço IP do Super Peer responsável pela cena. Além disso, nesse trabalho, diferente do primeiro, o Super Peer pode gerenciar segmentos que estão fora da cena pela qual é responsável (i.e., podem haver sobreposições de segmentos em cenas diferentes), dependendo do comportamento do grupo em baixar esses segmentos. Finalmente, no terceiro trabalho (LIM, 2016), o sistema Clustered Segment Index (CSI) apresenta a mesma ideia da nossa arquitetura híbrida, armazenando como chave na DHT o identificador da cena, mas se diferenciando ao armazenar como valor a lista de endereços IP dos nós que estão compartilhando os segmentos da cena (e não de um Super Peer que gerencia o grupo, como no caso da estrutura híbrida).

Nas alternativas apresentadas, apesar de eficientes na busca por segmentos e de tratarem a escalabilidade distribuindo as responsabilidades do tracker nos nós da DHT, o problema da escalabilidade ainda permanece em aberto. Assim como mencionado na seção de DHT do cenário de sensores, o problema surge quando a 
quantidade de nós que solicita ou atualiza informações sobre uma determinada chave (nesse caso, o identificador de um segmento) é próxima da quantidade de requisições que o nó encarregado por essa chave pode atender. Nesse contexto, o nó encarregado pela chave experimenta o mesmo comportamento do servidor da arquitetura cliente/servidor, tornando a estrutura menos escalável. Para tratar desse problema, somente alguns nós do grupo poderiam ser responsáveis pelo envio de informações. Além disso, um membro da DHT poderia criar novos membros da DHT caso as requisições o esteja sobrecarregando, aumentando a escalabilidade das alternativas. 


\section{ARQUITETURA}

Neste capítulo é mostrada a visão geral da arquitetura proposta, assim como os conceitos e as camadas que a compõem.

\subsection{Visão geral}

A arquitetura proposta, denominada MATe (Multiagent Architecture for Taming edevices), estabelece relacionamentos entre os agentes e os dispositivos, com o objetivo de aumentar a escalabilidade da arquitetura na atualização e busca de informações. A visão geral da arquitetura, composta por duas camadas, é mostrada na Figura 13.

$\mathrm{Na}$ camada de dispositivos, estes formam grupos baseados nas informações que estão compartilhando (dispositivos $d_{1}$ a $d_{4}$ formam parte de um grupo). Para aumentar a escalabilidade da arquitetura, diminuindo a quantidade de informações transmitidas, somente aqueles que estão na borda do grupo estabelecem conexões entre si para decidir quais serão os responsáveis por agregar e enviar requisições de atualização e busca para o agente responsável por gerenciar o grupo (dispositivos $d_{1}, d_{2}$ e $d_{4}$ da borda $B_{1}$ enviam informações para o agente $a_{1}$ ). Nesse sentido, cada nó da borda será responsável por agregar as informações dos dispositivos vizinhos, isto é, que distam menos que $\delta$ (dispositivo $d_{2}$ é vizinho de $d_{3}$ ).

Para oferecer uma arquitetura descentralizada e colaborativa, cujos membros possuam requisitos tais como autonomia, proatividade e decentralização na tomada de decisões, uma escolha natural foi a utilização da abordagem de agentes (uma argumentação mais detalhada pode ser observada em (FORTINO et al., 2014; SEGHROUCHNI et al., 2008)). Na camada multiagentes, composta por agentes baseados em utilidade, cada agente monitora o comportamento das bordas do grupo que gerencia (o agente $a_{1}$ gerencia a borda $B_{1}$ da camada de dispositivos). Nesse sentido, o agente cria canais de comunicação com os dispositivos da borda (o agente $a_{1}$ tem um canal de comunicação com o dispositivo $d_{1}$ ). Ainda, os agentes estabelecem relacionamentos sequenciais e de saltos entre si para aumentar escalabilidade e manter 
Figura 13: Camada de Agentes e Dispositivos.

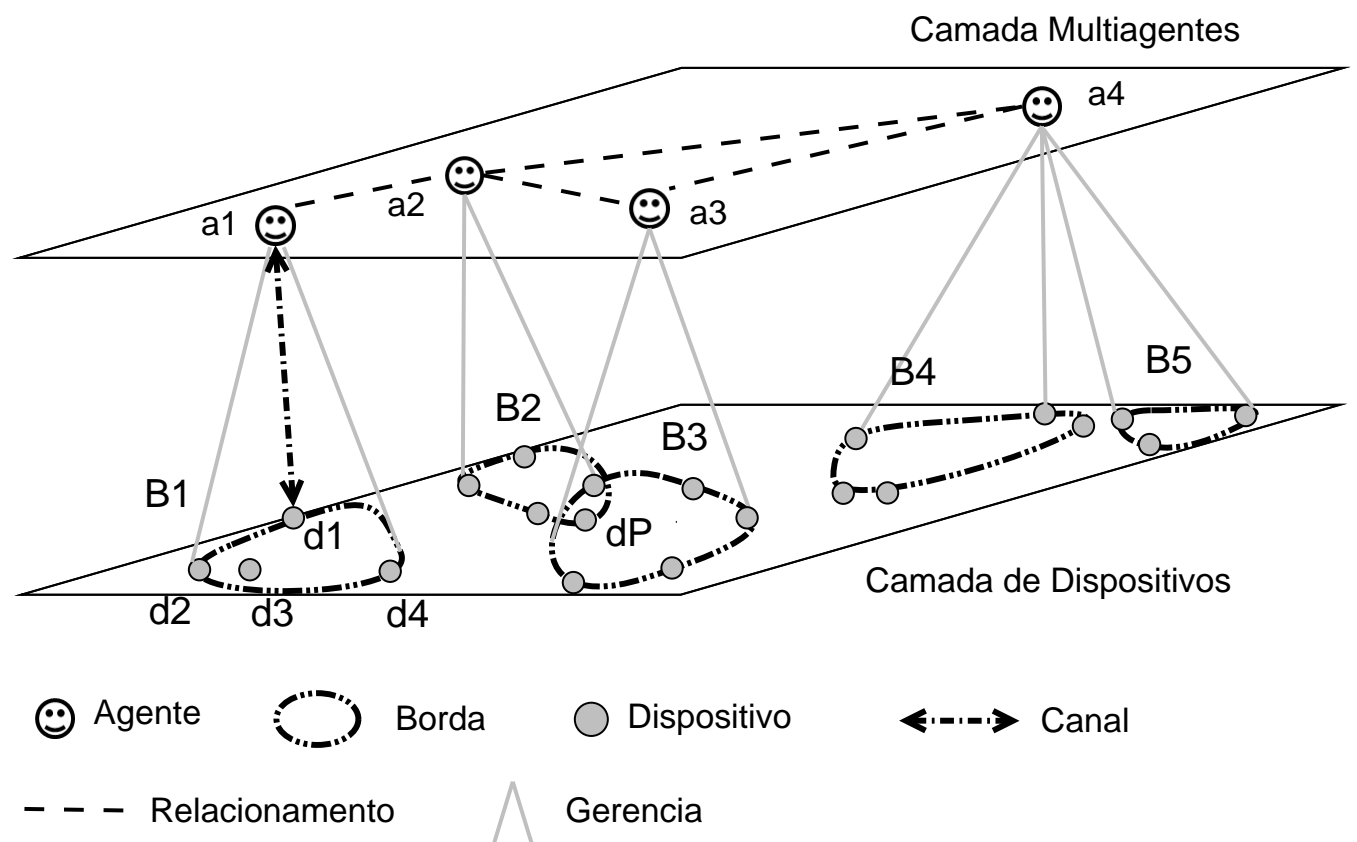

Fonte: Autor.

a eficiência da arquitetura. O relacionamento sequencial é aquele no qual os agentes estão próximos um do outro até uma distância $\phi$, utilizando por exemplo a distância euclidiana (o agente $a_{1}$ tem um relacionamento sequencial com $a_{2}$ ), o que lhes permite encaminharem as requisições quando a sobrecarrega está afetando a escalabilidade. O relacionamento de salto é aquele no qual os agentes estão separados além da distância de um relacionamento sequencial (o agente $a_{2}$ tem um relacionamento de salto com $a_{4}$ ), o que lhe permite buscar informações com eficiência ao fazer uso da ideia de roteamento da DHT. Quando dois agentes se relacionam, interagem trocando informações sobre suas bordas. O comportamento de uma borda pode ser de três estados: neutro, dividindo ou juntando. Uma borda aberta está em estado dividindo (o agente $a_{4}$ interage com os agentes $a_{2}$ e $a_{3}$ sobre a abertura da borda $B_{4}$ ). Por outro lado, uma borda que intersecta outras bordas está em estado juntando, isto é, os dispositivos das respectivas bordas estão até uma distância $\delta$ (o agente $a_{2}$ interage com o agente $a_{3}$ sobre a junção das bordas $B_{2}$ e $B_{3}$ ). Finalmente, uma borda está em estado neutro se não está nem no estado dividindo nem no estado juntando.

A seguir serão definidos os conceitos relacionados aos dispositivos e aos agentes, que podem ser observados nas Figuras 13 e 14, respectivamente. 


\subsection{Conceitos relacionados aos dispositivos}

Para formalizar os conceitos da arquitetura, seja $d_{i}$ um dispositivo, $D$ o conjunto de todos os dispositivos, $a$ um agente, $A$ o conjunto de todos os agentes, $S$ um espaço topológico subconjunto de $\mathbb{N}$ ou $\mathbb{R}^{2}, P$ um ponto em $S$ e $\delta, \phi, \epsilon \in \mathbb{R}$ definidos a priori. Cada dispositivo $d_{i}$ tem associado um tempo $t \in\{0,1, \ldots$, now $\}$, que não está sincronizado globalmente com outros dispositivos.

- $S e c_{i}$ : membro $i$ de uma n-partição de $S$ tal que:

$$
S=\bigcup_{i=1}^{n} S e c_{i}
$$

Para $S \subseteq \mathbb{N}$, cada $\operatorname{Sec}_{i}$ será considerado como um intervalo de valores. Já para $S \subseteq \mathbb{R}^{2}$, cada $\operatorname{Sec}_{i}$ será considerado como uma região quadrada. Além disso, $i$ é o identificador de $S_{e c}$. Na Figura 14 pode-se observar que $S$ foi particionado em quatro subconjuntos, também denominados setores.

- $\operatorname{Loc}\left(d_{i}, t\right)$ : a localização de $d_{i}$ no tempo $t$. A primeira e a última localização é dada quando $t=0$ e $t=$ now, respectivamente.

$$
\operatorname{Loc}\left(d_{i}, t\right)= \begin{cases}P, & \text { se } d \text { está ativo no tempo } t \\ 0, & \text { se } d \text { não está ativo no tempo } t .\end{cases}
$$

Para que um dispositivo $d_{i}$ esteja ativo no tempo $t$, é necessário que $d_{i}$ tenha capturado sua posição em um tempo $t_{i}$ tal que $\left|t-t_{i}\right|<\epsilon$, sendo $\epsilon$ um tempo predefinido de desvio (time skew). Além disso, sem perda de generalidade, foi escolhido a origem do sistema de coordenadas tal que $S$ resida no primeiro ortante.

- Historico $\left(d_{i}, t\right)$ : o conjunto composto pela união de todas as localizações de $d_{i}$ no intervalo $[0, t]$.

- Distancia $\left(d_{i}, d_{j}, t\right)$ : função que mede a distância entre os dispositivo $d_{i}$ e $d_{j}$ no tempo $t$.

- Vizinhos $\left(d_{i}, t\right)$ : o conjunto de dispositivos que distam de $d_{i}$ um valor menor ou 
igual a $\delta$, no tempo $t$, definido como:

$$
\operatorname{Vizinhos}\left(d_{i}, t\right)=\left\{d_{j} \in D: \operatorname{Distancia}\left(d_{i}, d_{j}, t\right) \leqslant \delta\right\}
$$

Cada elemento de $\operatorname{Vizinhos}\left(d_{i}, t\right)$ é chamado de vizinho de $d_{i}$.

- Conn $\left(d_{i}, d_{j}, t\right)$ : uma conexão virtual estabelecida entre os dispositivos $d_{i}$ e $d_{j}$ no tempo $t$, definida como:

$$
\begin{aligned}
\operatorname{Conn}\left(d_{i}, d_{j}, t\right)= & \left\{x * \operatorname{loc}\left(d_{i}, t\right)+(1-x) * \operatorname{loc}\left(d_{j}, t\right): x \in[0,1]\right. \\
& \left.\wedge d_{j} \in \operatorname{Vizinhos}\left(d_{i}, t\right)\right\}
\end{aligned}
$$

A fórmula pode ser entendida como o segmento de reta tendo como ponto inicial a localização de $d_{i}$ e como ponto final a localização de $d_{j}$. Na Figura 14 pode-se observar que os dispositivos $d_{a}$ e $d_{1}$ possuem uma conexão entre eles.

- $B$ : uma curva poligonal fechada e simples em $S$, no tempo $t$, tal que:

$$
B=\bigcup_{i=1}^{n-1} \operatorname{Conn}\left(d_{i}, d_{i+1}, t\right) \cup \operatorname{Conn}\left(d_{n}, d_{1}, t\right)
$$

Na Figura 14 pode-se observar que os dispositivos $d_{1}$ a $d_{6}$ pertencem à $B$, que denotaremos por borda. Além disso, é definido Interior $(B)$ como o interior da região limitada por $B$.

- $\operatorname{Grupo}(B, t)$ : o conjunto de dispositivos localizados na borda ou no interior de $B$ no tempo $t$, definido como:

$$
\begin{aligned}
\operatorname{Grupo}(B, t)= & \left\{d_{i} \in D: \exists d_{j} \in D \text { tal que } \operatorname{Conn}\left(d_{i}, d_{j}, t\right) \in B\right. \\
& \left.\cup \operatorname{loc}\left(d_{i}, t\right) \in \operatorname{Interior}(B)\right\}
\end{aligned}
$$

Na Figura 14 pode-se observar que $B=\cup_{i=1}^{5} \operatorname{Conn}\left(d_{i}, d_{i+1}, t\right) \cup \operatorname{Conn}\left(d_{6}, d_{1}, t\right)$ e $\operatorname{Grupo}(B, t)=\mathrm{B} \cup\left\{d_{a}, d_{b}\right\}$.

- Fronteira $(B, t)$ : o conjunto de dispositivos que distam de $B$ um valor menor ou igual a $\delta$, no tempo $t$, definido como:

$$
\begin{aligned}
\operatorname{Fronteira}(B, t)= & \left\{d_{i} \in D:\left(\exists d_{B} \in B\right) \wedge\right. \\
& \left.\left(d_{i} \in \operatorname{Vizinhos}\left(d_{B}, t\right)\right)\right\}
\end{aligned}
$$


Figura 14: Camada de Dispositivos.

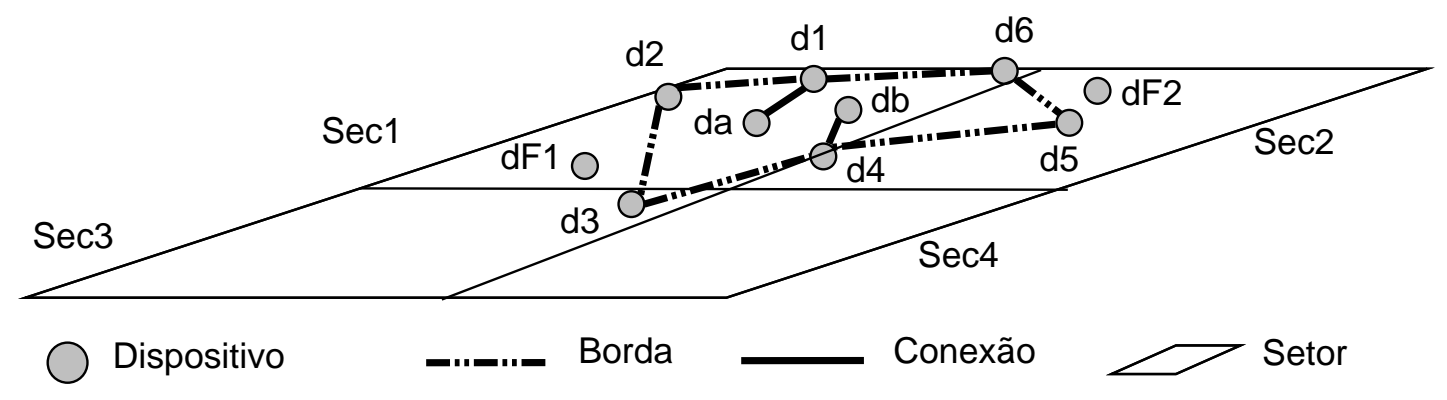

Fonte: Autor.

$\mathrm{Na}$ Figura 14, supondo que os dispositivos $d_{F 1} \in \operatorname{Vizinhos}\left(d_{3}, \mathrm{t}\right)$ e $d_{F 2} \in$ Vizinhos $\left(d_{5}\right.$, t) e que $d_{3}$ e $d_{5} \in B$, podemos afirmar que $d_{F 1}$ e $d_{F 2} \in \operatorname{Fronteira}(B, t)$.

- Setor $(B, t)$ : o conjunto de conjuntos $\operatorname{Sec}_{i} \in S$ que são interceptados pela borda $B$ ou pelo Interior $(B)$, definido como:

$$
\begin{aligned}
& \operatorname{Setor}(B, t)=\left\{\operatorname{Sec}_{i} \in S: \exists d_{i} \in \operatorname{Grupo}(B, t) \wedge\right. \\
&\left.\operatorname{Loc}\left(d_{i}, t\right) \in \operatorname{Sec}_{i}\right\}
\end{aligned}
$$

Na Figura 14 pode-se observar que os setores onde a borda está localizada são: $\mathrm{Sec}_{1}, \mathrm{Sec}_{2}$ e $\mathrm{Sec}_{3}$.

- $\operatorname{Dist}\left(B_{i}, B_{j}, t\right)$ como a distância entre as bordas $B_{i}$ e $B_{j}$, definida como:

$$
\begin{aligned}
\operatorname{Dist}\left(B_{i}, B_{j}, t\right)= & \min \left\{\operatorname{Distancia}\left(d_{k}, d_{l}, t\right):\right. \\
& d_{k} \in \operatorname{Grupo}\left(B_{i}, t\right) \wedge \\
& \left.d_{l} \in \operatorname{Grupo}\left(B_{j}, t\right)\right\}
\end{aligned}
$$




\subsection{Conceitos relacionados aos agentes}

- Canal $\left(a, d_{i}, t\right)$ como o canal de comunicação bidirecional entre o agente $a$ e o dispositivo $d_{i}$ no tempo $t$, definido como:

$$
\operatorname{Canal}\left(a, d_{i}, t\right)=\left\{\begin{aligned}
\text { true, } & \text { se há } \\
& \text { comunicação } \\
& \text { entre } a \text { e } d_{i} \\
\text { false, } & \text { caso contrário. }
\end{aligned}\right.
$$

Para evitar aumentar o número de mensagens transmitidas, foi estabelecido que dois agentes não podem ter um canal de comunicação com um mesmo dispositivo. Na Figura 13 pode-se observar que o agente $a_{1}$ tem um canal com 0 dispositivo $d_{1}$.

- Gerencia $(a, t)$ : o conjunto de bordas gerenciadas pelo agente $a$ no tempo $t$. Seja $\beta$ o conjunto de todas as bordas:

$$
\begin{aligned}
\operatorname{Gerencia}(a, t)= & \left\{B \in \beta \text { tal que } \exists d_{B} \in \operatorname{Grupo}(B, t)\right. \\
& \left.\wedge \operatorname{Canal}\left(a, d_{B}, t\right)=\operatorname{true}\right\}
\end{aligned}
$$

$\mathrm{Na}$ Figura 13 pode-se observar que $\circ$ agente $a_{1}$ gerencia a borda $B_{1}$ e que $\circ$ agente $a_{4}$ gerencia as bordas $B_{4}$ e $B_{5}$.

- AgentesEm(Loc $\left.\left(d_{i}, t\right)\right)$ : o conjunto de agentes que gerenciam bordas que limitam a região que contém $\operatorname{Loc}\left(d_{i}, t\right)$, definido como:

$$
\begin{aligned}
\operatorname{AgentesEm}\left(\operatorname{Loc}\left(d_{i}, t\right)\right)= & \left\{a \in A: \exists B_{a} \in \operatorname{Gerencia}(a, t)\right. \\
& \left.\wedge d_{i} \in \operatorname{Grupo}\left(B_{a}, t\right)\right\}
\end{aligned}
$$

Na Figura 13 pode-se observar que o ponto onde está localizado o dispositivo $d_{P}$ está sendo gerenciado pelos agentes $a_{2}$ e $a_{3}$.

Para os dois conceitos seguintes, sejam $B_{i} \in \operatorname{Gerencia}\left(a_{i}, t\right)$ e $B_{j} \in \operatorname{Gerencia}\left(a_{j}, t\right)$.

- SeqRel $\left(a_{i}, a_{j}, t\right)$ : o relacionamento lógico (denominado relacionamento sequencial) estabelecido entre os agentes $a_{i}$ e $a_{j}$ no tempo $t$ definido como: 


$$
\operatorname{SeqRel}\left(a_{i}, a_{j}, t\right)= \begin{cases}\text { true } & \text { if } \exists d_{i} \in \operatorname{Grupo}\left(B_{i}, t\right) \\ & \wedge \exists d_{j} \in \operatorname{Grupo}\left(B_{j}, t\right): \\ & \operatorname{Distancia}\left(d_{i}, d_{j}, t\right) \leqslant \phi \\ \text { false } & \text { caso contrário. }\end{cases}
$$

- SaltoRel $\left(a_{i}, a_{j}, t\right)$ : o relacionamento lógico (denominado relacionamento de salto) estabelecido entre os agentes $a_{i}$ e $a_{j}$ no tempo $t$ definido como:

$$
\operatorname{SaltoRel}\left(a_{i}, a_{j}, t\right)= \begin{cases}\text { true } & \text { if } \exists d_{i} \in \operatorname{Grupo}\left(B_{i}, t\right) \\ & \wedge \exists d_{j} \in \operatorname{Grupo}\left(B_{j}, t\right): \\ & \operatorname{Distancia}\left(d_{i}, d_{j}, t\right)>\phi \\ \text { false } & \text { caso contrário. }\end{cases}
$$

Formalizados os componentes da arquitetura e a relação entre eles, apresentamos nas próximas seções os componentes das camadas, explicitando as arquiteturas internas e seus processos de execução.

\subsection{Camada de dispositivos}

Nesta seção será detalhada a arquitetura interna dos dispositivos, como caracterizar um dispositivo da fronteira e, finalmente, quais são as atividades que esse dispositivo deve executar.

\subsubsection{Arquitetura interna do dispositivo}

Como mostrado na Figura 15, cada dispositivo é composto por dois módulos, necessários para que possa operar na camada de dispositivos, permitindo-Ihe comunicar-se com outros dispositivos e com um agente. Os módulos, descritos a seguir, são: (i) o módulo de agente e (ii) o módulo de serviços.

Módulo de Interação com Agente. Esse módulo é responsável por manter o canal de comunicação com o agente que gerencia o grupo ao qual pertence o dispositivo. Esse canal serve para que o dispositivo comunique ao agente (através de mensagens 
Figura 15: Arquitetura Interna do Dispositivo, traduzida de (ROCHA; BRANDãO, 2015).

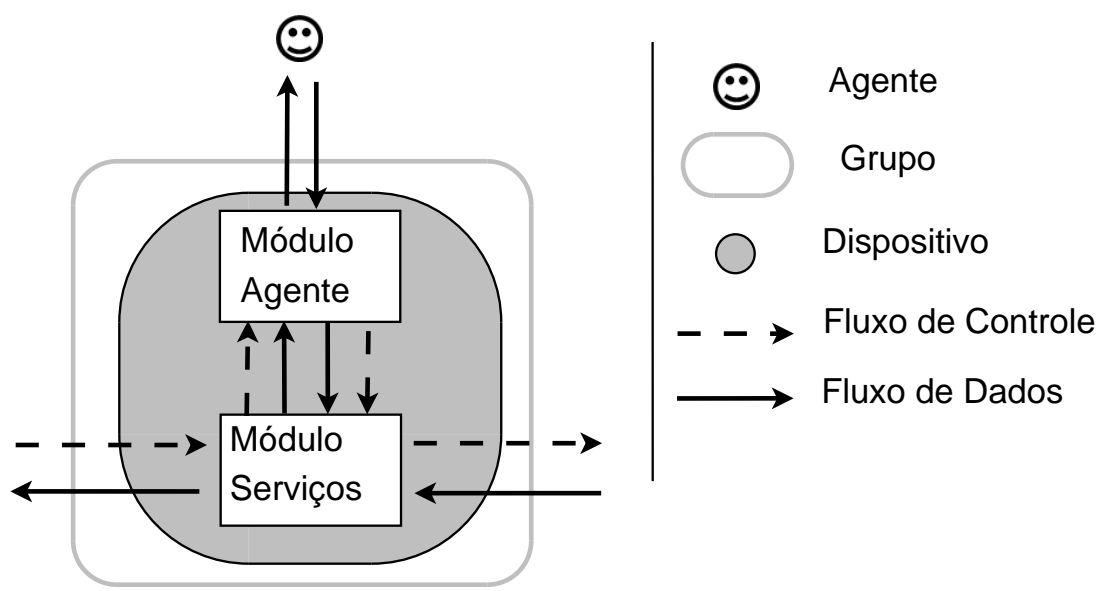

Fonte: Autor.

de fluxo de dados) as informações agregadas e para que o agente comunique ao dispositivo (através de mensagens de fluxo de controle) que foi escolhido para atuar como agente e que, portanto, deve se agentificar (i.e., transformar de dispositivo a agente).

Módulo de Serviço. Esse módulo é responsável pelas tarefas de armazenar e manter atualizados os estados internos do dispositivo (i.e., as conexões com seus vizinhos, sua localização atual e passadas e o tempo em que foram capturadas), assim como calcular, através de uma função de utilidade, se o dispositivo pode exercer certas responsabilidades.

A tarefa de armazenagem deve considerar que o dispositivo pode ter uma capacidade de armazenamento limitada. Assim, será necessário considerar a remoção de algumas das localizações passadas.

A tarefa de atualização dos estados internos deve ser realizada a cada $\Delta t$ predefinido (transcorridos desde a última vez que a tarefa foi realizada). Para atualizar seus estados internos, o dispositivo $d_{i}$ obtém uma lista atualizada de vizinhos (inicialmente a obtém do agente) e envia uma requisição para alguns dos dispositivos $d_{j}$ da lista. Assim que $d_{j}$ recebe a requisição, devolve para $d_{i}$ sua localização e seu tempo atual (denominado now), através de mensagens de fluxo de dados. De posse dessa informação, $d_{i}$ atualiza seu tempo atual e remove dos seus $\operatorname{Vizinhos}\left(d_{i}\right.$, now $)$ aqueles que não devolveram a requisição. 
Para atualizar o tempo atual (now) do dispositivo $d_{i}$ com os tempos atuais recebidos de outros dispositivos, pode-se utilizar o algoritmo modificado de Berkeley (GUSELLA; ZATTI, 1985), que permite a sincronização distribuída dos tempos, assumindo que nenhum dispositivo tem uma fonte confiável e precisa do tempo.

A função de utilidade é dependente do cenário onde será implantada a arquitetura e será explicada nas Seções 7.1.3 e 7.2.3 para os cenários de monitoramento de sensores e de VoD, respectivamente.

\subsubsection{Caracterizando dispositivos da fronteira}

A escolha da fronteira é uma atividade fundamental, pois, para uma borda $B$, somente os dispositivos $d_{i} \in \operatorname{Fronteira}(B, t)$ serão responsáveis por executar as atividades que atualizam as informações do grupo. Isso evita que todos os membros do grupo executem tais atividades, aumentando a escalabilidade da arquitetura. Para isso, o primeiro passo que todo dispositivo deve realizar é analisar se ele faz parte da fronteira do grupo. Como esse passo é completamente dependente do cenário onde será implantada a arquitetura, será explicado nas Seções 7.1.3 e 7.2.3 para os cenários de sensores e de VoD, respectivamente.

\subsubsection{Responsabilidades dos dispositivos da fronteira}

As atividades a serem executados pelos dispositivos que fazem parte da fronteira são: (D1) atualizar a localização da fronteira; (D2) perceber se existe alguma abertura na borda; (D3) atualizar as conexões com os dispositivos vizinhos; e (D4) agentificar o dispositivo. Cabe destacar que as atividades D1, D2 e D3 podem ser executadas em paralelo. Os algoritmos que implementam cada atividade são mostrados na Seção A.1.

D1 $\mathrm{Na}$ atividade de atualização da localização da fronteira, inicialmente cada dispositivo $d_{i} \in B$ é responsável por agregar e armazenar a localização dos seus vizinhos (utilizando as mensagens de fluxo de dados do módulo de serviço) e enviar essas informações ao agente que gerencia o grupo, a cada $\Delta t$. A responsabilidade por executar essa atividade é rotacionada entre os dispositivos $d_{f} \in \operatorname{Fronteira}(B, t)$, 
evitando que o dispositivo $d_{i}$ consuma toda sua energia. Para isso, $d_{i}$ analisa se pode continuar executando a atividade, usando a função de utilidade do seu módulo de serviço.

D2 $\mathrm{Na}$ atividade de percepção de abertura da borda, cada par de dispositivos consecutivos $d_{i}, d_{i+1} \in B$ deve verificar se a conexão entre eles continua existindo. Caso essa conexão deixe de existir (i.e., em qualquer momento o dispositivo $d_{i}$ pode sair do grupo e deixar de ser um vizinho de $d_{i+1}$ ), significa que foi gerada uma abertura (ou separação) na borda. Nesse caso, cada um deles deve, de forma independente, encontrar um caminho alternativo para preencher a separação e notificar ao agente desse caminho. Para isso, $d_{i}$ utiliza os seguintes passos: seleciona o dispositivo $d_{\min } \in \operatorname{Vizinhos}\left(d_{i}, t\right)$ tal que Distancia $\left(d_{\min }, d_{i+1}, t\right)$ é mínima e envia uma requisição de preenchimento para $d_{\min }$. De posse da requisição, $d_{\min }$ executa os mesmos passos, até que $d_{i+1}$ (ou algum dispositivo da borda) seja alcançado. Se o caminho for encontrado, $d_{i}$ notifica o novo caminho ao agente, que detectará e resolverá inconsistências caso $d_{i}$ e $d_{i+1}$ encontrem caminhos diferentes. Por outro lado, se o caminho não for encontrado, $d_{i}$ e $d_{i+1}$ notificam ao agente da separação da borda. $O$ agente então analisará se é necessário dividir o grupo ou não, como será descrito na Seção 5.5.3. A Figura 16(a) mostra que os dispositivos $d_{1}$ e $d_{2}$ estão desconectados, gerando uma borda aberta, e a Figura 16(b) mostra um caminho que fechou a borda, passando pelos dispositivos que pertencem à fronteira entre $d_{1}$ and $d_{2}$.

D3 $\mathrm{Na}$ atividade de atualização de conexões entre vizinhos, o dispositivo $d_{i}$ deve buscar seus Vizinhos $\left(d_{i}, t\right)$ utilizando para isso os seguintes passos: $d_{i}$ recebe uma lista $L$ de dispositivos, vinda do agente ou de outros dispositivos. Para cada $d_{L} \in L$, se Distancia $\left(d_{i}, d_{L}, t\right) \leqslant \delta, d_{i}$ cria uma conexão com $d_{L}$. A seguir, $d_{i}$ adiciona a $L$ cada $d_{j} \in \operatorname{Vizinhos}\left(d_{L}, t\right) \cap \operatorname{Vizinhos}\left(d_{i}, t\right)$, desde que $d_{j} \notin L$. Esses passos se repetem até que uma quantidade predefinida de dispositivo em $L$ foram analisados, utilizando o fluxo de mensagens de dados do módulo de serviço.

D4 $\mathrm{Na}$ atividade de agentificação, é feita uma requisição do agente para um dispositivo $d_{i}$ se agentificar com o objetivo de aumentar a escalabilidade da arquitetura. Nessa atividade, o dispositivo deve calcular se é capaz de realizar esse com- 
Figura 16: Atividade de Divisão, traduzida de (ROCHA; BRANDãO, 2016).

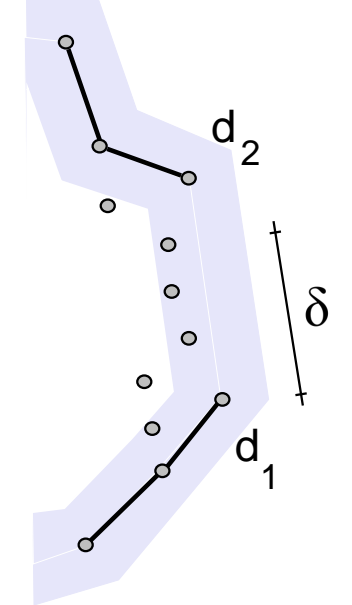

(a) Borda Aberta.

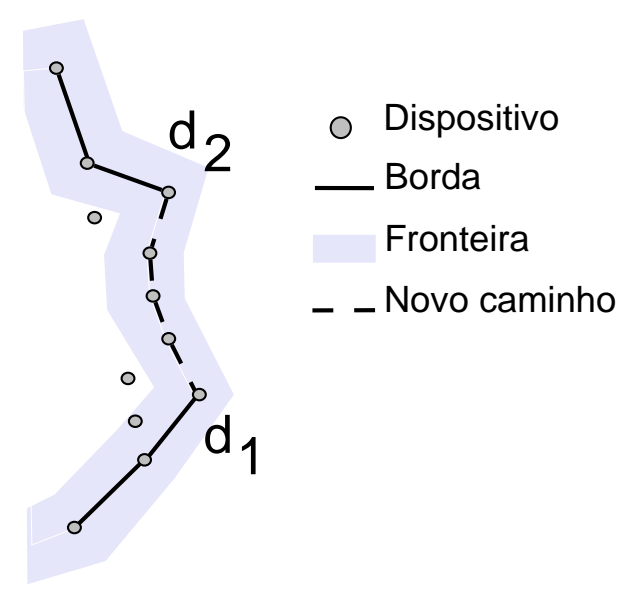

(b) Caminho Alternativo.

Fonte: Autor.

portamento, usando para isso a função de utilidade do seu módulo de serviço, aceitando ou negando o pedido. Note que ao agentificar o dispositivo, este passa a ter duplo papel, atuando como dispositivo na camada de dispositivos e como agente na camada de agentes.

\subsection{Camada multiagentes}

$\mathrm{Na}$ arquitetura proposta, a camada multiagentes consiste de agentes baseados na utilidade responsáveis por gerenciar um conjunto de bordas de dispositivos. Nesta camada, cada agente é responsável também por alcançar um objetivo global e um objetivo local. O objetivo global consiste em estabelecer relacionamentos de saltos com outros agentes, para encontrar de forma eficiente os agentes responsáveis pelas bordas próximas de uma determinada localização. O objetivo local consiste em administrar a escalabilidade do agente, distribuindo a carga gerada pela borda (i.e., pelas requisições recebidas) tanto entre os novos agentes que serão criados quanto entre os agentes com relacionamentos sequenciais.

Nesta seção será detalhada a estrutura interna do agente e como criar os relacionamentos de saltos. Em seguida, será analisado como buscar um agente com esses 
Figura 17: Arquitetura interna de três agentes traduzida de (ROCHA; BRANDãO, 2015).



Fonte: Autor.

relacionamentos. Finalmente, serão mostradas as atividades que o agente deve executar.

\subsubsection{Arquitetura interna do agente}

Como mostrado na Figura 17, cada agente é composto por três módulos, necessários para que possa operar na camada multiagentes: (i) o módulo de bordas; (ii) o módulo sequencial; e (iii) o módulo de saltos.

Módulo de Bordas. Esse módulo é responsável pela tarefa de armazenar e manter atualizadas as crenças do agente (i.e., os canais de comunicação, o espaço coberto e a carga aplicada por cada borda) assim como analisar as solicitações de ingresso de novos dispositivos.

As tarefas de atualização das crenças e análise de solicitações de ingresso são reativas às ações externas (e.g., reage quando um dispositivo envia uma informação ao agente via a atividade D1). Essas tarefas são realizadas através da troca de mensagens de controle de fluxo entre os agentes com relacionamentos sequenciais. Por outro lado, a tarefa da análise da escalabilidade é proativa. Nesse sentido, o agente verifica a carga gerada pelo gerenciamento de todas suas bordas em um certo período de tempo e calcula (utilizando uma função de utilidade) se essa carga, combinada com 
suas outras responsabilidades, pode afetar seu desempenho até o ponto de deixá-lo inacessível (portanto, afetando a escalabilidade da arquitetura).

A função de utilidade é dependente do cenário onde será implantada a arquitetura e será explicada nas Seções 7.1.4 e 7.2.4 para os cenários de monitoramento de sensores e de VoD, respectivamente.

Módulo Sequencial. Esse módulo é responsável por armazenar, criar e manter atualizados os relacionamentos sequenciais do agente $a$. Na arquitetura, os relacionamentos sequenciais de $a$ podem ser visualizados como os relacionamentos entre $a$ e o conjunto de agentes que gerenciam bordas localizadas no mesmo setor ou em setores adjacentes às bordas gerenciadas pelo agente $a$. A tarefa de atualização dos relacionamentos é proativa, permitindo analisar se é possível juntar algumas bordas (tanto das gerenciadas quanto das bordas de outros agentes com relacionamentos sequenciais), desde que essa junção não afete o desempenho do agente até o ponto de deixá-lo inacessível. Essa tarefa é realizada através da troca de mensagens de controle de fluxo entre os agentes com relacionamentos sequenciais.

Módulo de Saltos. Esse módulo é responsável por armazenar, criar e manter atualizados os relacionamentos de saltos do agente.

$\mathrm{Na}$ arquitetura, os relacionamentos de saltos podem ser visualizados como uma tabela, onde os setores são mapeados a agentes. Um agente, que gerencia bordas localizadas no setor $\mathrm{Sec}_{r}$ (cujo identificador é $r$ ), pode acessar duas tabelas: a tabela de predecessores e a tabela de sucessores. Na tabela de sucessores, cada registro $i$ aponta para vários agentes que gerenciam bordas localizadas no setor sucessor de $r$, calculados de acordo com a fórmula $r+2^{i}$ (STOICA et al., 2001). A tabela de predecessores, por sua vez, somente tem dois registros: o primeiro aponta para 0 $S e c_{1}$ (o identificador do primeiro setor) e o segundo aponta para o setor localizado no meio entre $S e c_{1}$ e $S e c_{r}$ (i.e., apontando para o agente que gerencia bordas localizadas no setor $S e c_{[r / 2\rfloor}$ ). A Figura 18 mostra as tabelas para um agente $a_{r}$ (identificado como $r$ ) com uma borda localizada no setor $\mathrm{Sec}_{r}$. Nessa figura é possível observar que o terceiro registro (i.e., $r+2^{3}$, ou $r+8$ ) da tabela de sucessores está apontando para três agentes (i.e., $a 8, a 9$ e $a 11$ ). Cabe destacar que a visão do agente, para esse setor, é parcial, podendo existir um outro agente $a_{x}$ que não foi considerado por $a_{r}$. 
Figura 18: Relacionamentos de Salto do Agente.

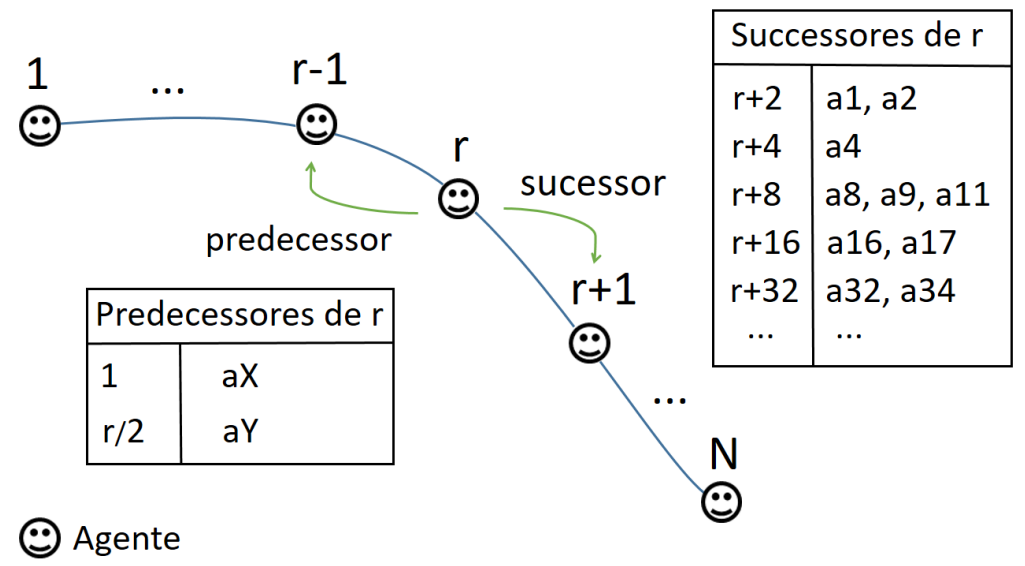

Fonte: Autor.

A tarefa de atualizar os relacionamentos de saltos é proativa e realizada através da troca de mensagens de controle de fluxo entre os agentes com relacionamentos de saltos.

Para determinar se um setor $S e c_{i}$ é predecessor ou sucessor de um $S e c_{j}$, é necessário ordená-los de alguma maneira. Para isso, existem diversas alternativas que já foram utilizadas em sistemas onde a informação está distribuída, tais como a curva de Hilbert(SCHMIDT; PARASHAR, 2003; GANESAN; BAWA; GARCIA-MOLINA, 2004), a Quad-tree(TANIN; HARWOOD; SAMET, 2007), entre outras.

\subsubsection{Buscando um agente}

A busca de um agente pode ser realizada tanto por um novo dispositivo $d_{\text {new }}$ que não faz parte da arquitetura (solicitando o ingresso ao sistema) quanto por um dispositivo $d_{\text {old }}$ que já faz parte dela (solicitando buscar ou entrar em outro grupo). Independente do tipo de solicitação, o dispositivo (denominemos este por $d_{i}$ ) deve enviar para algum agente da camada multiagentes a solicitação AgentesEm $\left(\operatorname{Loc}\left(d_{i}, t\right)\right)$, que retorna o conjunto de agentes que gerenciam alguma borda que está no mesmo setor de $\operatorname{Loc}\left(d_{i}, t\right)$. Para encontrar esses agentes, a camada multiagentes, realizará um processo de busca binária utilizando $O(\log N)$ troca de mensagens, com $N=|S|$ (i.e., a quantidade de subconjuntos do espaço $S$ ). Para explicar esse processo, seja $a_{r}$ o agente que recebeu a solicitação de $d_{i}$ e seja $\operatorname{Loc}\left(d_{i}, t\right) \in S e c_{i}$. Os passos executados pelo processo de busca são: 
1. Se o setor $\operatorname{Sec}_{i} \in \operatorname{Setor}(B, t)$ para algum $B \in \operatorname{Gerencia}\left(a_{r}, t\right), a_{r}$ aceita a solicitação (analisando no seu Módulo de Bordas se o novo membro não afetará sua escalabilidade), e notifica o dispositivo que será adicionado a $\operatorname{Grupo}(B, t)$. Por outro lado, se $a_{r}$ não aceita a solicitação, este deverá encaminhá-la aos agentes com relacionamentos sequenciais, utilizando o Módulo Sequencial, os quais repetirão o mesmo processo.

2. Se o setor $\operatorname{Sec}_{i} \notin \operatorname{Setor}(B, t), a_{r}$ procura nas suas tabelas de precessores ou sucessores do Módulo de Saltos por um agente $a_{C}$ que gerencia uma borda (localizada em $\mathrm{Sec}_{C}$ ) próxima de $\mathrm{Sec}_{i}$ em termos de distância. Note que, como um registro na tabela pode armazenar vários agentes (vide Figura 18), $a_{C}$ será escoIhido aleatoriamente dentre eles, distribuindo assim as solicitações de ingresso.

3. De posse do agente $a_{C}$ (obtido no passo anterior), o pedido de solicitação é reenviado a ele através da troca de mensagens de controle de fluxo, via o Módulo de Saltos, que repetirá os passos 1 e 2 .

\subsubsection{Responsabilidades do agente}

As atividades a serem executadas pelos agentes são: (A1) buscar um determinado setor, a partir de uma solicitação de ingresso ou de busca realizada por um dispositivo; (A2) monitorar o comportamento dos dispositivos do grupo; (A3) receber as atualizações de localização da borda; (A4) perceber se o grupo está se juntando com outros; (A5) perceber se o grupo está se separando, evitando que a borda seja aberta; (A6) perceber se o grupo deve ser dividido. Cabe destacar que as atividades A2, e A4 a A6 podem ser executadas em paralelo às demais. Os algoritmos que implementam cada atividade são mostrados na Seção A.2.

A1 $\mathrm{Na}$ atividade de busca por um setor, quando $\operatorname{Loc}\left(d_{i}, t\right)$ é recebida pelo agente $a$, é verificado no seu Módulo de Bordas se $d_{i}$ está localizado em um $\operatorname{Grupo}(B, t)$ para algum $B \in$ Gerencia $(a, t)$. Se assim for, $a$ notifica $d_{i}$ que ele será adicionado a $\operatorname{Grupo}(B, t)$. Caso contrário, $a$ utiliza a busca da seção anterior para encontrar o agente $a_{i}$ responsável por $d_{i}$. Em seguida, se a informação $\operatorname{Loc}\left(d_{i}, t\right)$ é de interesse do agente $a$, ele adiciona o agente $a_{i}$, na sua tabela de roteamento. É 
importante destacar que em uma próxima solicitação pela mesma informação, a alteração realizada na tabela aumentará a eficiência na busca de $O(\log n)$ para $O(1)$. Além disso, a mudança em um registro $i$ da tabela de roteamento de um agente $a_{r}$ que gerencia uma borda no setor $S e c_{r}$, não afetará a corretude da busca desde que aponte para um agente que gerencie uma borda no setor cujo identificador esteja no intervalo $\left[r+2^{i}, r+2^{i+1}\right]$ (TANENBAUM; STEEN, 2006).

Por exemplo, vamos supor que inicialmente um agente (identificado como $r$ ) gerencia um grupo do setor $S e c_{r}$ e começa a receber repetidamente solicitações pelo setor $r+21$ (Figura 19(a)). Nesse contexto, se usarmos o processo de busca da Seção 5.5.2, a solicitação será encaminhada ao agente $a_{y}$ que gerencia a informação $r+16$ (o mais próximo de $r+21$ ) que, por sua vez, fará o mesmo até encontrar o responsável por $r+21$. Na nossa arquitetura, o agente pode aprender sobre esse comportamento (de repetitivas solicitações sobre uma determinada informação) e alterar alguns registros da sua tabela de roteamento. Assim, como mostra a Figura 19(b), o registro, ao invés de apontar para o agente $a_{y}$ que gerencia a informação $r+16$ (na linha pontilhada), apontará diretamente para o agente $a_{n}$ que gerencia a informação $r+21$, deixando os outros registros inalterados.

A2 $\mathrm{Na}$ atividade de monitoramento de dispositivos, o agente administra, a cada $\Delta t$, a quantidade de dispositivos que fazem parte da borda. Para tanto, baseado na função de utilidade do Módulo de Bordas, o agente permite o ingresso de novos membros e elimina aqueles cujo comportamento difira das responsabilidades atribuídas. Por exemplo, um dispositivo que pertença à fronteira será removido do grupo caso não colete as informações dos seus vizinhos ou não as envie ao agente. É importante destacar que esse monitoramento permite que a escalabilidade da arquitetura aumente, evitando que o agente fique sobrecarregado pelas solicitações advindas da fronteira.

A3 $\mathrm{Na}$ atividade de atualização da borda, quando a informação das localizações dos dispositivos da fronteira $\operatorname{Loc}\left(d_{i}, t\right)$ é recebida (através da atividade D1 que atualiza a fronteira), o agente atualiza a borda coberta pelo grupo do Módulo de Bordas e notifica seus relacionamentos sequenciais a respeito dessas informações, utilizando mensagens de controle de fluxo via o Módulo Sequencial. As 
Figura 19: Relacionamentos de saltos modificados.

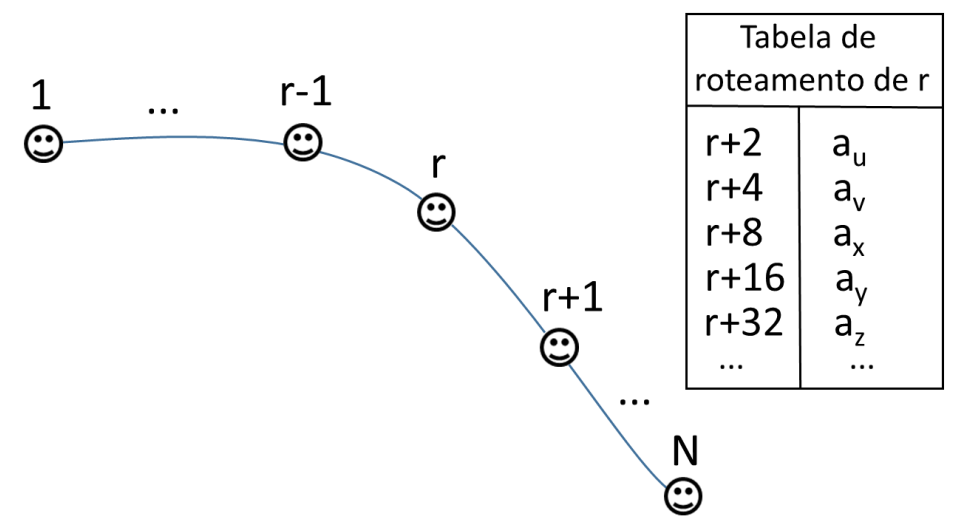

(a) Relacionamentos Iniciais.

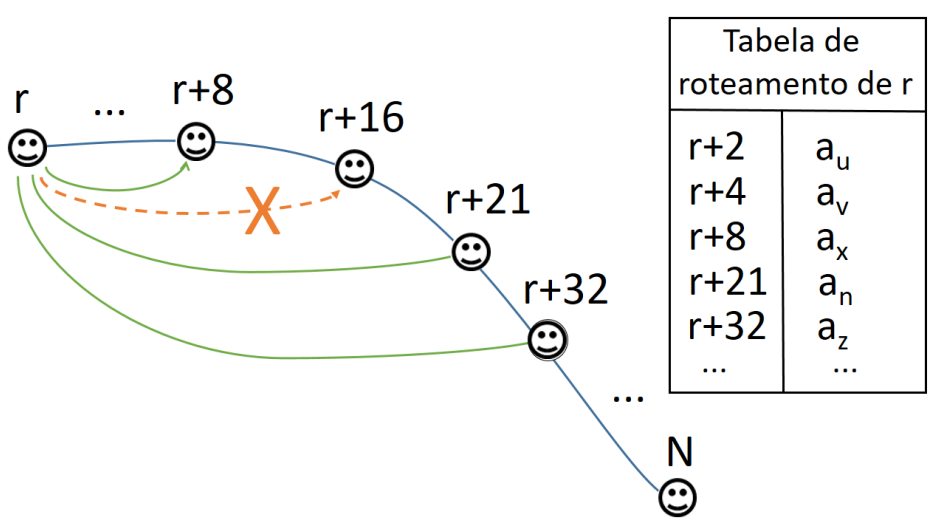

(b) Relacionamentos Modificados.

Fonte: Autor.

notificações servirão para que os agentes possam analisar se os grupos estão se intersectando e devem ser juntados, pela atividade A4.

A4 $\mathrm{Na}$ atividade de junção de grupos há uma interação entre o agente $a$ e os agentes dos relacionamentos sequenciais para analisar se existe uma intersecção entre suas bordas. Em caso positivo, eles negociam e decidem por votação (baseados na função de utilidade do Módulo de Bordas) quem será o responsável por gerenciar a borda resultante da junção. Nesse caso, o agente eleito $a_{i}$ calculará a nova borda e eliminará os outros agentes da camada multiagentes. Cabe destacar que essa atividade não é obrigatória caso o grupo formado pela junção gere algum problema de escalabilidade no agente $a_{i}$ e que, durante a votação, um agente pode rejeitar ser o responsável. No entanto, assim que for eleito, o agente não poderá desfazer sua decisão. 
A5 $\mathrm{Na}$ atividade de percepção da separação do grupo, quando o agente $a$ recebe a notificação de separação (advinda da atividade D2 que divide da borda) é analisado se a separação entre os dispositivos gera ou não uma abertura na borda. Se gera a abertura, $a$ tenta encontrar algum dispositivo $d$ da fronteira (do seu Módulo de Bordas) que esteja habilitado a ser agentificado, baseando-se no resultado da sua função de utilidade. Em seguida, o agente $a$ transforma $d$ em um novo agente, usando a atividade D4 (de agentificação), e negocia com este as responsabilidades sobre o grupo resultante da divisão. Finalmente, o agente $a$ divide o grupo em dois e notifica seus relacionamentos sequenciais (do Módulo Sequencial) sobre as novas bordas e sobre a inclusão do novo agente. Por outro lado, caso a notificação recebida (também pela atividade D2) seja um caminho alternativo, $a$ o utiliza para atualizar a borda.

A6 $\mathrm{Na}$ atividade de divisão do grupo, que ocorre quando um agente percebe que a quantidade de solicitações advindas dos dispositivos da fronteira está diminuindo seu desempenho (e portanto comprometendo a escalabilidade), o agente pode dividir o grupo em dois, criando um novo agente (o qual gerenciará um dos grupos) e notificando seus relacionamento sequenciais sobre ele, da mesma forma que a atividade $A 5$ faz. Diferentemente de $A 5$, em A6 é o próprio agente que identifica a necessidade de dividir o grupo.

\subsection{Análise da arquitetura}

A arquitetura proposta neste capítulo, composta pela visão geral, os módulos internos dos componentes e suas responsabilidades, está diretamente relacionada à questão de pesquisa sobre a reutilização da arquitetura em diversos domínios de aplicação QP2. Note que se bem as atividades são independentes do domínio, mencionamos que existem algumas funcionalidades que são específicas destes.

A escalabilidade da arquitetura é ampliada tanto na camada de dispositivos quanto na camada de agentes. Tal fato fica evidenciado pela criação e eliminação de agentes e pelo uso da fronteira, mas a análise à questão de pesquisa sobre o aumento da escalabilidade QP1 só será realizada no Capítulo 8. Apesar disso, a arquitetura apresenta algumas vantagens e desvantagens, se comparada com os trabalhos do 
Capítulo 4, que serão analisadas a seguir.

Do ponto de vista da camada de dispositivos, analisaremos a quantidade de mensagens trocadas, a eficiência na busca por um dispositivo específico, o custo de criar uma borda e os casos onde não é possível gerar uma borda. Do ponto de vista da camada de agentes, analisaremos a distribuição de carga entre os agentes com relacionamentos sequenciais, a quantidade de mensagens trafegadas e a busca recorrente por uma mesma informação.

\subsubsection{Análise da camada de dispositivos}

- Quantidade de Mensagens. A arquitetura propõe o uso da borda para diminuir a quantidade de mensagens trafegadas na atualização de informações, sendo uma vantagem da arquitetura em pró da escalabilidade. Nos trabalhos relacionados, todos os dispositivos de um determinado grupo enviam as informações a um dispositivo responsável por agregá-las (e.g, Group Master - GM). Nesse sentido, se houverem $n$ dispositivos, serão enviadas $n$ mensagens para o GM. Entretanto, se a borda é composta por uma quantidade de dispositivos $m \ll n$, o uso dela diminui a sobrecarga no GM responsável pelo grupo. Na nossa arquitetura o GM corresponde a um agente.

- Eficiência na Busca por um Dispositivo. Como mencionado na Seção 5.2, a borda é composta somente pelos dispositivos que circundam um determinado grupo de dispositivos, sendo uma das responsabilidades do dispositivo da borda agregar a informação dos seus vizinhos. Nesse sentido, o agente responsável por esse grupo somente receberá informações da fronteira (dispositivos da borda e seus vizinhos), mas não poderá buscar de forma eficiente as informações de um dispositivo que esteja no interior do grupo, sendo uma desvantagem da arquitetura. Em contrapartida, os trabalhos relacionados permitem a busca de qualquer dispositivo de forma eficiente, pois todos os dispositivos do grupo enviam suas informações ao agente.

- Criação da Borda. Como mencionado na atividade A3 (de atualização da borda), cabe ao agente a responsabilidade de criar e manter atualizada a borda do grupo. Neste caso, o agente obrigatoriamente terá a sobrecarga inicial da 
criação da borda, sendo uma desvantagem da arquitetura. Para isso, o agente precisará executar algum processo que gere uma borda inicial, por exemplo, utilizando o algoritmo de Graham, que gera o fecho convexo de $n$ pontos (GRAHAM, 1972).

- Grupos sem Borda. Existem alguns casos em que a borda não poderá ser gerada. Um exemplo ocorre quando os dispositivos estão localizados de tal forma que, pela distância entre eles, não conseguem criar uma conexão virtual para se comunicarem. Outro exemplo será analisado na Seção 7.1.4, quando dois dispositivos consecutivos da borda geram uma abertura não remediada nem pelos dispositivos (na atividade D2 da percepção de abertura da borda) nem pelo agente (na atividade A5 que separa o grupo). Nesses casos, o grupo da nossa arquitetura terá o mesmo comportamento do grupo dos trabalhos relacionados, ou seja, todos os dispositivos enviarão as informações ao agente responsável pelo grupo. No entanto, o agente continuará tentando criar a borda, originando-lhe uma sobrecarga que os nós da DHT dos trabalhos relacionados não possuem, sendo uma desvantagem da nossa arquitetura.

\subsubsection{Análise da camada de agentes}

- Distribuição de Carga. Como mostrado na Figura 18 , um agente $a_{r}$ possui uma tabela de roteamento, cujo terceiro registro mapeia diversos agentes para um mesmo setor $\mathrm{Sec}_{i}$ (diferente dos trabalhos relacionados, onde somente há um agente por setor). Esse aumento de agentes por setor traz duas vantagens: (1) distribuição da carga na atividade de recepção de atualizações; (2) distribuição da carga no processo de busca.

No primeiro aspecto, se o setor $S e c_{i}$ tiver uma grande quantidade de dispositivos, nossa arquitetura poderá criar diversos agentes para esse mesmo setor, distribuindo a carga gerada pelas informações transmitidas pelos dispositivos. No caso dos trabalhos relacionados, essa situação não é considerada.

No segundo aspecto, se é solicitada ao agente $a_{r}$ uma busca por um setor sucessor de $S e c_{i}$, ele pode escolher qualquer agente do setor $S_{e c}$ para Ihe encaminhar a busca. Nesse sentido, a busca será distribuída entre os agentes do setor $S_{e c}$. 
Nos trabalhos relacionados, a busca sempre será recebida pelo único agente responsável pelo setor.

- Quantidade de Mensagens. Como mencionado no Módulo de Bordas da Seção 5.5.1, a adição de novos agentes ao setor traz consigo a mudança no registro da tabela de roteamento. Assim, cada entrada ou saída de um agente nesse setor gera um incremento na quantidade de mensagens que devem ser transmitidas para atualizar o registro correspondente, sendo uma desvantagem da arquitetura. Entretanto, supondo que no máximo há $k$ agentes por setor (lembrando que podem haver $m$ agentes no setor, mas a visão parcial permite que o agente perceba apenas $k$ ), a quantidade de atualizações desses registros somente será afetada por essa constante (nos trabalhos relacionados, $k$ tem o valor 1). Cabe destacar que $k$ diminuirá cada vez que um agente sair do sistema (dado pela atividade $\mathrm{A} 4$ que une os grupos).

- Busca da Mesma Informação. Como mencionado na atividade A1 (de busca por um setor), a busca recorrente por um determinado setor poderá ser aprendida pelo agente, significando que existirá um apontador direto para o setor. Essa mudança faz com que a próxima busca pelo mesmo setor, se passar pelo mesmo agente, seja respondida imediatamente, melhorando a eficiência, sendo uma vantagem da arquitetura. Cabe destacar que nos trabalhos relacionados, essa situação não é considerada.

Apesar de a análise conter numericamente mais desvantagens que vantagens, estas últimas devem ser consideradas mais relevantes quando o problema a ser tratado é a escalabilidade da arquitetura. 


\section{CICLO DE VIDA DA ARQUITETURA}

Como apresentado no capítulo anterior, existem atividades que devem ser executadas pela camada de dispositivos enquanto outras devem ser executadas pela camada de agentes. Para entender como ambas camadas interagem, dividimos a modelagem da arquitetura em oito passos, sendo o primeiro relacionado à inicialização da arquitetura e os restantes ao seu ciclo de vida. A Figura 20 mostra o processo da modelagem como se os passos fossem sequenciais, apesar de que do passo 2 ao 8 podem ser executados em paralelo.

No passo 1, o sistema inicializa ambas camadas da arquitetura. A camada de dispositivos é inicializada com o ingresso do primeiro dispositivo $d_{1}$. Neste caso, $d_{1}$ é agentificado com a atividade D4 (de agentificação), inicializando assim a camada multiagentes, que cria e registra o agente em um repositório global. Para implementar esse repositório, diversas alternativas podem ser utilizadas, entre elas o diretório de agentes (DIMAKOPOULOS; PITOURA, 2003) ou as estruturas distribuídas de agentes (KAMBAYASHI; HARADA, 2007). As Figuras 21(a) e 21(b) mostram as camadas antes e depois do ingresso do primeiro dispositivo.

No passo 2, novos dispositivos ingressam no sistema e formam grupos. Cada novo dispositivo $d_{n}$ solicita o ingresso a qualquer agente $a_{i}$ do repositório global. Baseado na localização $\operatorname{Loc}\left(d_{n}, t\right), a_{i}$ utiliza a atividade A1 (de busca por um setor) para encontrar o agente $a_{j}$ responsável por $d_{n}$. Se $a_{j}$ aceitar a solicitação de ingresso de $d_{n}$ a um dos seus grupos, ele cria um Canal $\left(a_{j}, d_{n}, t\right)$ por onde envia a $d_{n}$ uma lista $L$ de dispositivos da fronteira mais próximos de $\operatorname{Loc}\left(d_{n}, t\right)$. Por outro lado, se $a_{j}$ não aceitar a solicitação, pode usar a atividade A6 (de divisão do grupo) para separá-lo em dois, permitindo a $d_{n}$ ingressar em um deles. As Figuras 22(a) e 22(b) mostram os dispositivos antes e depois de ingressarem na camada de dispositivos.

No passo 3, cada novo dispositivo $d_{n}$ escolhe alguns dispositivos (da lista $L$ recebida do agente no passo anterior) para encontrar aqueles que serão seus vizinhos, utilizando a atividade D3 (de atualização de conexões entre vizinhos). Esse passo é necessário porque a lista de dispositivos da fronteira recebidos do agente não neces- 
Figura 20: Processo de Modelagem das Camadas.

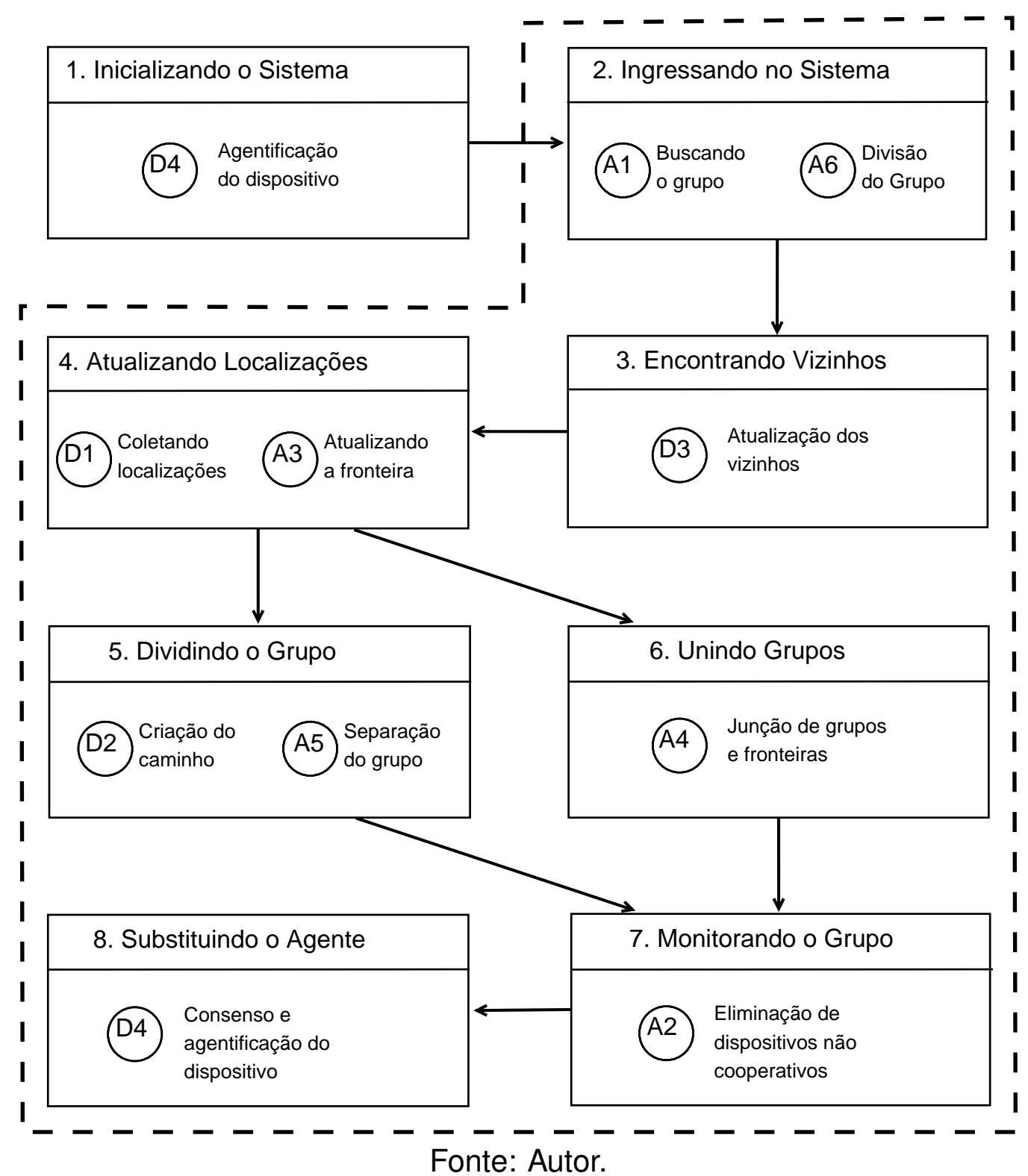


Figura 21: Passo 1 do processo.

\begin{tabular}{|l|}
\hline Diretório \\
Agentes
\end{tabular}
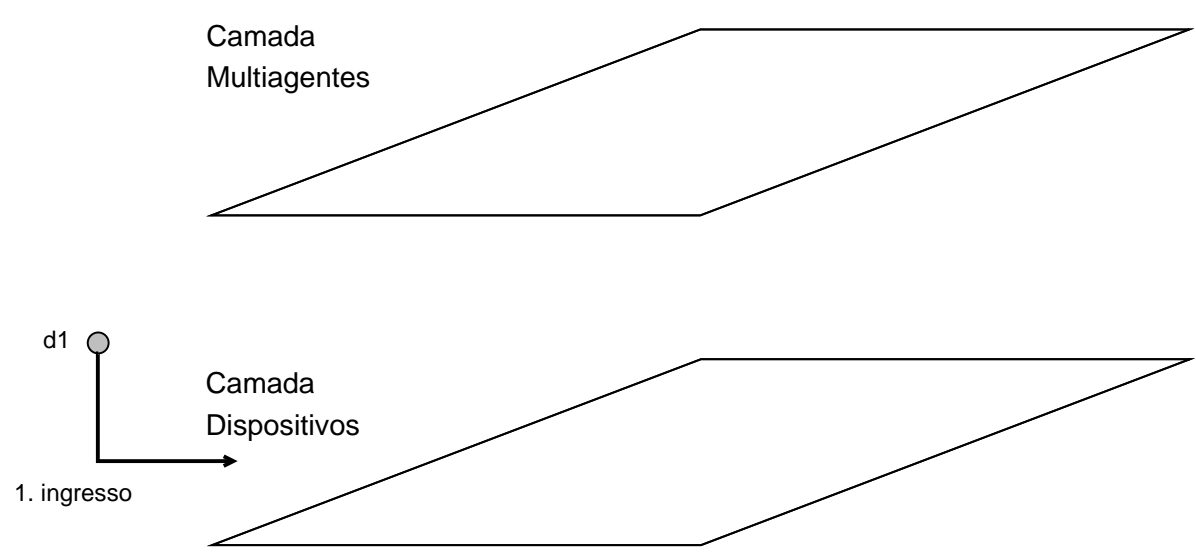

(a) $1^{\circ}$ dispositivo $d_{1}$ ingressando na camada de dispositivos.

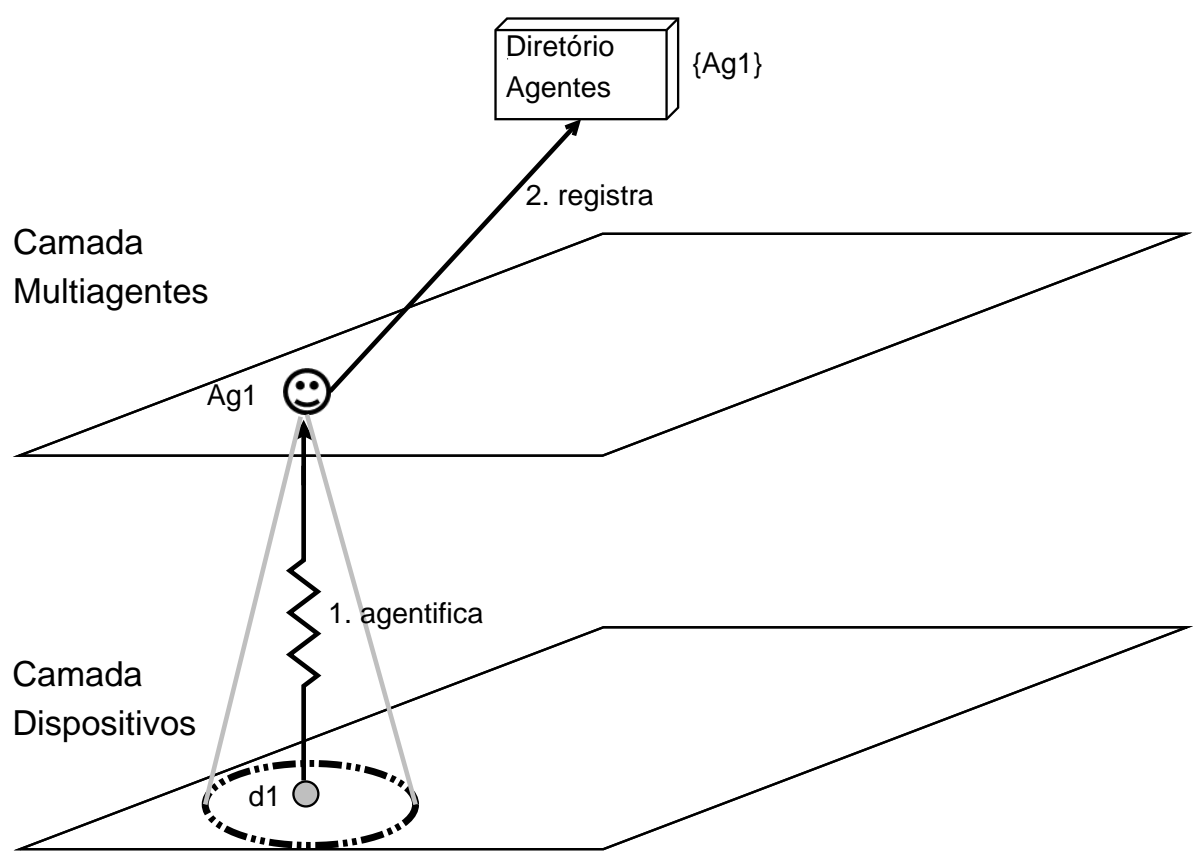

(b) $d_{1}$ agentificado e registrado.

Fonte: Autor.

sariamente contém apenas vizinhos de $d_{n}$. A Figura 23 mostra os dispositivos com as conexões geradas depois de aplicar a atividade D3.

No passo 4 , cada $d_{i} \in B$ agrega a localização de seus $\operatorname{Vizinhos}\left(d_{i}, t\right)$ e as envia ao agente que gerencia $B$ através do canal criado no passo 2 . Uma vez que $d_{i}$ percebe, pela análise da função de utilidade do seu módulo de serviço, que seu estado não permite exercer as responsabilidades da borda, ele se permuta (rotaciona) com al- 
Figura 22: Passo 2 do processo.

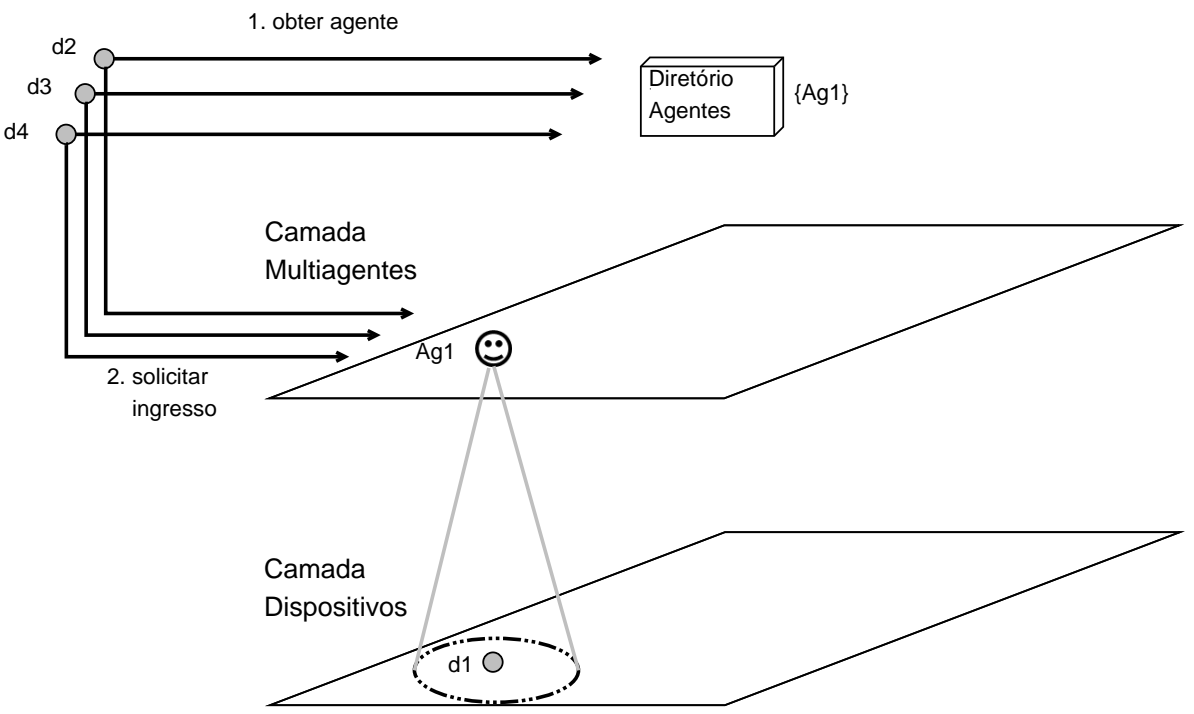

(a) Dispositivos ingressando na camada de dispositivos.
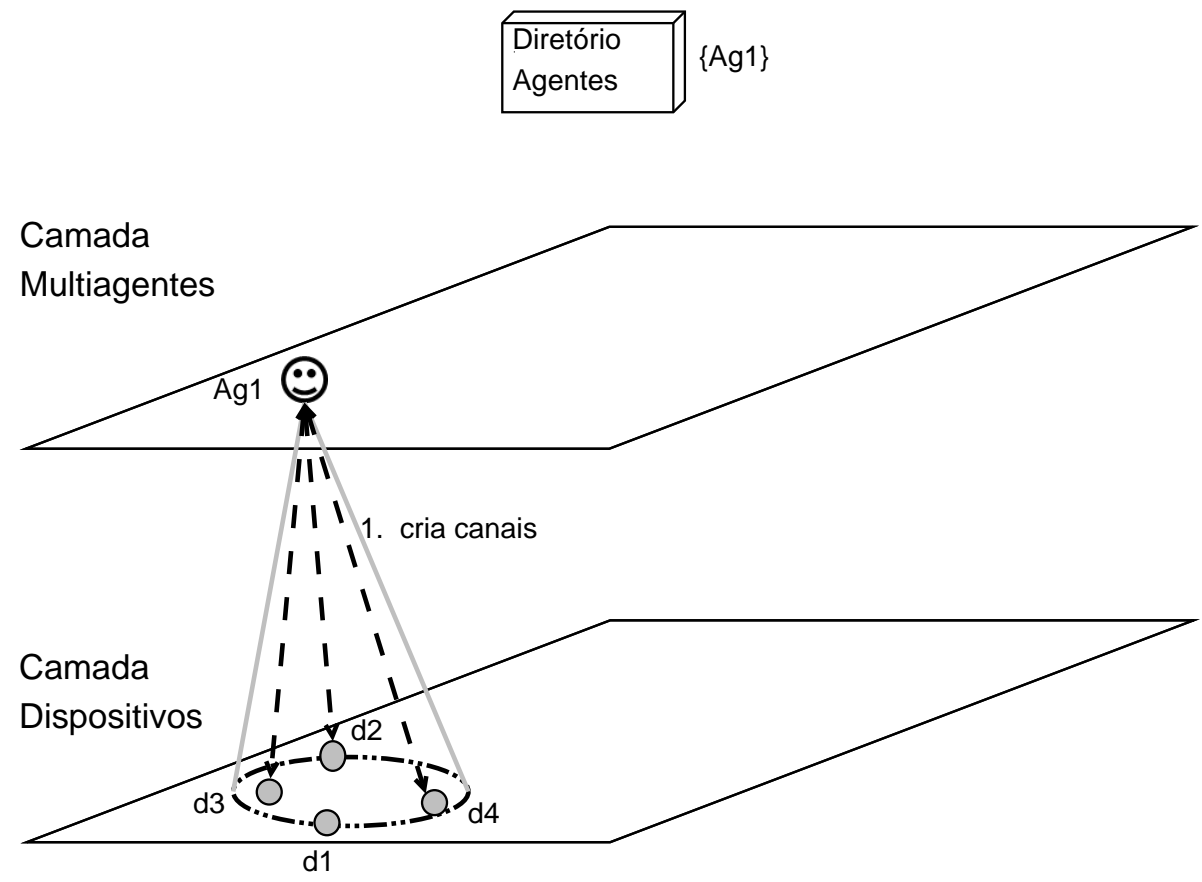

(b) Dispositivos ingressados.

Fonte: Autor.

gum dos seus vizinhos, utilizando a atividade D1 (de atualização da localização da fronteira). Por sua vez, o agente recebe a informação e atualiza a fronteira do grupo, utilizando a atividade A3 (de atualização da borda). A Figura 24(a) mostra que o dispositivo $d_{4}$ faz parte da borda e que o dispositivo $d_{5}$ faz parte da borda. A Figura 24(b) mostra que os dispositivos se rotacionaram e mudaram suas localizações, alterando a 
Figura 23: Passo 3 do processo.

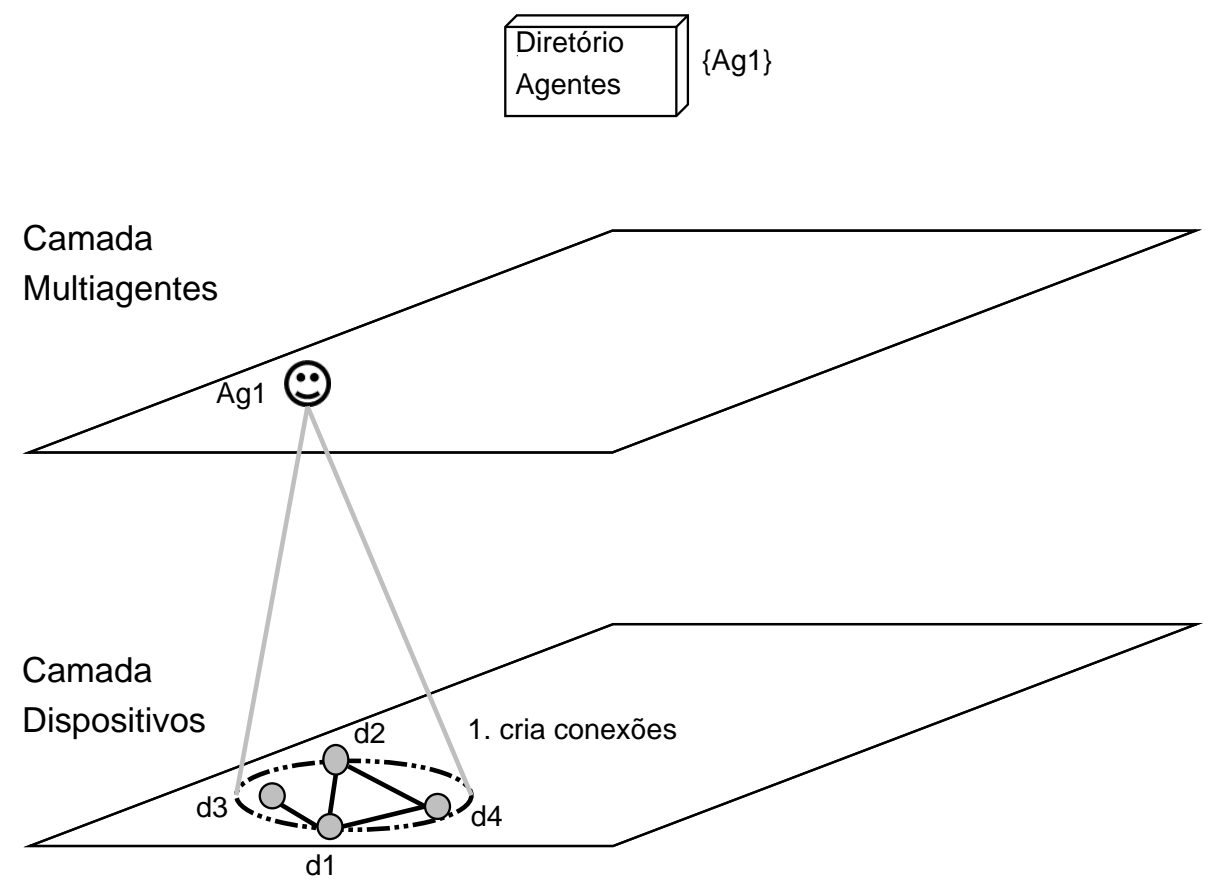

Fonte: Autor.

fronteira do grupo.

No passo 5 , cada dispositivo $d_{i} \in B$ percebe que seu vizinho mais próximo $d_{i+1} \in$ $B$ está se afastando ou saiu do sistema, abrindo a borda $B$. Assim, $d_{i}$ tenta criar um caminho alternativo com $d_{i+1}$ ou $d_{i+2} \in B$ (i.e., um dispositivo próximo a $d_{i+1}$ ) utilizando a atividade D2 (de percepção de abertura da borda). Se o caminho não for encontrado, $d_{i}$ envia essa informação ao agente $a$ que gerencia $B$ (utilizando o canal criado no passo 2), que analisará se outros dispositivos próximos a $d_{i}$ também perceberam essa situação. Se o agente $a$ encontrar algum caminho que feche a borda $B, a \circ$ faz. Se $B$ não puder ser fechada, $a$ divide a borda utilizando a atividade A5 (de percepção da separação do grupo). Na Figura 25(a), o dispositivo $d_{4}$ gerou uma abertura na borda que não poderá ser fechada. Assim, o dispositivo $d_{4}$ será agentificado e registrado no diretório. A Figura 25(b) mostra o resultado final da divisão do grupo depois de executada a atividade $\mathrm{A} 5$.

No passo 6, os agentes com relacionamentos sequenciais trocam informações sobre seus grupos. Se eles perceberem que as bordas estão se intersectando (analisando suas posições atuais) ou próximas a se intersectarem (analisando suas últimas posições) os agentes podem uni-las utilizando a atividade A4 (de junção de grupos), 
Figura 24: Passo 4 do processo.

\begin{tabular}{|l|l}
\hline Diretório \\
Agentes
\end{tabular}

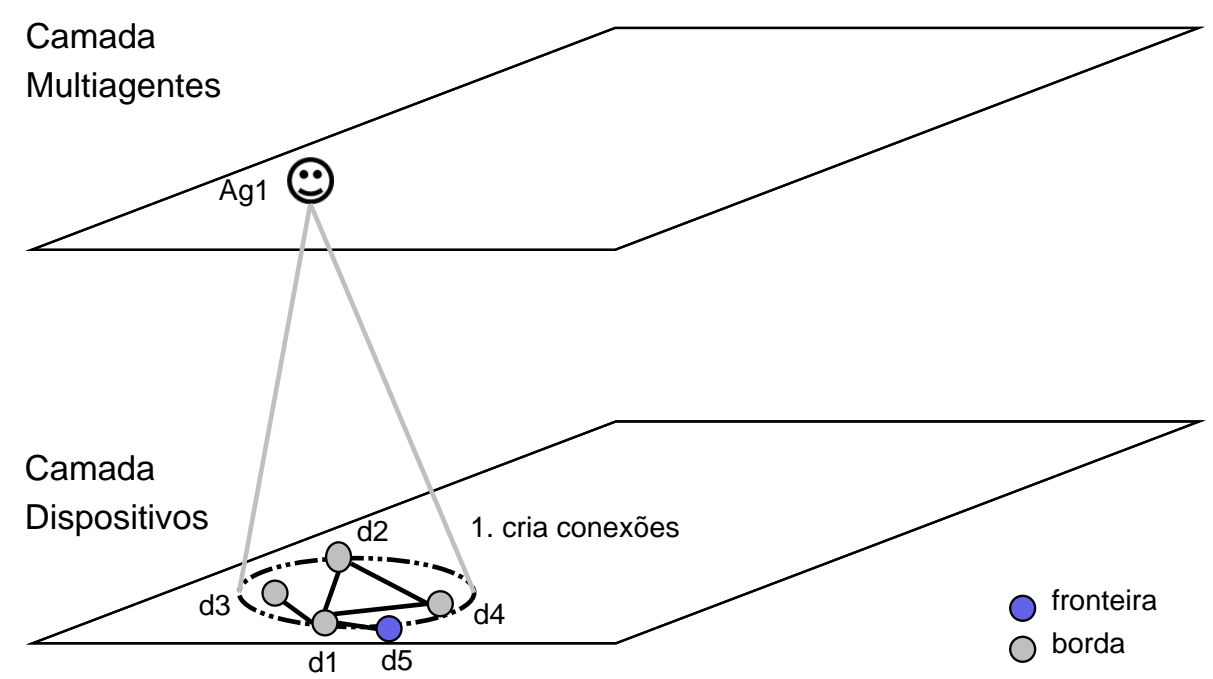

(a) Dispositivos se rotacionando.


(b) Agente atualizando a fronteira.

Fonte: Autor.

desde que a união não afete a escalabilidade da arquitetura. Na Figura 26(a), as bordas $B_{1}$ e $B_{2}$ estão se intersectando e na Figura 26(b), o agente $A g_{1}$ ficou como responsável pela união das mesmas depois de aplicada a atividade A4. 
Figura 25: Passo 5 do processo.

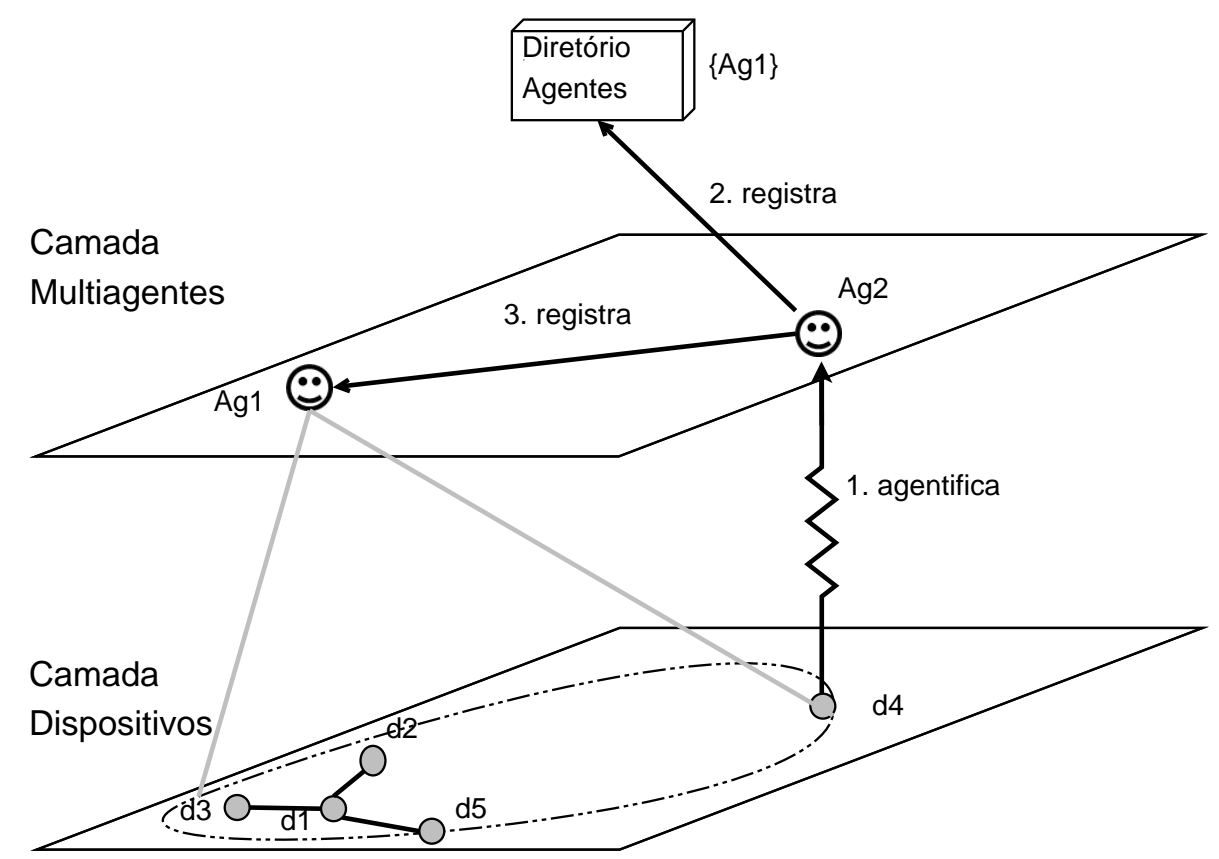

(a) Dispositivo $d_{4}$ gerando abertura na borda.
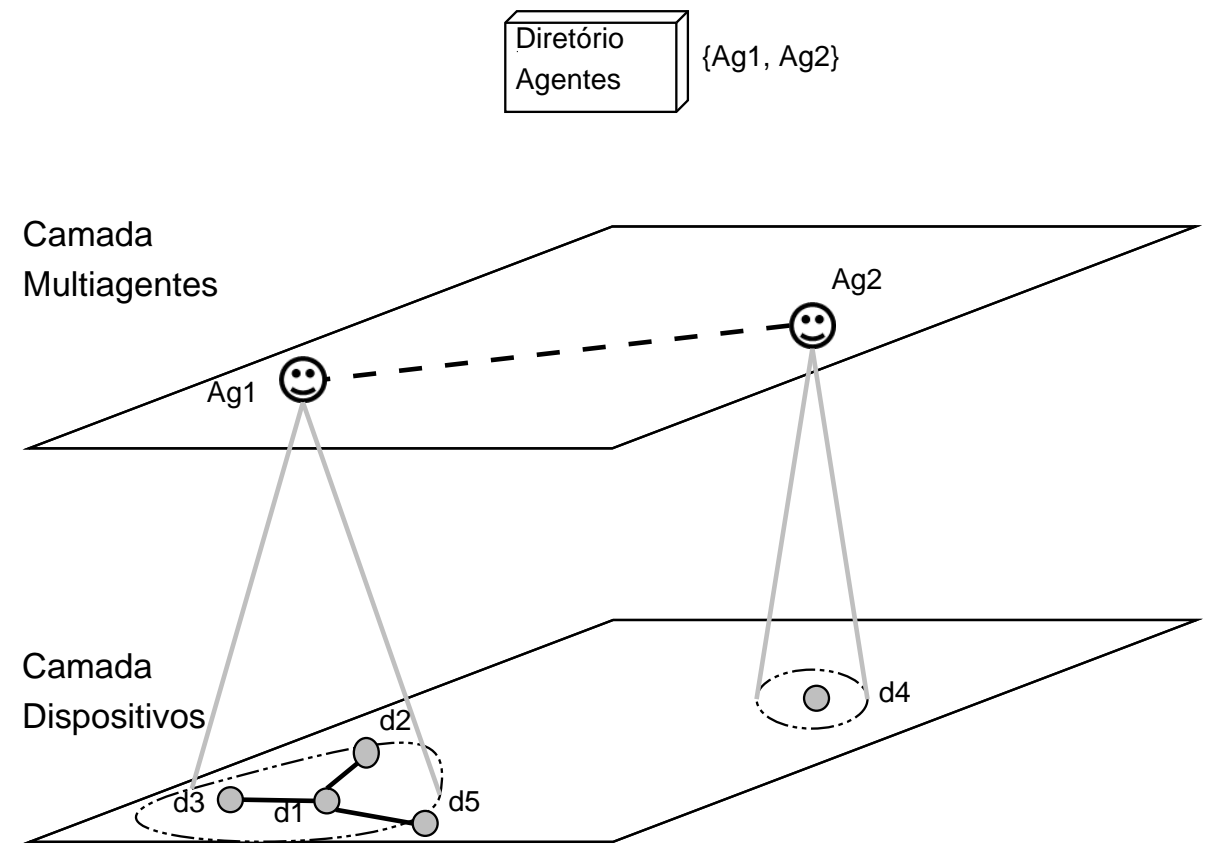

(b) Divisão do grupo depois de aplicada A5.

Fonte: Autor.

No passo 7 , cada agente que gerencia uma borda $B$ monitora o comportamento de cada $d_{i} \in B$, eliminando aqueles que não estão cumprindo com suas responsabilidades, utilizando para isso a atividade A2 (de monitoramento de dispositivos).

No passo 8 , quando um agente $a$ sai do sistema, seu dispositivo associado $d_{a}$ (o 
Figura 26: Passo 6 do processo.

\begin{tabular}{|l|}
\hline Diretório \\
Agentes
\end{tabular}$\{\mathrm{Ag} 1, \mathrm{Ag} 2\}$

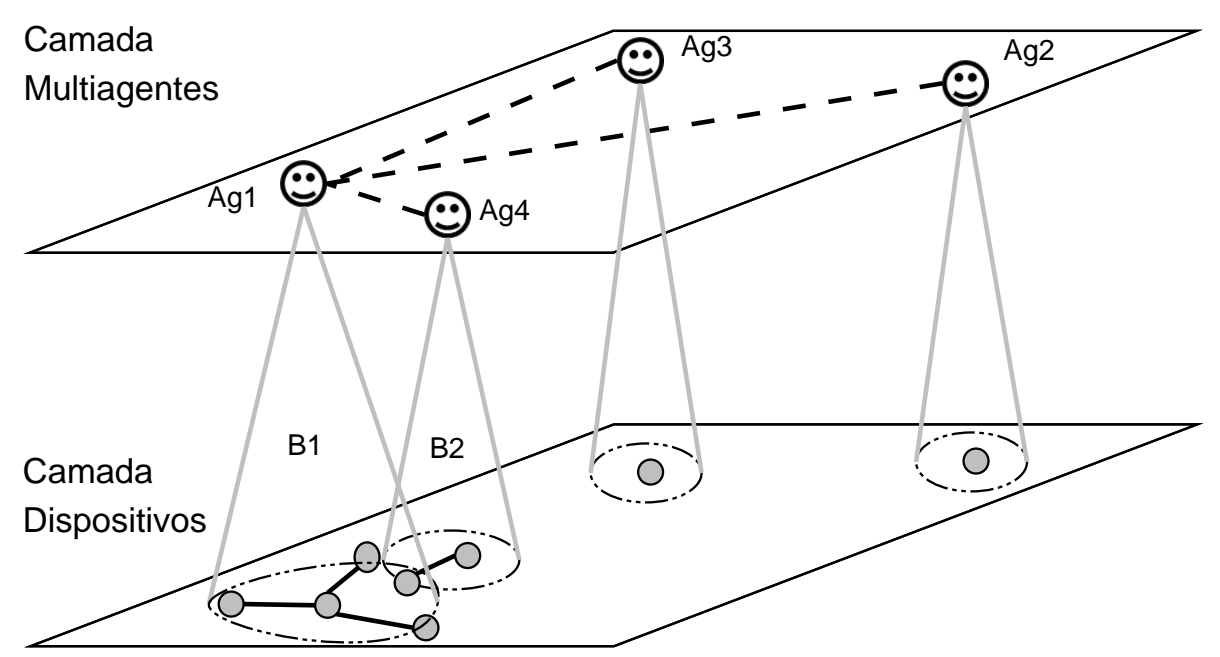

(a) Bordas $B_{1}$ e $B_{2}$ se intersectando.

\begin{tabular}{|l|l|l|l}
\hline Diretório & $\{\mathrm{Ag} 1, \mathrm{Ag} 2\}$ \\
Agentes
\end{tabular}



(b) União das bordas depois de aplicada A4.

Fonte: Autor.

qual foi agentificado) também sai. Nesse sentido, cada dispositivo $d_{b} \in B$, onde $B$ é gerenciada por $a$, fica ciente desta situação (dado que o canal de comunicação com $a$ foi fechado). Em seguida, cada $d_{b}$ analisa se pode ser considerado um dispositivo estável, através da função de utilidade do seu módulo de serviço, enviando essa infor- 
mação aos seus vizinhos. Como vários dispositivos podem ser considerados estáveis, é necessário escolher qual deles será agentificado e assumirá a responsabilidade de gerenciar $B$. Na arquitetura proposta, o dispositivo selecionado é aquele que tiver o maior valor, utilizando o processo de eleição do valentão (GARCIA-MOLINA, 1982). Finalmente, esse dispositivo será transformado em agente utilizando a atividade D4 (de agentificação). Na Figura 27(a), o dispositivo $d_{4}$ sai do sistema (assim como 0 agente $\mathrm{Ag}_{2}$ associado) e o dispositivo $d_{7}$ foi o escolhido para ser agentificado. $\mathrm{Na} \mathrm{Fi-}$ gura $27(\mathrm{~b}), d_{7}$ se agentifica e se registra tanto no diretório de agentes quanto com seus novos relacionamentos sequenciais obtidos do diretório. 
Figura 27: Passo 8 do processo.

\begin{tabular}{|l|}
\hline Diretório \\
Agentes
\end{tabular}$\{\mathrm{Ag} 1, \mathrm{Ag} 2, \mathrm{Ag} 3\}$

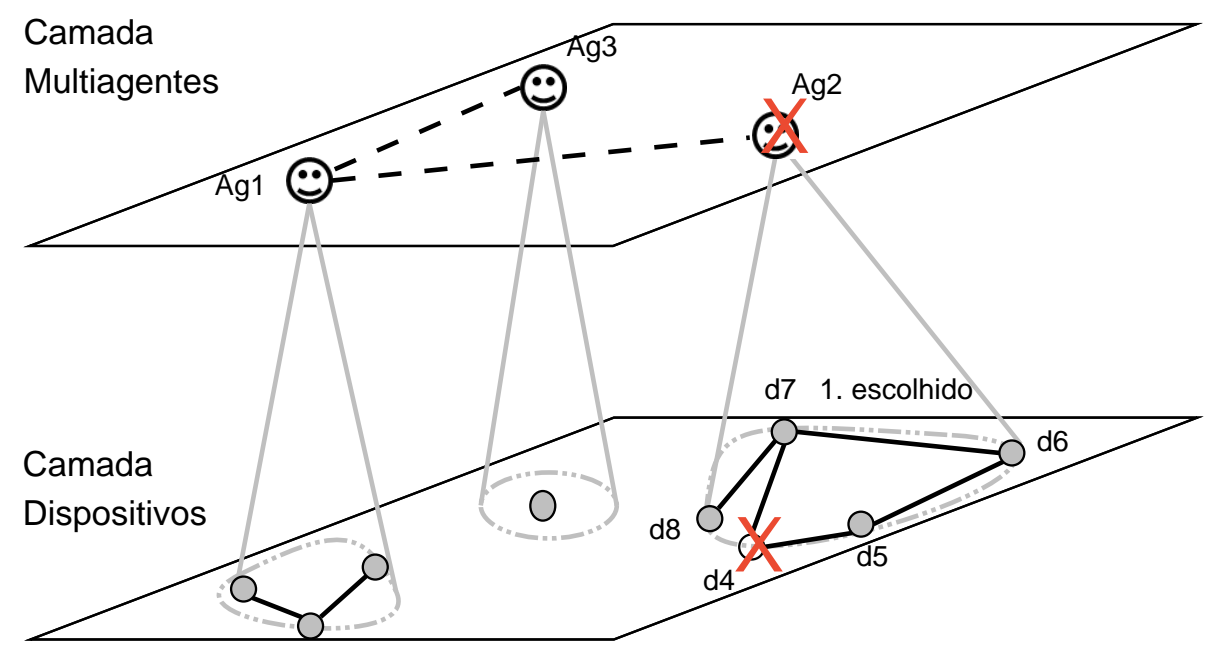

(a) Agente saindo do sistema.



(b) Novo agente selecionado.

Fonte: Autor. 


\section{INSTANCIANDO A ARQUITETURA}

Neste capítulo será apresentado o processo de instanciação da arquitetura, definida de forma abstrata no capítulo 5, para os dois cenários descritos no capítulo 2.

\subsection{Arquitetura para o cenário de monitoramento de sensores}

No capítulo 5 formalizamos os conceitos associados à arquitetura. Nesta seção especificamos somente aqueles que são dependentes do cenário de sensores.

\subsubsection{Visão geral}

Como mencionado na Seção 2.3.1, os cenários de monitoramento de sensores permitem monitorar de forma contínua a localização de sensores em diversos setores de interesse. Na nossa arquitetura, cada setor, por sua vez, é gerenciado por um ou mais agentes, encarregados de agregar as localizações dos dispositivos posicionados naquele setor.

O cenário de monitoramento de sensores, utilizando a arquitetura proposta, pode ser resumido da seguinte maneira:

- O espaço é dividido em setores, cujos gerenciamentos serão distribuídos entre os agentes.

- Cada setor é caracterizado com um identificador único, incremental e discreto, que corresponde a uma região do espaço.

- Um setor pode ser gerenciado por vários agentes, mas um agente é responsável apenas por um setor, designado quando o dispositivo é agentificado, de acordo com o setor onde está localizado esse dispositivo.

- Um agente gerencia grupos de dispositivos junto com as bordas que as localizações desses dispositivos geram. 
- Um dispositivo escolhe um agente (dentre aqueles que gerenciam bordas cujo interior contém a localização do dispositivo) e lhe envia as atualizações da sua localização.

- Um dispositivo possui uma quantidade de energia que é consumida em cada requisição, até deixá-lo inutilizável.

\subsubsection{Conceitos}

Nesta seção especificamos os conceitos mencionados nas seções 5.2 e 5.3.

Para o cenário de monitoramento de sensores, $S$ é um subconjunto de $\mathbb{R}^{2}$ particionado em $n$ regiões quadradas. $\operatorname{Sec}_{i}$ representa um quadrado da partição de $S$, onde cada um deles está associado a outro de acordo com a ordem dada pela curva de Hilbert.

A localização de um dispositivo $\operatorname{Loc}\left(d_{i}, t\right)$ é um ponto no sistema de coordenadas $\mathbb{R}^{2}$. A localização pode ser obtida, por exemplo, utilizando o sensor de posição GPS (Global Positioning System) instalado no dispositivo.

A comunicação entre dois dispositivos $d_{i}$ e $d_{j}$ é realizada através das antenas de transmissão, cujo alcance, em metros, tem um valor $\delta$. Para medir a distância entre eles, i.e., Distancia $\left(d_{i}, d_{j}, t\right)$, utilizaremos a distância Euclidiana.

Finalmente, $\phi$ é uma constante que depende da área que o sistema que utilizará nossa arquitetura quer cobrir por cada setor e da mobilidade dos dispositivos. Nesse sentido, se o sistema for implantado em um ambiente de transporte aéreo, provavelmente a área a ser coberta será maior que em um ambiente de mobilidade urbana para pessoas. Já $\epsilon$ é uma constante que depende da precisão que o sistema quer fornecer na captura de informações.

\subsubsection{Camada de dispositivos}

Esta seção apresenta as definições do dispositivo, na escolha e nas responsabilidades da fronteira, aplicadas no cenário de monitoramento de sensores.

\section{Arquitetura Interna do Dispositivo}


Como mencionado na Seção 5.4.3, as atividades D1 (de atualização da localização da fronteira) e D4 (de agentificação) fazem uso de uma função de utilidade implementada no módulo de serviços do dispositivo. Nesse sentido, a função deve calcular se o dispositivo está apto para exercer alguma responsabilidade adicional (como agregar informações dos vizinhos). Na arquitetura proposta, a análise somente considera se o nível de energia do dispositivo está acima ou abaixo de um determinado valor, devolvendo alto ou baixo, respectivamente.

\section{Caracterizando dispositivos da Fronteira}

Como mencionado na Seção 5.4.2, somente os dispositivos da fronteira serão encarregados de executar as atividades de atualização de informações. Nesse contexto, cada dispositivo precisa analisar se pertence à fronteira quando ingressa no sistema e periodicamente durante seu ciclo de vida.

No primeiro caso, a análise é realizada quando um novo dispositivo $d_{n}$ ingressa na camada de dispositivos. Como visto no passo 2 da modelagem das camadas da Seção 6 , depois que $d_{n}$ ingressa num $\operatorname{Grupo}(B, t)$ para alguma borda $B \in \operatorname{Gerencia}(a, t)$, o agente $a$ envia a $d_{n}$ uma lista de dispositivos $L$ que pertencem à fronteira e que estão próximos da $\operatorname{Loc}\left(d_{n}, t\right)$. A seguir, para saber se $d_{n}$ também pertence à fronteira, basta encontrar em $L$ algum dispositivo $d_{b} \in B$ tal que Distancia $\left(d_{n}, d_{b}, t\right) \leqslant \delta$. Caso contrário, $d_{n}$ não faz parte da fronteira e não precisará executar as atividades de atualização.

No segundo caso, durante o ciclo de vida de um dispositivo $d_{i}$ que já faz parte da camada, a análise é realizada quando o dispositivo muda sua localização e verifica (sondando a área com sua antena ou perguntando ao agente) se existem novos vizinhos. Se algum desses novos vizinhos pertençer à borda do grupo, o dispositivo passa a fazer parte da fronteira.

\subsubsection{Camada de agentes}

Esta seção apresenta as definições do agente, na sua arquitetura interna e nas suas responsabilidades, aplicadas no cenário de monitoração de sensores.

\section{Arquitetura Interna do Agente}

Como mencionado na Seção 5.5, as atividades A2 (de monitoramento de dispositi- 
vos), A4 (de junção de grupos) e A6 (de divisão do grupo) fazem uso de uma função de utilidade implementada no módulo de bordas do agente. Nesse sentido, a função deve calcular se o agente pode ou não estar sendo afetado pela sobrecarga da fronteira, o que influencia no seu desempenho e, portanto, na escalabilidade da arquitetura. $\mathrm{Na}$ arquitetura proposta, a análise somente considera se a energia utilizada no processamento das informações recebidas, tanto pela fronteira quanto pelas solicitações de ingresso e busca, está acima ou abaixo de um determinado valor, devolvendo baixo ou alto, respectivamente. Em outras palavras, baixo significa que o agente consumiu energia acima de um certo valor o que compromete sua escalabilidade.

\section{Implementação das Responsabilidades do Agente}

Como mencionado na Seção 5.5.3, as atividades A5 (de percepção da separação do grupo) e A6 (de divisão do grupo) precisam de um algoritmo, específico para o cenário de sensores, capaz de separar um grupo em dois. A implementação do algoritmo é descrita na Seção B.1.

\subsection{Arquitetura para o cenário de vídeo sob demanda}

No capítulo 5 formalizamos os conceitos associados à arquitetura. Nesta seção especificamos somente aqueles que são dependentes do cenário de vídeos sob demanda.

\subsubsection{Visão geral}

Como mencionado na Seção 2.3.2, os cenários de vídeo sob demanda permitem ao usuário reproduzir um vídeo enquanto está sendo baixado. Nesses cenários, o vídeo é dividido em $M$ segmentos e distribuídos nos usuários que os assistiram, tornando-se provedores desses segmentos para outros usuários.

O cenário de vídeo sob demanda, utilizando a arquitetura proposta, pode ser resumido da seguinte maneira:

- O vídeo é dividido em $M$ segmentos (identificados como números sequenciais que vão do 1 até $M$ ), cujos gerenciamentos serão distribuídos nos agentes. 
Figura 28: Cenário de Vídeo sob Demanda.

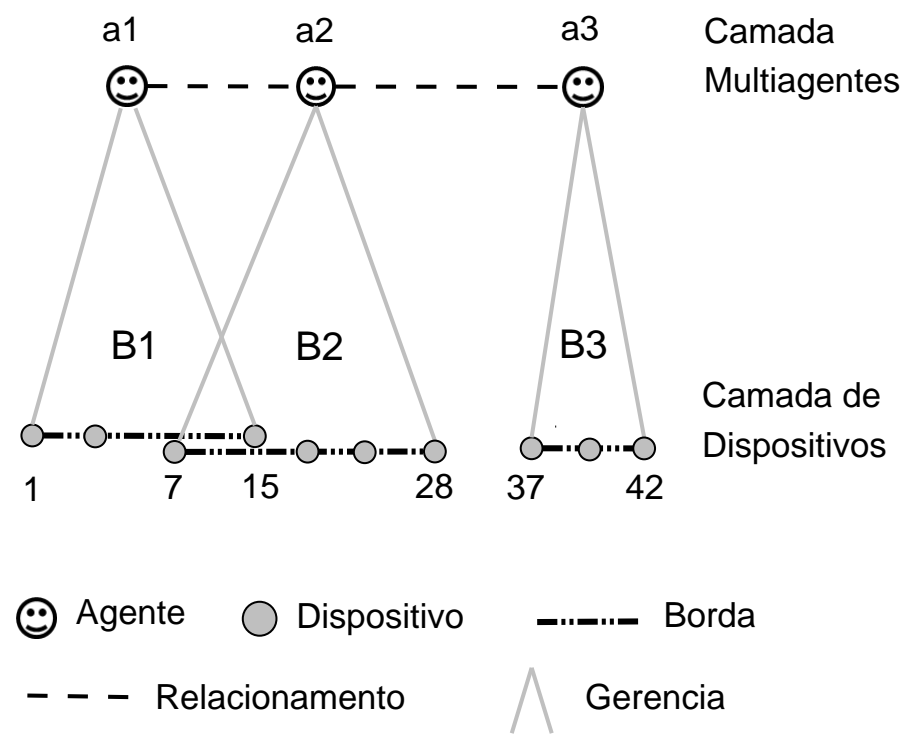

Fonte: Autor.

- Um segmento pode ser gerenciado por um ou mais agentes, mas um agente é responsável somente por um segmento, designado quando o dispositivo é agentificado, de acordo com o segmento baixado pelo dispositivo.

- Um agente gerencia grupos de dispositivos, cujas bordas geram intervalos de segmentos que também serão gerenciados pelo agente.

- Um dispositivo baixa um segmento de um dos agentes responsáveis por esse segmento. A partir daí, atualizará os outros segmentos baixados no agente escolhido.

$\mathrm{Na}$ Figura 28 pode-se observar que o agente $a_{1}$ gerencia um intervalo $[1,15]$ de segmentos (isto é, os dispositivos da borda $B_{1}$ baixaram todos os segmentos nesse intervalo). Já o agente $a_{2}$ gerencia um intervalo $[7,28]$ que intersecta com $B_{1}$.

\subsubsection{Conceitos}

Nesta seção especificamos os conceitos mencionados nas seções 5.2 e 5.3.

Para o cenário de vídeo sob demanda, $S$ é um subconjunto de $\mathbb{N}$. Já $\operatorname{Sec}_{i}$ representa cada um dos $M$ segmentos em que foi dividido o vídeo, e está associado a um segmento predecessor $\operatorname{Sec}_{i-1}$ e a um sucessor $\operatorname{Sec}_{i+1}$. 
Para entender a localização do dispositivo, considere que um usuário está assistindo um determinado instante do vídeo através do dispositivo $d_{i}$. Como mencionado na introdução, esse instante de tempo tem uma correspondência com um segmento do vídeo. Nesse sentido, a localização de um dispositivo $\operatorname{Loc}\left(d_{i}, t\right)$ representa o segmento baixado, ou que está sendo baixado, pelo dispositivo $d_{i}$, no tempo $t$. Por exemplo, se $d_{i}$ baixa no tempo zero o segmento 2 do vídeo, $\operatorname{Loc}\left(d_{i}, 0\right)=\{2\}$. Já o histórico Historico $\left(d_{i}\right)$ é o conjunto ordenado de todos os segmentos baixados, ou que estão sendo baixados, pelo dispositivo $d_{i}$ no intervalo de tempo $[0, t]$, com $t=n o w$. Por exemplo, se $\operatorname{Loc}\left(d_{i}, 0\right)=\{2\}, \operatorname{Loc}\left(d_{i}, 1\right)=\{3\}$ e $\operatorname{Loc}\left(d_{i}, 2\right)=\{5\}$, então Historico $\left(d_{i}\right)=\{2,3,5\}$.

A distância entre dois dispositivos, i.e., Distancia $\left(d_{i}, d_{j}, t\right)$, é definida para dois casos, quando Historico $\left(d_{i}, t\right) \cap$ Historico $\left(d_{j}, t\right)$ é igual ou diferente de $\varnothing$ (em outras palavras, se $d_{i}$ e $d_{j}$ compartilham ou não algum segmento em comum, respectivamente).

Para analisar esses casos, primeiro devemos definir o conceito de Intervalos $\left(d_{i}\right)$ que representa o conjunto de subconjuntos formados por subsequências de números consecutivos do Historico $\left(d_{i}\right)$. Por exemplo, se Historico $\left(d_{i}\right)=\{1,2,4,5,6,11,12,13,15\}$, Intervalos $\left(d_{i}\right)=\{\{1,2\}\{4,5,6\}\{11,12,13\}\{15\}\}$.

Voltando aos dois casos, seja $I_{\min }=\max \left(\min \left(I_{i}\right), \min \left(I_{j}\right)\right)$ e $I_{\max }=$ $\min \left(\max \left(I_{i}\right), \max \left(I_{j}\right) \forall I_{i} \in \operatorname{Intervalos}\left(d_{i}\right)\right.$ e $\forall I_{j} \in \operatorname{Intervalos}\left(d_{j}\right)$. A distância Distancia $\left(d_{i}\right.$, $\left.d_{j}, t\right)$ é definida como:

$$
\operatorname{Distancia}\left(d_{i}, d_{j}, t\right)\left\{\begin{array}{l}
0, \quad \text { se Historico }\left(d_{i}\right) \cap \operatorname{Historico}\left(d_{j}\right) \neq \varnothing \\
\min \left(\left|I_{\min }-I_{\max }\right|\right), \quad \text { caso contrário. }
\end{array}\right.
$$

Por exemplo, seja $I_{i}=\{15,16,17,18,19,20\}$ e $I_{j}=\{8,9,10,11\}$, então a distância será $|15-11|=4$.

Já o grupo, seguindo com a definição apresentada na Seção 5.2, pode ser entendido como todos os segmentos de vídeo que foram baixados pelos dispositivos. Finalmente, $\phi$ é uma constante que depende da distância que o sistema que utilizará nossa arquitetura define na criação de um relacionamento sequencial. Por exemplo, VMesh define $\phi=1$ (isto é, dado um agente $a_{i}$, com uma borda no $S e c_{i}$, seus relacionamentos sequenciais serão aqueles agentes que possuem uma borda em $S e c_{i-1} \mathrm{e}$ $\left.S e c_{i+1}\right)$. Por outro lado, o TDM utiliza $\phi=M / k$, com $k=5$, mas é um valor deixado em 
aberto. Já $\epsilon$ é uma constante que depende da precisão que o sistema quer fornecer na captura de informações.

\subsubsection{Camada de dispositivos}

Esta seção apresenta as definições do dispositivo, na escolha e nas responsabilidades da fronteira, aplicadas no cenário de vídeo sob demanda.

\section{Arquitetura Interna do Dispositivo}

Como mencionado na Seção 5.4.3, as atividades D1 (de atualização da localização da fronteira) e D4 (de agentificação) fazem uso de uma função de utilidade implementada no módulo de serviços do dispositivo. Nesse sentido, a função deve calcular se o dispositivo está apto para exercer alguma responsabilidade adicional (como coletar informações dos vizinhos). Na arquitetura proposta, a análise considera se o tempo de atividade e a largura de banda disponível do dispositivo está acima ou abaixo de um determinado valor, devolvendo alto ou baixo, respectivamente.

\section{Caracterizando dispositivos da Fronteira}

Como mencionado na Seção 5.4.2, somente os dispositivos da fronteira serão encarregados por executar as atividades de atualização de informações. Nesse contexto, cada dispositivo precisa analisar se pertence à fronteira após baixar um segmento. Para isso, o dispositivo $d_{i}$ analisa o seu estado, utilizando a função de utilidade do seu módulo de serviço. Se o estado for alto, notifica ao agente que está disponível para pertencer à fronteira do grupo. O agente, por sua vez, analisará se a fronteira tem suficientes dispositivos para cada segmento baixado. Caso o agente entenda que são necessários mais dispositivos, notificará a $d_{i}$ que a partir desse momento pertence à fronteira.

Como exemplo, na Figura 29 pode-se observar que o agente $a_{1}$ gerencia uma borda $B_{1}$ com intervalo [1,7]. Por sua vez o segmento 1 (baixado por um dispositivo da borda) possui dois dispositivos da fronteira que também baixaram esse segmento. Já o segmento 5 somente foi baixado por um dispositivo da borda, sem ter sido baixado por ninguém do grupo. Se um dispositivo $d_{i}$ notificasse ao agente que baixou o segmento 5 e que está disponível ser parte da fronteira, $a_{1}$ lhe notificará que pertence à fronteira. 
Figura 29: Fronteira de uma borda.

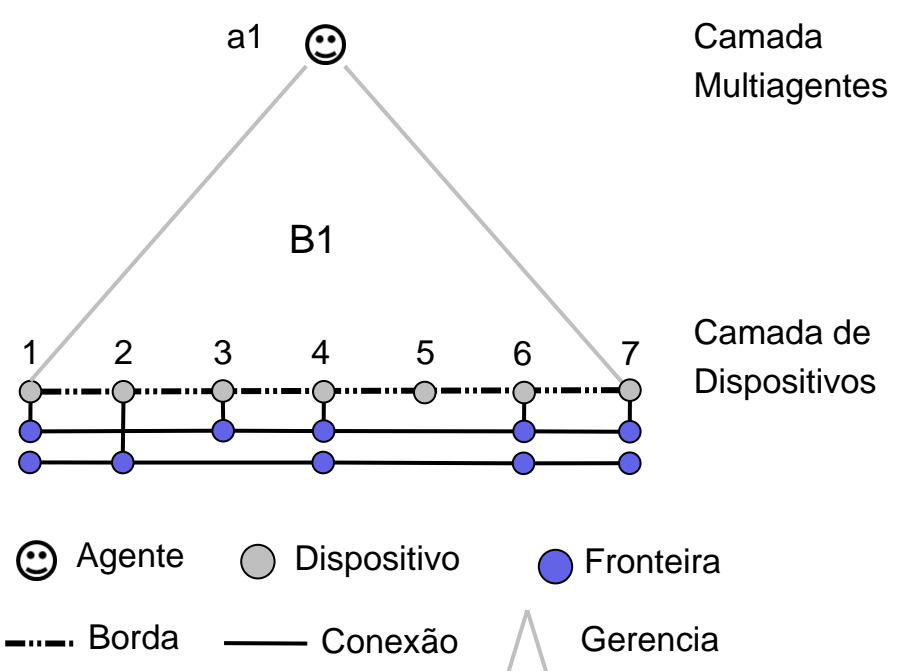

Fonte: Autor.

\subsubsection{Camada de agentes}

Esta seção apresenta as definições do agente, na sua arquitetura interna e nas suas responsabilidades, aplicadas no cenário de vídeo sob demanda.

\section{Arquitetura Interna do Agente}

Como mencionado na Seção 5.5, as atividades A2 (de monitoramento de dispositivos), A4 (de junção de grupos) e A6 (de divisão do grupo) fazem uso de uma função de utilidade implementada no módulo de bordas do agente. Nesse sentido, a função deve calcular se o agente pode ou não estar sendo afetado pela sobrecarga da fronteira, o que influencia no seu desempenho e, portanto, na escalabilidade da arquitetura. $\mathrm{Na}$ arquitetura proposta, a análise somente considera se a largura de banda utilizada pelas informações recebidas em um determinado período de tempo, tanto pela fronteira quanto pelas solicitações de ingresso e busca, está acima ou abaixo de um determinado valor, devolvendo baixo ou alto, respectivamente.

\section{Implementação das Responsabilidades do Agente}

Como mencionado na Seção 5.5.3, as atividades A5 e A6 precisam de um algoritmo, específico para o cenário de vídeo sob demanda, capaz de separar um grupo em dois. A implementação do algoritmo é descrita na Seção B.2. 


\subsection{Análise da instanciação da arquitetura}

A arquitetura proposta conceitualmente no capitulo 5 foi reaproveitada na implantação para os domínios de monitoramento de sensores e vídeos sob demanda. De acordo com o apresentado neste capítulo, há de se observar que existem atividades, específicas para cada domínio, cujas implementações não podem ser reutilizadas. Nesse sentido, respondendo à questão de pesquisa QP2, a implementação da arquitetura poderá ser reutilizada nas atividades comuns, mas deverá ser reimplementada em atividades e conceitos dependentes do domínio (e.g., separação de grupos e função de utilidade). 


\section{RESULTADOS EXPERIMENTAIS}

Neste capítulo avaliamos a arquitetura em relação à eficiência, à escalabilidade e a métricas específicas utilizadas no cenário de vídeo sob demanda e no cenário de monitoramento de sensores. A eficiência foi analisada em termos da quantidade de mensagens transmitidas e do tempo (em segundos) necessário para localizar uma determinada informação, tendo com limite 1 segundo, como proposto por (JIMENEZ; OSMANI; KNUTSSON, 2011). A escalabilidade também foi analisada em termos da quantidade de mensagens e do tempo, mas observando o comportamento da arquitetura quando o número de dispositivos aumenta. Já as métricas específicas para cada cenário serão explicadas nas Seções 8.4 e 8.5. Cada simulação foi realizada 20 vezes, mostrando nos resultados a média e o desvio padrão.

\subsection{Parâmetros}

Para simular o comportamento da arquitetura, as camadas foram implementadas em Java, utilizando o PeerSim (MONTRESOR; JELASITY, 2009) como o framework de simulação para avaliar os algoritmos desenvolvidos para a camada de agentes e para a camada de dispositivos.

No caso da conectividade dos dispositivos, foi utilizada uma topologia de rede baseada no King (GUMMADI; SAROIU; GRIBBLE, 2002). Esta topologia, amplamente utilizada em pesquisas científicas, representa um modelo realista da latência entre os nós da Internet, cujo valor médio de ponta-a-ponta entre quaisquer dois nós da rede é de aproximadamente $200 \mathrm{~ms}$, com picos de $300 \mathrm{~ms}$.

No caso do dispositivo, os parâmetros utilizados nos experimentos foram:

- O tamanho do conjunto de $\operatorname{Vizinhos}\left(d_{i}, t\right)$ é 50 , como mencionado no parâmetro numwant (COHEN, 2008b).

- As atividades D1 à D3 são realizadas a cada 30 segundos, seguindo o mesmo intervalo de tempo utilizado pela rotina de atualização de conexões do protocolo de compartilhamento BitTorrent (BRAM, 2003). 
- Os dispositivo entram e saem do sistema em qualquer momento, de forma independente um do outro.

- O dispositivo não informa nenhum membro da estrutura (agentes ou vizinhos) sobre sua saída (PAGANELLI; PARLANTI, 2012; STOICA et al., 2001).

- O dispositivo possui uma largura de banda de entrada (para receber informações, por exemplo baixar segmentos ou obter a localização de um dispositivo) de 2 Mbps e uma largura de saída (para enviar informações) de 2 Mbps a não ser que seja especificado o contrário.

No caso do agente, os parâmetros utilizados nos experimentos foram:

- O tamanho da lista de relacionamentos sequenciais e de saltos é de 5 e 7 , respectivamente, como mencionado no parâmetro $r$ (ZAVE, 2015), a não ser que seja especificado o contrário.

- O agente devolve 50 endereços IP (com suas respectivas portas) quando um dispositivo solicitar o ingresso no sistema, como mencionado no parâmetro numwant (COHEN, 2008b), totalizando aproximadamente 1.2 Kilobytes de informação.

- O agente repassa uma requisição de ingresso para outro agente, totalizando aproximadamente 20 bytes de informação, como mencionado no parâmetro peer_id (COHEN, 2008b).

- As atividades A2 à A6 são realizadas a cada 30 segundos, seguindo o mesmo intervalo de tempo utilizado pela rotina de atualização do Chord (STOICA et al., 2001).

Cabe destacar que o agente na nossa arquitetura corresponde a um nó na DHT. Nesse sentido, os dois primeiros itens da lista de parâmetros pertencem tanto ao nó quanto ao agente, mas os três últimos pertencem somente ao agente. 


\subsection{Testes relativos à eficiência}

Nos testes da eficiência, foi necessário entender se as duas extensões realizadas na DHT (a adição das responsabilidades do agente nos nós da DHT e as mudanças dos seus relacionamentos de salto) poderiam afetar seu funcionamento normal, entendendo-se por funcionamento normal o uso desta estrutura sem afetar sua escalabilidade. Para simular esse funcionamento normal, cada agente da estrutura realizou 7 solicitações de busca por bordas localizadas em setores aleatórios, seguindo as estatísticas de (ZHENG; SHEN; LI, 2005).

Para esses testes, comparamos nossa arquitetura MATe com a solução, de cada cenário, mais próxima à nossa, sendo o VMesh para o cenário de Vídeo sob Demanda e a ADHT para o cenário de monitoramento de sensores.

Nas Figuras 30 e 31 podem-se observar o experimento relativo à eficiência na adição de responsabilidades, medida na quantidade de agentes contatados (cada agente contatado corresponde a uma mensagem transmitida) e no tempo consumido para encontrar uma informação específica.

Como mencionado nos trabalhos relacionados ao cenário de Vídeo sob Demanda (Seção 4.2), no VMesh, a busca por uma informação (i.e., um segmento $s_{i}$ ) devolve como resultado uma lista com os nós que baixaram $s_{i}$. Dado que a chave da DHT é o segmento $s_{i}$, e o valor é a lista dos nós que o baixaram, o resultado é entregue em $O(\log N)$ mensagens. Já no trabalho relacionado ao cenário de sensores (Seção 4.1), - ADHT primeiro busca pelo IP virtual do agente responsável por um dispositivo, para depois obter dele o acesso ao dispositivo. Dado que a chave da DHT é o endereço do agente, o resultado é entregue em $O(\log N)+1$ mensagens, onde a mensagem extra corresponde ao acesso ao dispositivo. Nesse contexto, nossa arquitetura possui o mesmo comportamento do ADHT, dado que para ter acesso ao dispositivo primeiro é necessário buscar o agente responsável pelo dispositivo. Como mencionado, essa busca é realizada pelo setor onde está localizada a borda que contém o dispositivo.

Na Figura 30(a), pode-se observar que, em uma DHT composta por 300.000 agentes (seja a DHT do VMesh, do ADHT, ou a modificada na nossa camada multiagentes), a busca por uma informação $s_{i}$ (que pode ser um segmento, um IP Virtual ou um setor) 
precisa contatar $9 \pm 0.36$ nós para o VMesh, $9.7 \pm 0.39$ agentes para o ADHT e $10 \pm 0.3$ agentes para a nossa. A diferença é dada pela mensagem extra que deve ser enviada ao agente das duas últimas arquiteturas. Entretanto, a mensagem extra da busca por uma informação não altera a curva logarítmica. Na Figura 30(b) pode-se observar o mesmo experimento da Figura 30(a), porém do ponto de vista do tempo. Assim, para o mesmo caso dos 300.000 agentes, a busca por uma informação $s_{i}$ na nossa arquitetura consome $1769 \pm 28 \mathrm{~ms}$ (147 ms mais lento que no VMesh) onde a diferença é dada pela mensagem extra que deve ser enviada ao agente. Por outro lado, o tempo total permanece próximo a 1 segundo, concordando com os testes realizados em (JIMENEZ; OSMANI; KNUTSSON, 2011). As Figuras 31(a) e 31(b) representam o mesmo experimento mencionado anteriormente, porém com um $10 \%$ de mudança na estrutura (saída dos agentes). Nestas duas últimas figuras é possível observar que existe uma diminuição na eficiência se comparada com os testes sem mudança na DHT (da Figura 30). Entretanto, a curva permanece logarítmica, o que nos permite concluir que a eficiência é mantida.

Cabe destacar que, a busca por uma informação $s_{j}$ (que não está armazenada nos registros da tabela de relacionamentos de salto) precisará consumir novamente 1622 ms para o VMesh e 1769 para o ADHT. Por outro lado, nossa arquitetura pode utilizar o aprendizado do grupo para modificar os relacionamentos de salto, apontando diretamente para o agente responsável por $s_{j}$, consumindo somente $147 \mathrm{~ms}$ (tempo correspondente à mensagem extra).

Na Figura 32 pode-se observar o experimento relativo à eficiência na mudança dos relacionamentos de salto. Nesse experimento, analisou-se se a quantidade de agentes contatados para encontrar uma informação aumenta quando os relacionamentos de salto mudam (mudança realizada no aprendizado do agente do processo de busca da Seção 5.5.3). Nesta figura, a curva denominada "DHT" mostra a alternativa na qual as tabelas de roteamento não sofrem modificações (VMesh e ADHT utilizam esta alternativa). As curvas denominadas "Trinta" e "Setenta" mostram o número de agentes contatados para encontrar uma informação quando 30\% e 70\% dos relacionamentos de saltos (de todos os agentes) mudam. Da figura é possível observar que não há perda da eficiência porque a quantidade de agentes contatados permanece aproximadamente a mesma para as três curvas. 
Figura 30: Testes de eficiência sem modificação nos agentes da estrutura.

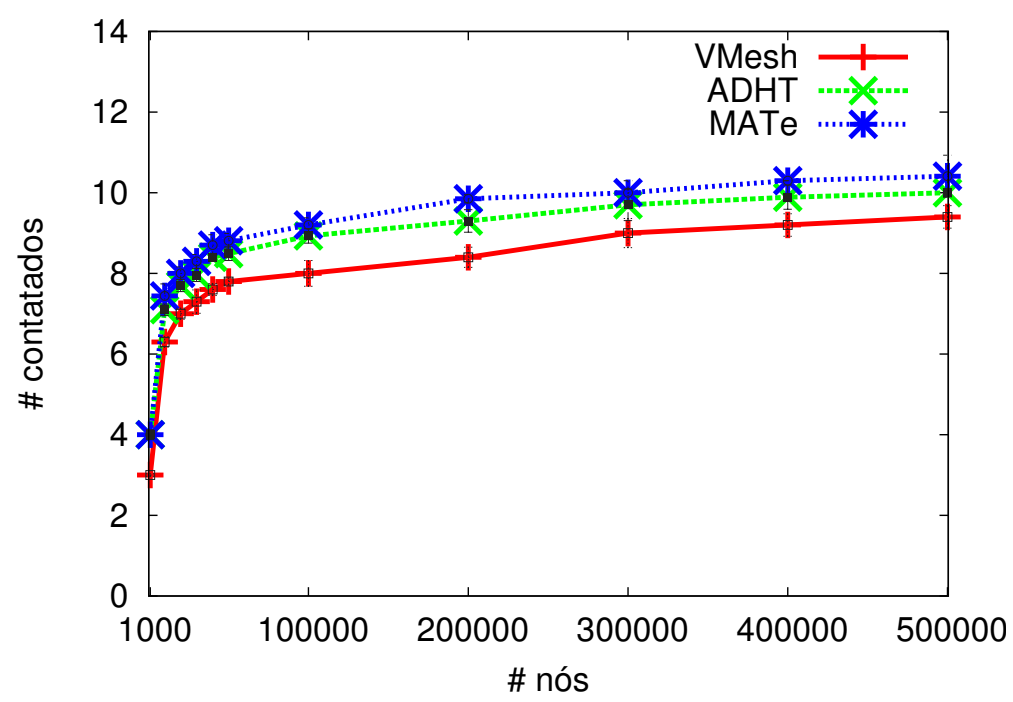

(a) Quantidade de agentes contatados.

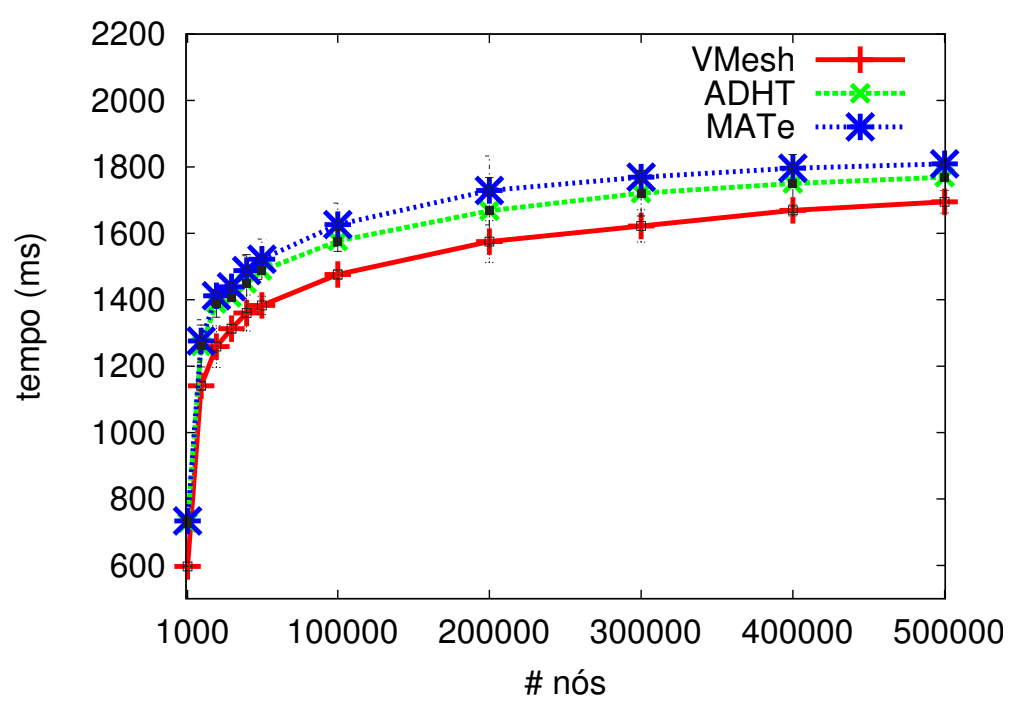

(b) Tempo para responder a requisição.

Fonte: Autor.

De acordo com a questão de pesquisa QP1, os testes relativos à eficiência mostraram que a arquitetura baseada em agentes diminui o desempenho da DHT na busca de informações, porém a diminuição é de no máximo uma mensagem. Nesse sentido, dado que o desempenho da DHT é $O(\log N)$, podemos afirmar que a mensagem extra, por ser uma constante, não altera o desempenho da busca. 
Figura 31: Testes de eficiência com saída de 10\% de agentes da estrutura.

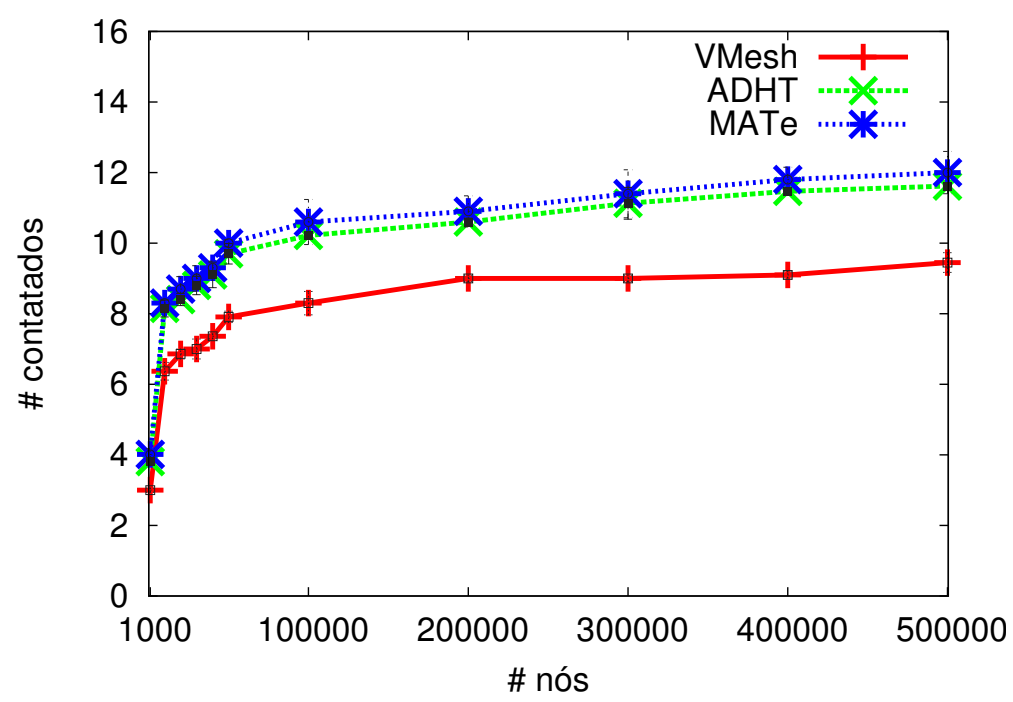

(a) Quantidade de agentes contatados.



(b) Tempo para responder a requisição.

Fonte: Autor.

\subsection{Testes relativos à escalabilidade}

Nos testes de escalabilidade, foi necessário entender como a quantidade de requisições enviadas diminui o desempenho do agente responsável por atender essas requisições. Para isso, no primeiro passo, foi definido o que se entende por desempenho e qual seria o recurso computacional que, ao ser afetado pelas requisições, diminui o desempenho da arquitetura. De acordo com o estudo em (SCHROEDER; 
Figura 32: Teste de eficiência na modificação dos relacionamentos de saltos.

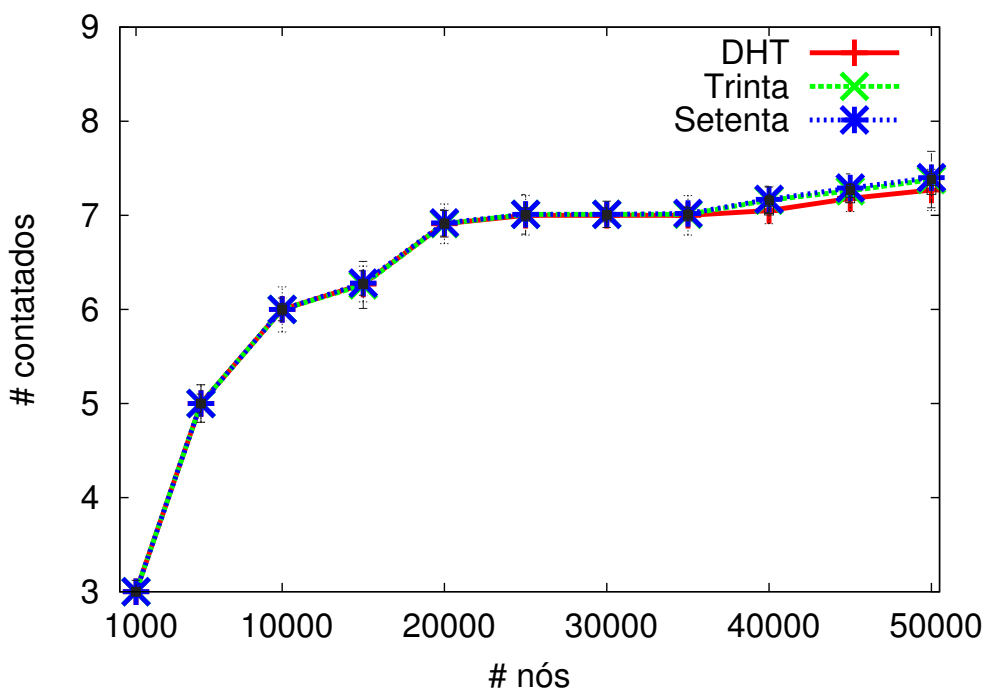

Fonte: Autor.

HARCHOL-BALTER, 2006), o desempenho da arquitetura é definido como o tempo necessário para buscar uma informação, sendo afetado por diversos recursos computacionais, tais como a CPU, a memória RAM e a largura de banda. Neste trabalho foi mantida a definição do desempenho mencionado anteriormente, mas foi considerado somente a largura de banda como o recurso que pode influenciar o desempenho da arquitetura.

No segundo passo, foi definido quais seriam os comportamentos que um agente executaria ao receber uma requisição. Os comportamentos analisados foram:

1. O agente limita a quantidade de requisições que pode atender simultâneamente, eliminando as novas requisições recebidas (denominado de admission control (CHERKASOVA; PHAAL, 1998));

2. O agente atende todas as requisições recebidas (utilizado pelos nós das implementações atuais da DHT);

3. O agente limita a quantidade de requisições simultâneas atendidas, mas cria novos agentes para que se encarreguem das requisições não atendidas (utilizado pela nossa arquitetura MATe).

Finalmente, no terceiro passo, foi definido como os agentes realizariam as bus- 
cas. Nos experimentos realizados, em um determinado instante, todos os agentes existentes nesse momento na estrutura realizaram 1 busca pela mesma informação.

$\mathrm{Na}$ Figura 33(a) pode-se observar os comportamentos 2 e 3 mencionados anteriormente em relação às requisições realizadas e atendidas (a Figura 33(b) apresenta as requisições não atendidas pelo comportamento 3 - MATe) ${ }^{1}$. Vamos analisar 0 caso de uma rede de 300.000 agentes, que representam 300.000 requisições enviadas para um único agente $a_{i}$. No comportamento 1 , o agente $a_{i}$ somente atende em torno de 208 requisições de forma simultânea, que consomem totalmente seus 2 Mbps de largura de banda de saída (lembrando que cada requisição atendida envia aproximadamente 1.2 Kilobytes). No comportamento 2 (DHT), o agente $a_{i}$ atende todas as requisições enviadas pelos agentes da rede. Já no comportamento 3 (MATe), pode-se observar que, para um agente $a_{i}$ com $2 \mathrm{Mbps}$ e $10 \mathrm{Mbps}$ de largura de banda de saída, foram atendidas $296.573 \pm 480$ e $299.217 \pm 545$ requisições, respectivamente. Desta figura surgem as seguintes perguntas:

1. O comportamento 1 permite atender mais de 208 requisições?

2. Já que o comportamento 2 (DHT) pode atender todas as requisições, faz com que esta seja a alternativa mais escalável?.

3. Porquê o comportamento 3 (MATe) não consegue atender todas as requisições como o comportamento 2 ?

4. No comportamento 3, qual é o benefício em ter uma maior ou menor quantidade de relacionamentos sequenciais?

Para responder estas perguntas, deve-se observar os comportamentos sob a perspectiva do tempo. A Figura 34 apresenta os comportamentos 2 (DHT) e 3 (MATe) em relação ao tempo consumido para atender às requisições da Figura 33.

Respondendo à primeira pergunta, um agente podería atender mais de 208 requisições de forma simultânea. Entretanto, ao aumentar a quantidade de requisições, aumenta-se também o tempo para atendê-las, haja vista que a largura de banda não

\footnotetext{
${ }^{1} \mathrm{O}$ comportamento 1 atendeu 208 requisições simultâneas sem afetar a escalabilidade da arquitetura. A partir dessa quantidade, novas requisições foram rejeitadas.
} 
Figura 33: Teste de escalabilidade nas requisições enviadas e atendidas.



(a) Requisições atendidas.

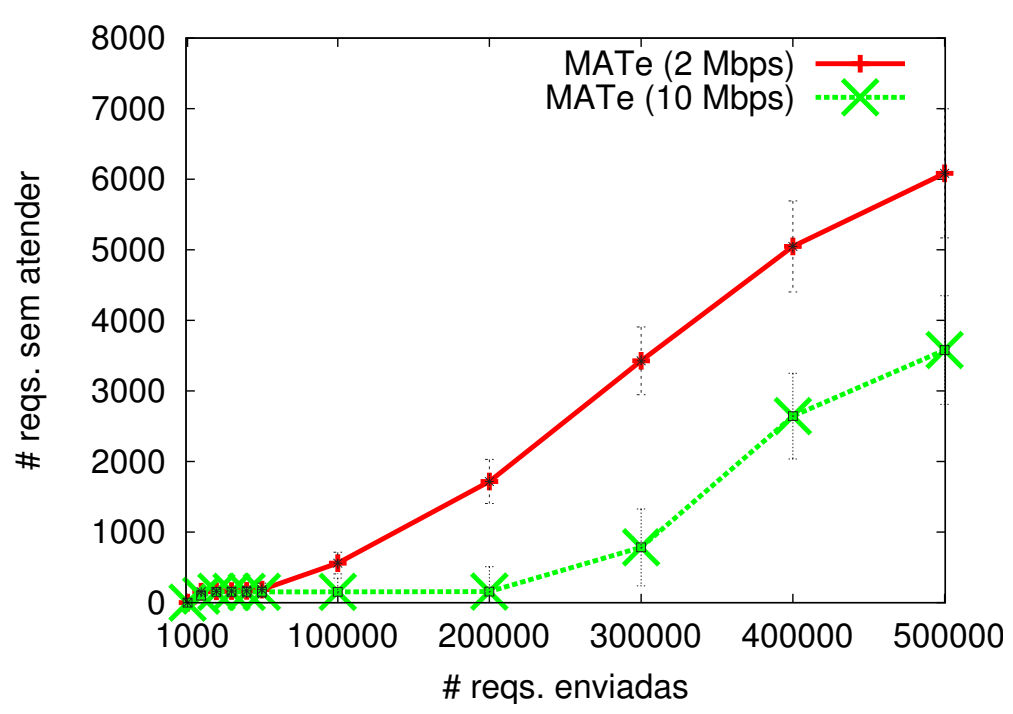

(b) Requisições não atendidas.

Fonte: Autor.

aumenta. Vejamos um exemplo, no caso das 208 requisições, que totalizam aproximadamente 249 Kilobytes de informação a ser enviada como resposta, todas estas são atendidas em aproximadamente 1 segundo (lembrando que de acordo com (JIMENEZ; OSMANI; KNUTSSON, 2011), o tempo total para responder uma requisição deve permanecer próximo a 1 segundo). Se dobramos as requisições atendidas, ou seja, o agente deve atender 416 requisições, o consumo total será de aproximadamente 498 Kilobytes, que serão atendidas em 2 segundos, obtendo um menor desempenho que 
a alternativa com 208 requisições, já que se afasta do limite de 1 segundo mencionado anteriormente.

Figura 34: Teste de escalabilidade no tempo para responder as requisições.



(a) Tempo na resposta das requisições.



(b) Zoom nos primeiros 50.000 agentes.

Fonte: Autor.

Respondendo à segunda pergunta, se olharmos a escalabilidade somente do ponto de vista da quantidade de requisições atendidas, o comportamento 2 (DHT) é o mais escalável dentre todos. Nesse contexto, o nó da DHT precisará ter uma fila suficientemente grande para armazenar as requisições ao mesmo tempo que as atende. Porém, pode-se observar na Figura 34 que, a partir das 5.000 requisições, 
o tempo necessário para atender as requisições (curva DHT) é maior que o tempo do comportamento 3 (curvas MATe de 2 e $10 \mathrm{Mbps}$ ). Se olharmos a escalabilidade tomando em conta tanto a quantidade de requisições atendidas quanto o tempo em atendê-las (e considerando também que o tempo de resposta deve estar próximo de 1 segundo, como mencionado anteriormente), o comportamento 3 é mais escalável que o comportamento 2 .

Respondendo à terceira pergunta, nossa alternativa deve não só atender às requisições (assim como o comportamento 1 e 2), mas também repassar, aos relacionamentos sequenciais, aquelas que não foram atendidas. Em seguida, esses agentes também executarão o processo de atender e repassar. Assim, no cálculo de requisições atendidas (isto é, da largura de banda necessária para atender as requisições em um tempo próximo a 1 segundo) deve ser considerado também a largura de banda e do tempo consumido pelo repasse. Como consequência do repasse e do tempo, algumas requisições não conseguem ser processadas, levando a que a quantidade de requisições atendidas é menor que a do comportamento 2 .

Respondendo à quarta pergunta, foi analisando a quantidade de requisições atendidas pelo agente, que gerencia bordas em um setor $S e c_{r}$, quando recebe 1000 requisições de ingresso. Na Figura 35(a) pode-se observar que, quanto maior o número de relacionamentos sequenciais, menor o número de requisições que cada agente desses relacionamentos deve receber, processar e responder. A Figura 35(b) mostra o mesmo resultado, mas começando com 5 relacionamentos sequenciais. Nesse sentido, como o número de requisições atendidas por cada agente desses relacionamentos diminui, a escalabilidade da arquitetura aumenta, haja vista que a carga total para processar e atender as mensagens é distribuída nesses agentes. Por exemplo, para agentes com 15 relacionamentos sequenciais, o número médio de mensagens recebidas por agente é de 68 (com um mínimo de 47 e um máximo de 89), diferentemente da DHT, onde somente um nó deve receber e responder às 1000 requisições.

De acordo com a questão de pesquisa QP1, os testes relativos à escalabilidade mostraram que a arquitetura baseada em agentes aumenta a escalabilidade da DHT ao distribuir as requisições entre vários agentes. Além disso, a distribuição na nossa arquitetura permite que as requisições sejam atendidas com um melhor desempenho que a da DHT quando a escalabilidade em um nó é comprometida. 
Figura 35: Teste de escalabilidade na recepção de requisições por agente.

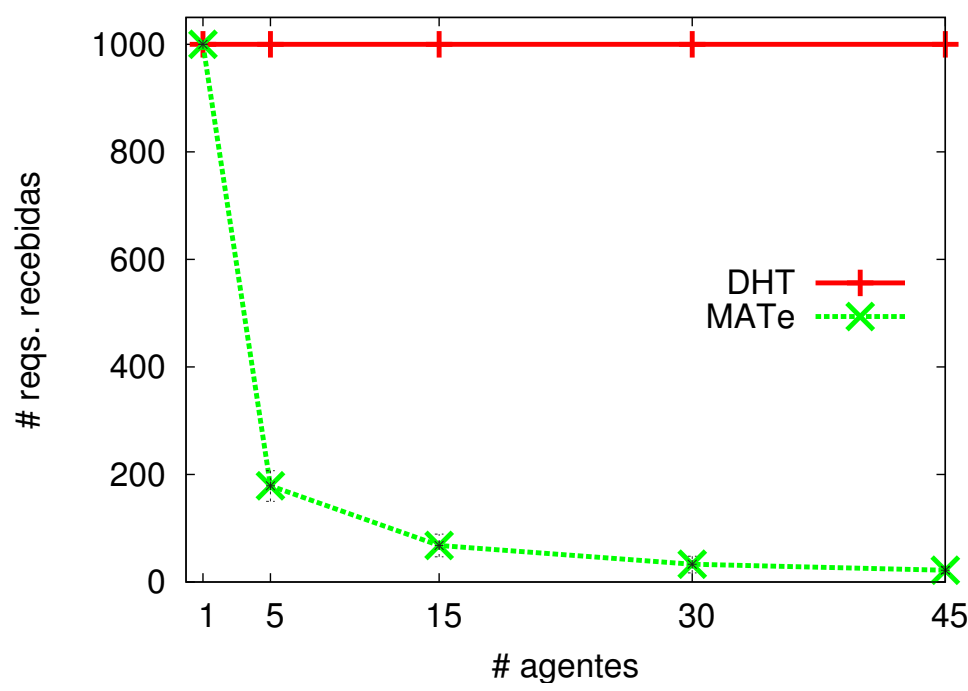

(a) Requisições recebidas.

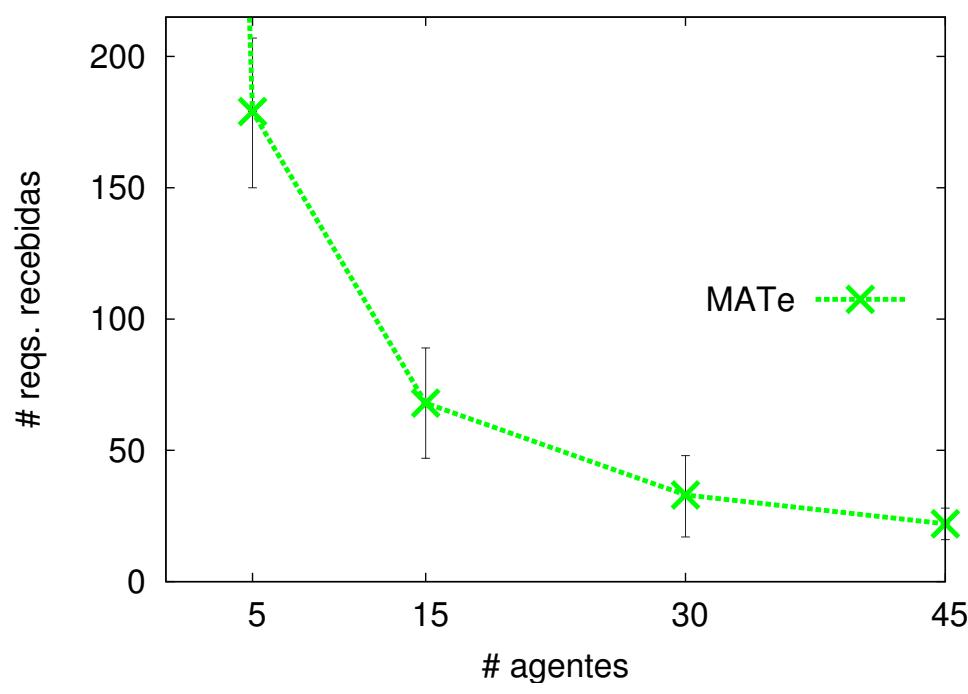

(b) Zoom começando em 5 agentes.

Fonte: Autor.

As duas seguintes seções abordarão experimentos que utilizam métricas específicas para os cenários de sensores e de vídeos sob demanda, respectivamente.

\subsection{Monitoramento de sensores}

Neste cenário, foi analisado como a utilização de uma fronteira pode aumentar a escalabilidade da arquitetura (diminuindo a quantidade de mensagens que o agente responsável deve receber do grupo). O cenário foi dividido em três casos de uso: o pri- 
meiro está relacionado com o monitoramento do movimento da biodiversidade, especificamente das aves; o segundo está relacionado com o monitoramento do movimento de pessoas que carregam seus telefones celulares; o terceiro está relacionado com o monitoramento do movimento de veículos que carregam sensores de geolocalização.

No primeiro caso, foi simulado o movimento do voo das aves conhecido como flocking. No flocking, as aves se movimentam como se fossem uma só, i.e., emerge um comportamento único, mesmo não havendo nenhum ente centralizador que coordene suas ações (por exemplo, todas as aves voam para a direita e a seguir todas voam para abaixo).

Para simular esse comportamento, foi utilizado o modelo 2D definido por Craig Reynolds (REYNOLDS, 1987) e implementado em código Java por Lalena (Lalena, 2016). Nesses trabalhos, três simples regras permitem simular o movimento realista do flocking, sendo estas: separação, alinhamento, e coesão. A separação permite criar uma área de repulsão entre duas ou mais aves (que se encontram a uma certa distância), evitando que se choquem. O alinhamento permite direcionar duas ou mais aves no mesmo sentido. A coesão permite criar uma área de atração entre duas ou mais aves, evitando que se dispersem.

Os parâmetros utilizados no simulador para executar os experimentos foram ${ }^{2}$ :

- A área monitorada era um quadrado de 1000 metros de lado.

- O valor da separação foi de 0.4 metros de raio.

- O alinhamento da ave era calculado com a média dos direcionamentos das aves que se encontravam em uma área de até 40 metros de raio.

- O valor da coesão da ave foi de 30 metros de raio.

- O valor da velocidade da ave foi de 30 metros por segundo (aproximadamente a velocidade máxima de um andorinhão-preto).

Nesses experimentos, cada ave possui um sensor de localização com uma antena para comunicação sem fio. $O$ alcance da antena utilizado foi de 40 metros, obtido do

\footnotetext{
${ }^{2} \mathrm{~A}$ separação, coesão e velocidade foram obtidos dos valores padrão do simulador.
} 
maior valor entre a separação, alinhamento e coesão. Para esse caso, o dispositivo se rotaciona com outro quando seu nível de energia atinge o valor zero, gerado pelo envio ou recebimento de aproximadamente 2200 requisições ${ }^{3}$, como mencionados em (HARJULA et al., 2014; DEKEL, 2016).

A Figura 36 compara as alternativas de utilizar todos os dispositivos, ou somente a borda ou a fronteira, para enviar as atualizações ao agente (realizadas pelo processo D1). Na Figura 36(a) pode-se observar que o uso da fronteira ou da borda diminui o número de mensagens (a Figura 36 (b) mostra os mesmos resultados, mas percentualmente, onde 1 representa 100\%). Por exemplo, no grupo cuja soma dos membros totaliza 10.000 dispositivos, a nossa solução supera as outras alternativas, enviando somente $562 \pm 63$ mensagens ao invés das 10.000 (que corresponde ao envio de uma mensagem por dispositivo), que representa uma diminuição de aproximadamente $94 \%$. Por outro lado, como já mencionado anteriormente, nossa arquitetura utiliza a fronteira somente depois de ter sido formada.

No segundo caso, foi simulado o comportamento social exibido pelas pessoas. Nesse contexto, foi utilizado o SWIM (Small World In Motion) (MEl; STEFA, 2009), que apresenta um modelo simples para reproduzir os padrões de mobilidade e de contatos entre os indivíduos. O SWIM se fundamenta nas seguintes três premissas: 1) uma pessoa tende a visitar lugares que são populares ou que estão próximos ao lugar onde permanece a maior parte do tempo (denominado de home); 2) as pessoas permanecem a maior parte do tempo em poucos lugares (como a residencia, oficina, escola, etc.) enquanto existem muitos lugares onde permanecem pouco tempo (agência bancária, cafeteria, etc.); 3) a velocidade do movimento depende de quão próxima a pessoa está do lugar ao qual quer chegar. $O$ trabalho explica que, se o lugar de destino onde a pessoa pretende ir está mais próximo, sua velocidade será menor, haja vista que a pessoa deverá caminhar para chegar à esquina, correr (ou ir de ônibus) para chegar a outro município, ou voar para chegar a outro continente.

Os parâmetros, em idioma inglês, utilizados no simulador para executar os experimentos foram:

- SimulationSeconds com valor de 3600 (60 minutos).

\footnotetext{
${ }^{3}$ Cada requisição consome $450 \mu \mathrm{A}$ de um total de $1000 \mathrm{~mA}$ (e.g. bateria de litio CR2477).
} 
Figura 36: Bordas em biodiversidade

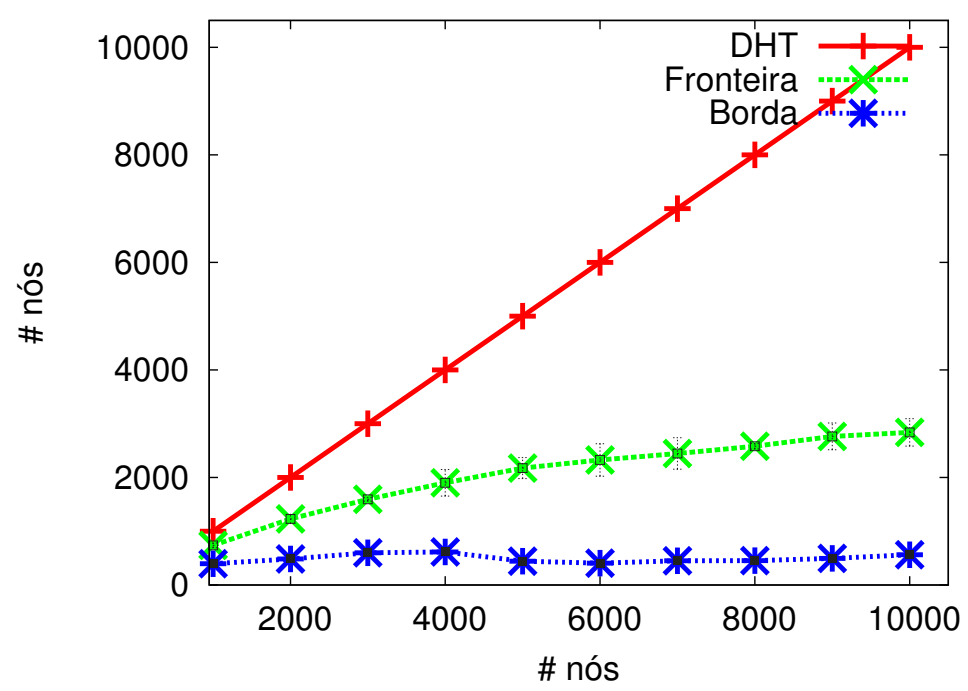

(a) Dispositivos nas bordas e fronteiras.

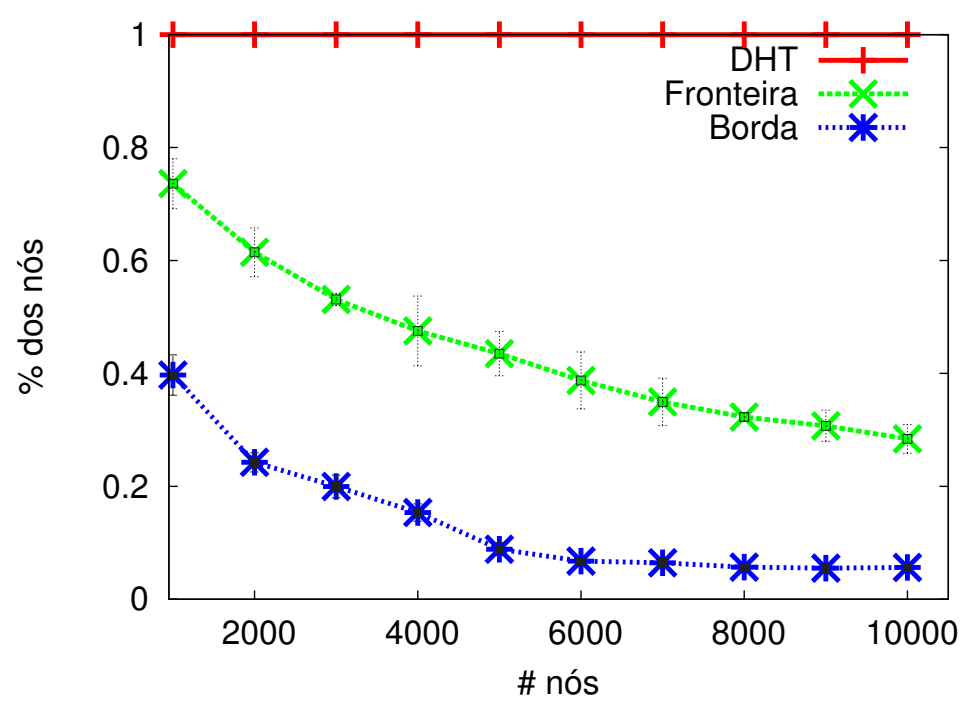

(b) Percentual dos dispositivos.

Fonte: Autor.

- NodeRadius $\in[0,1]$ que representa a proporção entre o raio da área coberta pela antena do telefone celular e o lado da área total do cenário (com um valor máximo de 1). Nesse sentido, para representar um cenário quadrado de lado $1000 \mathrm{~m}$, 2000 m, 4000 m e 8000 m, utilizando uma antena para comunicação sem fio (e.g., bluetooth (SABLE, 2014) ou zigbee (ALLIANCE, 2005)) com alcançe de $100 \mathrm{~m}$, os valores utilizados foram $0.1,0.05,0.025$ e 0.013 . Como exemplo, o parâmetro 0.1 foi calculado da seguinte maneira: supondo $1000 \mathrm{~m}$ de lado, com 
$100 \mathrm{~m}$ de alcance, $100 / 1000=0.1$.

- CellDistanceWeight $\in[0,1]$ que representa a probabilidade de uma pessoa escolher um lugar próximo de casa ou um lugar popular como seu próximo destino. Valores próximos de 1 representam lugares mais próximos de casa, enquanto valores próximos de 0 representam lugares mais populares. $O$ valor utilizado foi 0.8 .

- WaitingTimeUpperBound que indica quantos segundos, como máximo, uma pessoa permanecerá em um determinado lugar. O valor utilizado foi 10.

A Figura 37 mostra a quantidade de bordas que um agente deve gerenciar quando o parâmetro NodeRadius é $0.1,0.05,0.025$ e 0.013 . A quantidade de bordas está relacionada com a quantidade de vezes que o agente deve executar a atualização da borda (atividade A3). Nesse sentido, quanto menor for a quantidade de bordas, menor o consumo de energia do agente. Na figura 37(a), é possível observar que quanto maior o NodeRadius (ou seja, menor a área do cenário a ser monitorado), menor a quantidade de bordas que serão geradas. Por exemplo, para uma rede de 3.000 dispositivos, os parâmetros 0.1 e 0.05 geram somente 1 borda, porém os parâmetros 0.025 e 0.013 geram $39 \pm 4$ e $1320 \pm 66$, respectivamente. Já para uma rede de 10.000 dispositivos, o parâmetro 0.025 também gera 1 borda, mas o de 0.013 ainda precisa gerenciar $180 \pm 16$ bordas. Uma atenção especial merece a curva do parâmetro 0.013 . $\mathrm{Na}$ Figura 37(a), a quantidade de bordas aumenta (até os 3.000 dispositivos) para logo diminuir. Para esclarecer esse comportamento, na Figura 37(b) pode-se observar que, percentualmente (onde 1 representa 100\%), a quantidade de bordas diminui com a quantidade de dispositivos. Finalmente, é possível notar também que, a partir dos 3.000 dispositivos, somente haverá 1 borda para cenários com áreas menores a 4.000 metros de lado.

A Figura 38 mostra o percentual de dispositivos que existem nas bordas de todos os grupos do experimento anterior (onde 1 representa 100\%). Na figura, é possível observar que quanto maior o NodeRadius, menor a quantidade de dispositivos que pertencem à borda, diminuindo assim a quantidade de atualizações que o agente deve receber (lembrando que só os dispositivos da borda enviam mensagens ao agente). Por exemplo, em uma rede de 10.000 dispositivos, os parâmetros $0.1,0.05,0.025$ e 
Figura 37: Bordas em mobilidade humana

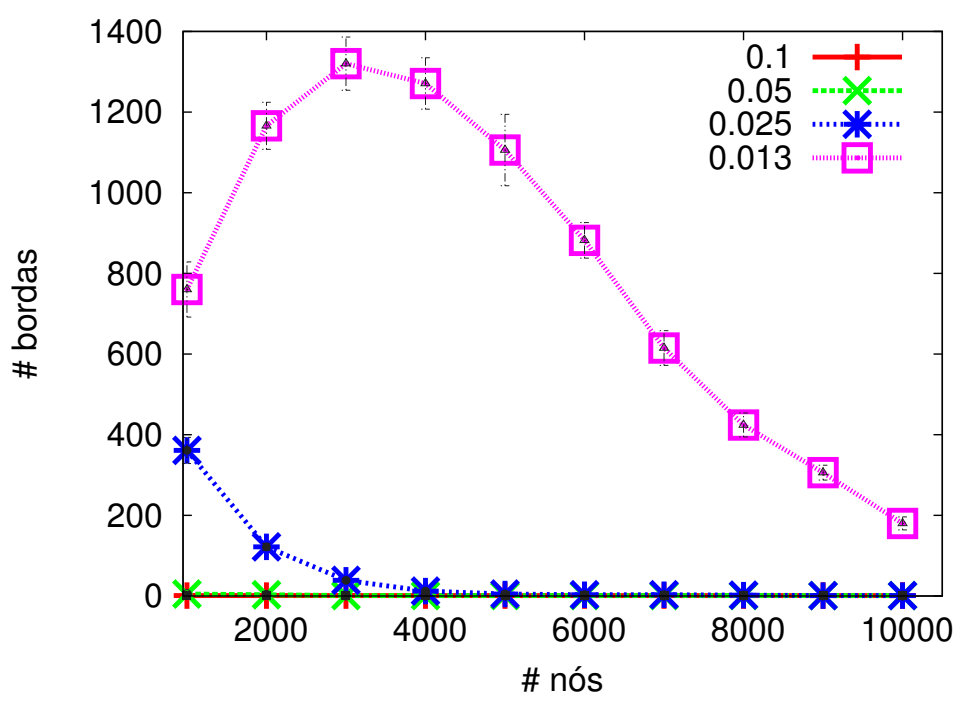

(a) Quantidade de bordas.

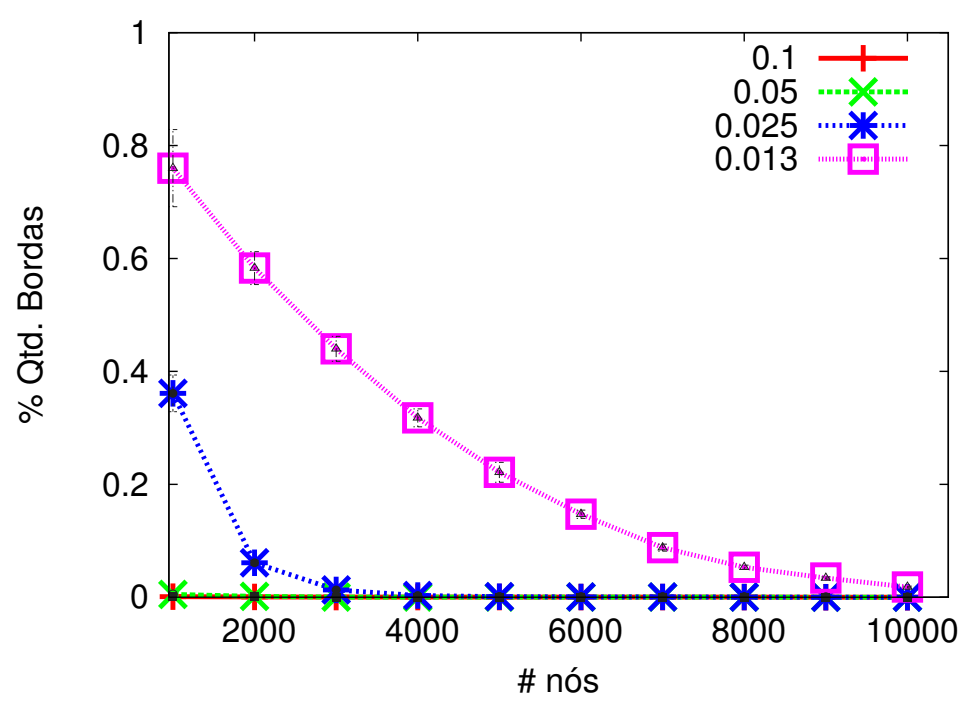

(b) Percentual da quantidade de bordas.

Fonte: Autor.

0.013 geram $300 \pm 28,600 \pm 71,1.000 \pm 112$ e $1.600 \pm 181$ dispositivos na borda (representando $3 \%, 6 \%, 10 \%$ e $16 \%$ respectivamente). Por outro lado, é possível observar que até os 3.000 dispositivos, a quantidade de dispositivos nas bordas dos parâmetros $0.05,0.025$ e 0.013 não possuem diferença se comparada com as alternativas atuais, onde todos os dispositivos enviam as informações ao agente. Finalmente, é possível notar que, a partir dos 8.000 dispositivos, todas as curvas diminuem em pelo menos $50 \%$ a quantidade de dispositivos na borda, superando as alternativas atuais 
mencionadas anteriormente.

Figura 38: Percentual de dispositivos na borda em mobilidade humana.

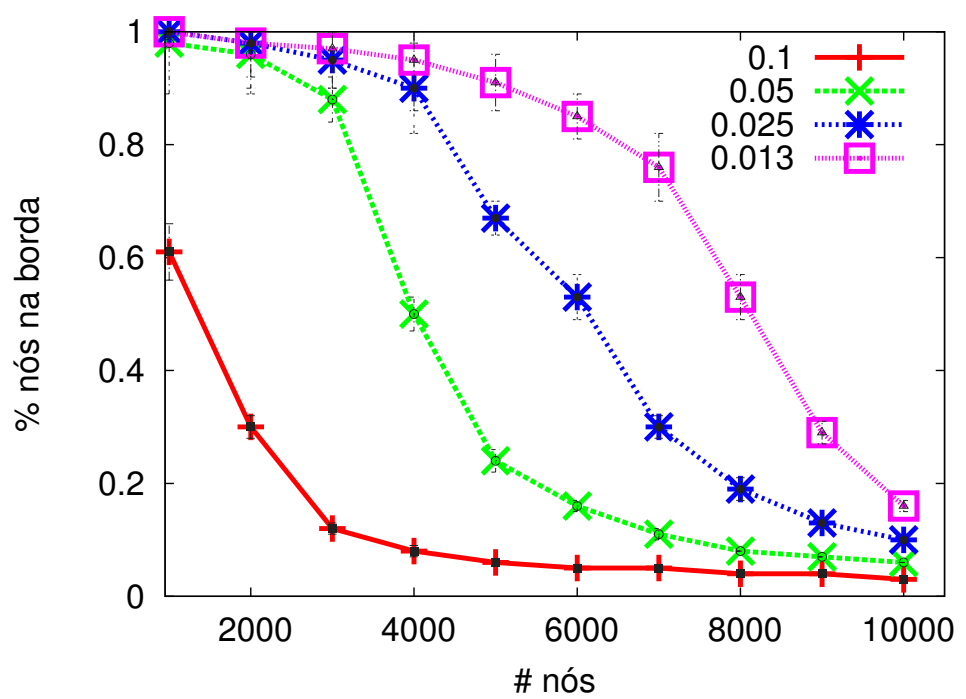

Fonte: Autor.

No terceiro caso, foi simulado o comportamento exibido pelos veículos transitando em uma cidade. Nesse contexto, foi utilizado o modelo Manhattan Grid (BAI; SADAGOPAN; HELMY, 2003), que apresenta o movimento de veículos em uma topologia em grade que corresponde ao ambiente das ruas de uma cidade. Nesse modelo, os veículos se movimentam por caminhos pré-definidos na direção horizontal ou na vertical de um mapa urbano. O simulador utilizado para gerar tanto o mapa quanto os caminhos dos veículos foi o BonnMotion (ASCHENBRUCK et al., 2010).

Os parâmetros utilizados no simulador para executar os experimentos foram:

- $d$ (duração) com valor de 300 segundos.

- x (largura do mapa) com valor 8000 (em metros).

- y (comprimento do mapa) com valor 8000 (em metros).

- e (velocidade mínima do veículo) com valor 10 (em metros/segundo).

- m (velocidade média do veículo) com valor 15 (em metros/segundo).

- u (número de intersecções no eixo x) com valor 40 (representando quadras de largura 200 metros). 
- $v$ (número de intersecções no eixo y) com valor 40 (representando quadras de comprimento 200 metros).

Nesses experimentos, cada veículo possui um sensor de localização com uma antena para comunicação sem fio. O alcance da antena utilizado foi de 100, $200 \mathrm{e}$ 300 metros, valores de referência para aplicações que querem utilizar o serviço de comunicação estendido (extended range) do padrão DSRC (Dedicated Short Range Communication) (IEEE, 2017).

A Figura 39 mostra o percentual de dispositivos que existem nas bordas de todos os grupos gerados para os diferentes alcances da antena. Na figura, é possível observar que quanto maior o alcance da antena, menor a quantidade de dispositivos que pertencem à borda, diminuindo assim a quantidade de atualizações que o agente deve receber. Por exemplo, em uma rede de 10.000 dispositivos, uma antena de alcance de 100, 200 e 300 metros geram $6.560 \pm 147,4.781 \pm 63$ e $3.400 \pm 209$ dispositivos na borda (representando $66 \%, 48 \%$ e $34 \%$ respectivamente). Por outro lado, é possível observar que a quantidade de dispositivos nas bordas, independente dos alcances das antenas mencionadas, não gera um diferencial se comparada com o caso do movimento da mobilidade humana da Figura 38. Note por exemplo que até os 8.000 dispositivos, tanto as antenas de 100 e 200 metros de alcance geram uma fronteira com quase $80 \%$ dos dispositivos.

\subsection{Vídeo sob demanda}

Nesta seção foi comparado o desempenho e escalabilidade da arquitetura com aquelas que utilizam, na camada de dispositivos, uma rede P2P para streaming de vídeos (especificamente, com a rede P2P do VMesh (YIU; JIN; CHAN, 2007) e da estrutura híbrida (ROCHA et al., 2016) mencionadas nos trabalhos relacionados).

Nesses experimentos, foi utilizado um vídeo composto de 100 segmentos de 1024 Kilobytes cada um. Além disso, foi utilizado um servidor (que atua como servidor de streaming) para prover os segmentos aos dispositivos que não conseguiram baixá-los dos seus vizinhos antes de serem reproduzidos. Finalmente, a largura de banda de saída desse servidor é de 1 Mbps. 
Figura 39: Percentual de dispositivos na borda em mobilidade de veículos.

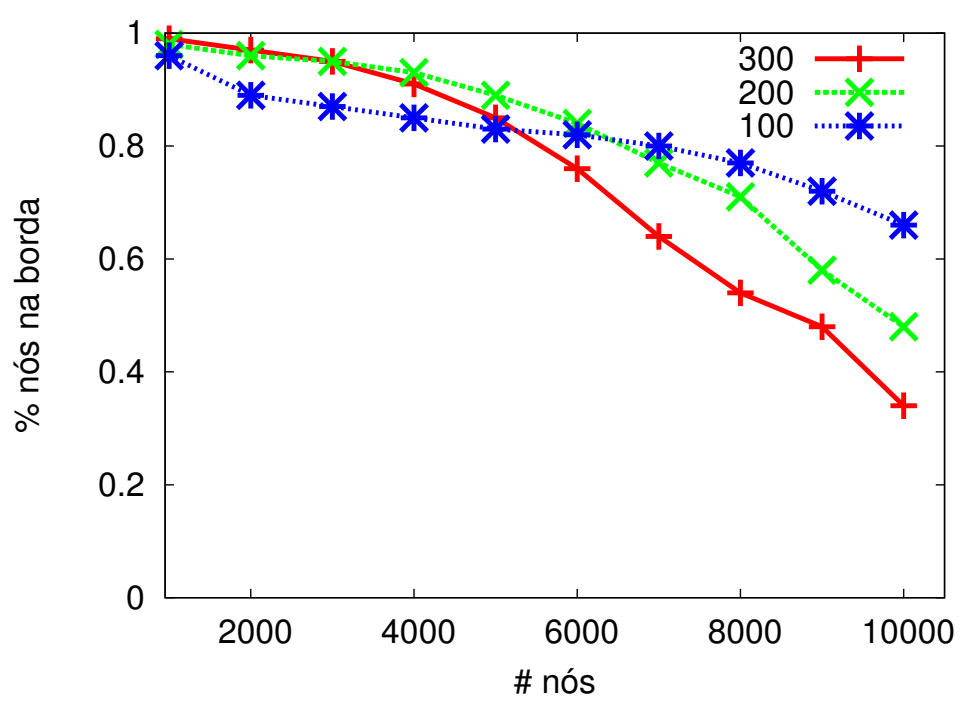

Fonte: Autor.

A avaliação considerou as seguintes métricas:

- Tempo para baixar o vídeo. Definido como o período de tempo entre o instante que o dispositivo ingressa no sistema e o instante em que o dispositivo baixa todos os segmentos do vídeo de forma sequencial (isto é, dos segmentos identificados do 1 ao 100, nessa ordem). Quanto menor o tempo para baixar o vídeo, maior é o desempenho da arquitetura.

- Tempo de espera. Definido como o tempo total que um dispositivo espera enquanto baixa o segmento que devia começar a ser reproduzido. Quanto menor o tempo de espera, maior é o desempenho da arquitetura.

- Estresse do servidor. Definido como a carga aplicada no servidor de streaming para dar suporte a aqueles dispositivos que não encontraram um determinado segmento. A carga foi normalizada para indicar o número de conexões necessárias. Quanto menor o número de conexões, maior é a escalabilidade da arquitetura.

- Tempo de inicialização. Definido como o período de tempo entre o instante que o dispositivo ingressa no sistema e o instante em que o dispositivo começa a reproduzir o primeiro segmento do vídeo depois de ter sido baixado. Um menor 
tempo de inicialização significa que a arquitetura responde de forma eficiente às solicitações de ingresso.

Para a métrica do tempo para baixar o vídeo, foi medido o tempo que um dispositivo precisa esperar para baixar todos os segmentos de um vídeo. No caso do VMesh, um dispositivo $d_{i}$ (que quer baixar o segmento identificado como $j$ ) se conecta com outro $d_{j}$ desde que este possua o segmento $j$. Em seguida, o dispositivo $d_{i}$ baixa o segmento e se conecta com algum dispositivo que possua o segmento seguinte, identificado como $j+1$. Entretanto, a busca pelo segmento seguinte pode sofrer uma demora caso o dispositivo $d_{j}$ saia da rede (ao ter que buscar o segmento na DHT). Por outro lado, na estrutura híbrida, um dispositivo $d_{i}$ se conecta com vários dispositivos que possuem os segmentos de uma cena (as cenas foram definidas a priori como intervalos de 10 segmentos, sem sobreposição). Essa abordagem melhora o desempenho, se comparado com o VMesh, ao permitir a $d_{i}$ ter à disposição conexões com dispositivos que baixaram segmentos além do seguinte. Nossa proposta utiliza a mesma abordagem da estrutura híbrida, mas cada grupo possui intervalos de segmentos que não são predefinidos e podem conter sobreposições. Na Figura 40(a) é possivel observar que a estrutura híbrida e a nossa solução superam o VMesh (como na nossa o intervalo de segmentos é variável, mostra-se a curva para um intervalo de 10 segmentos). Para uma rede entre 5.000 e 10.000 dispositivos (mostrada na Figura 40(b), que faz um zoom do eixo Y), tanto a estrutura híbrida quanto a nossa têm aproximadamente o mesmo comportamento, superando o VMesh. Como exemplo, em uma rede de 10.000 dispositivos, a estrutura híbrida e a nossa superam o VMesh por $47.49 \%$ e $39.58 \%$ ( $436 \pm 18.1$ e $384 \pm 10.3$ segundos), respectivamente.

Para a métrica do tempo de espera, foi medido o tempo total que um dispositivo deve esperar enquanto baixa um segmento que deveria estar sendo reproduzido (note que esse segmento é necessário para continuar a reprodução do vídeo, portanto não é possível simplesmente descartá-lo). Na Figura 41(a) é possível observar que, em uma rede entre 1.000 a 7.000, a estrutura híbrida e a nossa solução superam o VMesh. Já para uma rede entre 7.000 e 10.000 dispositivos (mostrada na Figura 41(b), que faz um zoom do eixo $\mathrm{Y}$ ), todas as alternativas têm aproximadamente o mesmo comportamento, mas tanto a estrutura híbrida quanto a nossa são novamente melhores que o VMesh. Como exemplo, em uma rede de 8.000 dispositivos, tanto a estrutura hí- 
Figura 40: Métrica do tempo para baixar o vídeo

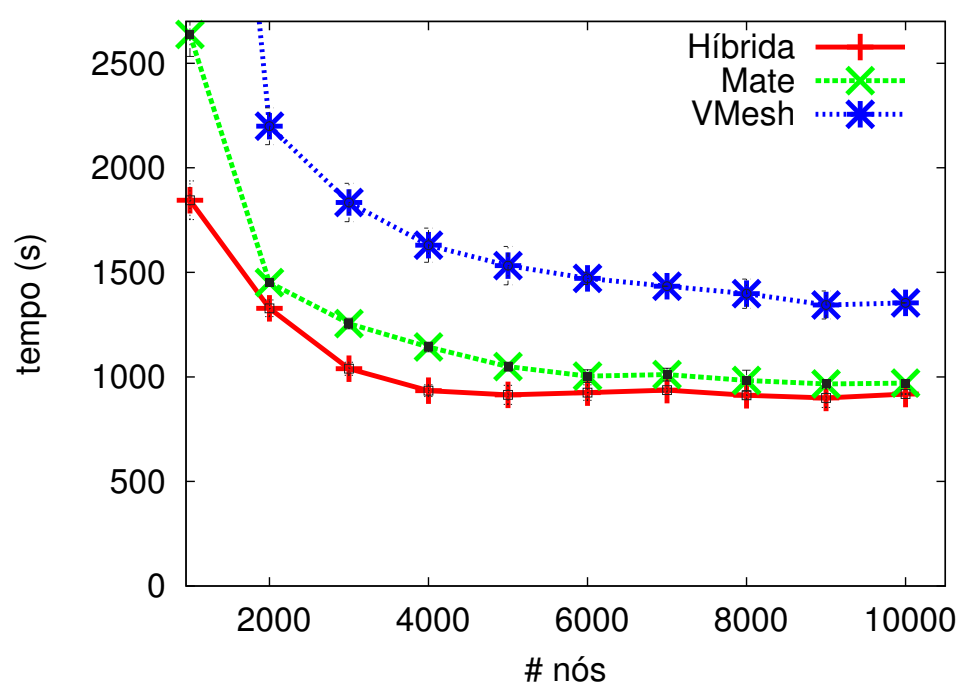

(a) Tempo para baixar todos os segmentos.

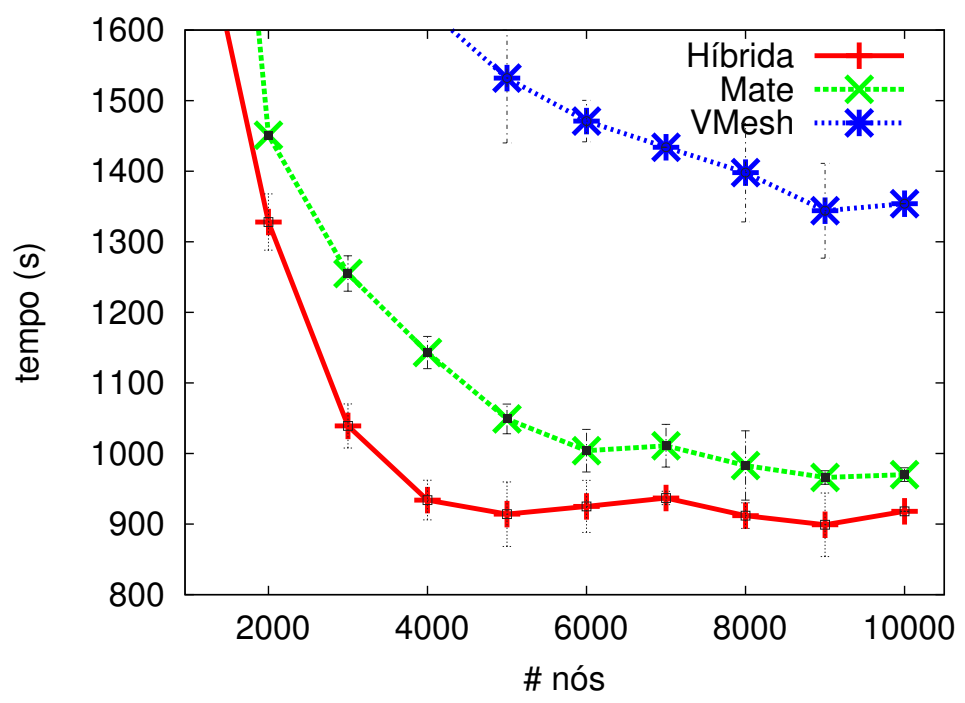

(b) Zoom no eixo Y.

Fonte: Autor.

brida quanto a nossa alternativa superam o VMesh por $51.29 \%$ e $37.86 \%(158 \pm 10.4$ e $128 \pm 6.7$ segundos), respectivamente.

Para a métrica do estresse do servidor, foi medida a carga aplicada no servidor de streaming, cujo valor está diretamente relacionado como a escalabilidade da arquitetura. O propósito dessa simulação foi determinar quão sobrecarregado fica o servidor de streaming quando um dispositivo precisa contatá-lo diretamente para baixar um determinado segmento. Essa situação acontece quando o dispositivo não consegue 
Figura 41: Métrica do tempo de espera



(a) Tempo de espera do dispositivo.

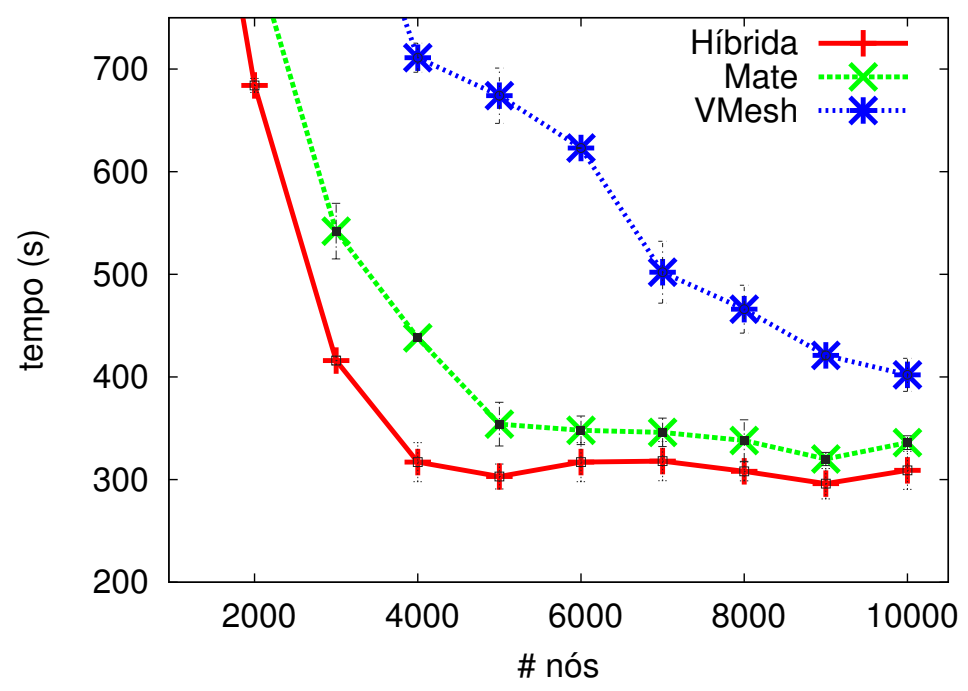

(b) Zoom no eixo Y.

Fonte: Autor.

baixar a tempo um segmento (cuja reprodução é iminente) da lista de dispositivos vizinhos. Como observado na Figura 42, todas as três alternativas (VMesh, estrutura híbrida e a nossa) têm aproximadamente o mesmo comportamento, mas tanto a estrutura híbrida quanto a nossa superam o VMesh. Como exemplo, em uma rede de 7.000 dispositivos, a estrutura híbrida e a nossa reduzem o número de conexões em $74 \pm 33$ e $81 \pm 17$, respectivamente.

Para a métrica do tempo de inicialização, foi medido quanto tempo um dispositivo 
Figura 42: Métrica do estresse do servidor.

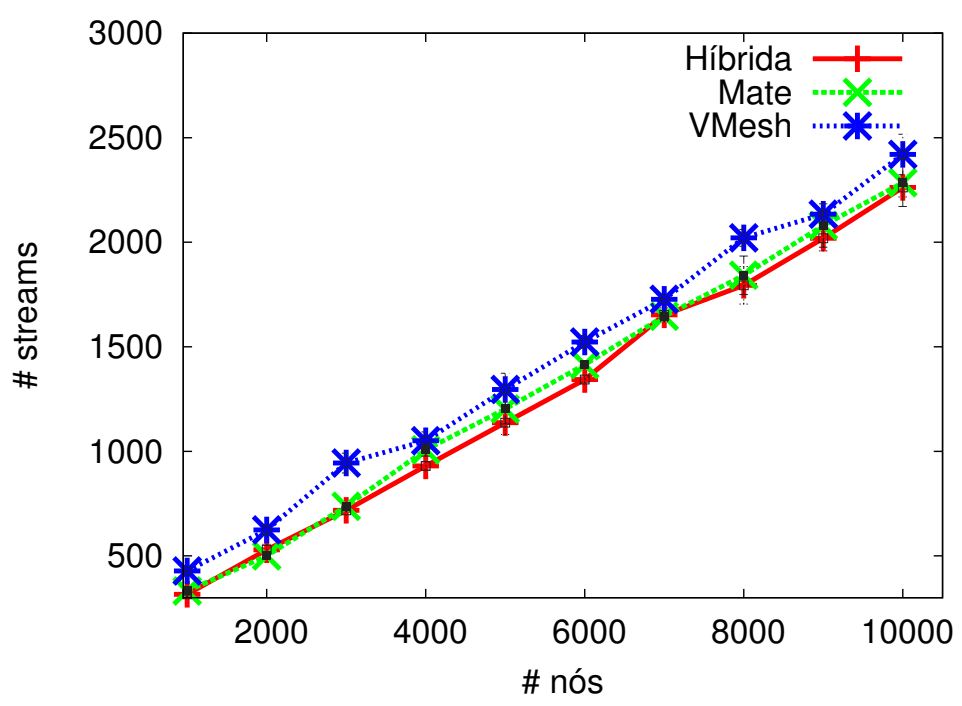

Fonte: Autor.

precisa esperar até poder reproduzir o primeiro segmento. Em geral, o dispositivo primeiro deve contatar algum membro da DHT (ou da camada multiagentes) quem por sua vez entregará ao dispositivo uma lista de dispositivos. Em seguida, o dispositivo se conecta com um dispositivo da lista e baixa o segmento. Na Figura 43, pode-se observar que o VMesh supera tanto a estrutura híbrida quanto a nossa solução, haja vista que a DHT entrega imediatamente uma lista de dispositivos, sem precisar passar por um agente que intermedia essa negociação. Por outro lado, a nossa solução tem um desempenho menor que a híbrida dado que um agente pode estar sobrecarregado e precisará encaminhar a requisição do dispositivo para um dos relacionamentos sequenciais. Como exemplo, em uma rede de 7.000 dispositivos, o VMesh supera a estrutura híbrida e a nossa por $4.8 \pm 1.53$ e $6.3 \pm 2.08$ segundos, respectivamente. Cade destacar que, entre a estrutura híbrida e a nossa, há no máximo $4 \%$ de diferença no tempo de inicialização.

\subsection{Análise dos resultados}

Dos testes relativos à eficiência pode-se concluir que:

- O uso de agentes adiciona uma mensagem extra (e portanto um tempo extra) na busca por uma informação. Entretanto, essa mensagem extra não afeta a curva 
Figura 43: Métrica do tempo de inicialização.

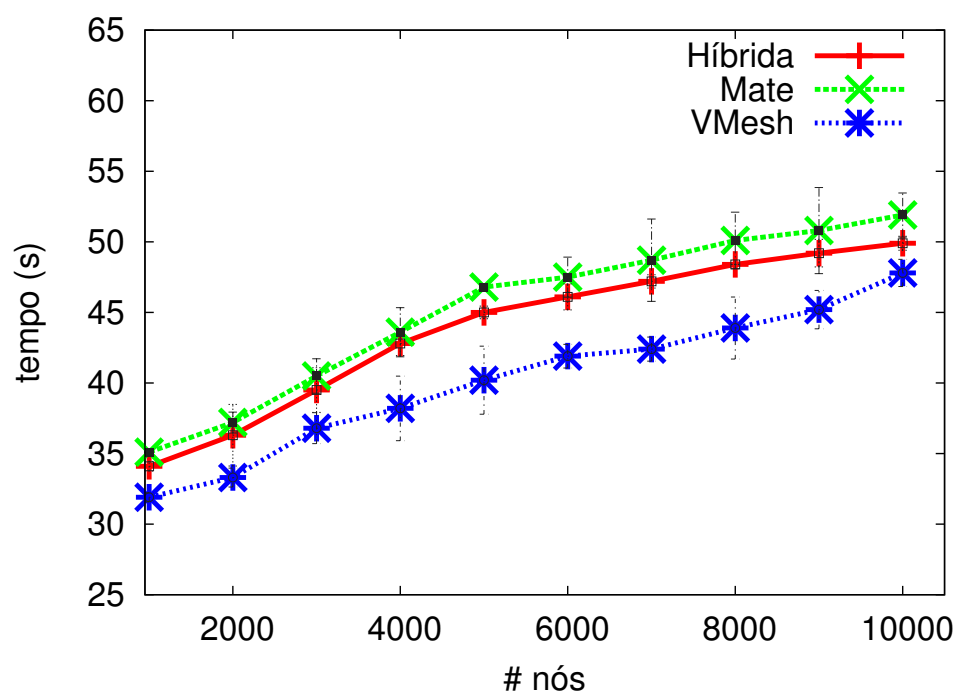

Fonte: Autor.

da eficiência da arquitetura se comparada com a da DHT.

- O uso de relacionamentos de salto que mudam de acordo com as requisições do grupo pode aumentar a eficiência da arquitetura. Nesse sentido, em uma busca recorrente de uma informação, não seria necessário utilizar a busca $O(\log N)$ da $\mathrm{DHT}$, dado que haveria um registro que aponta diretamente o agente responsável por ela.

- A mudança nos relacionamentos de salto de um agente (i.e., a inserção ou modificação dos registros da tabela de roteamento) não afeta a eficiência da arquitetura se comparada com a da DHT.

Dos testes relativos à escalabilidade pode-se concluir que:

- Nossa alternativa é escalável na quantidade de requisições atendidas (sem diminuir o desempenho em atendê-las), porém nem todas as requisições enviadas são atendidas.

- A alternativa de limitar as requisições em uma certa quantidade (eliminando as outras) é a menos escalável (em termos de requisições atendidas), porém é a que tem melhor desempenho em atendê-las. 
- A alternativa de atender todas as requisições, utilizada nas implementações atuais da DHT, possui o problema da escalabilidade (em termos do desempenho) quando o nó consome todos seus recursos.

- Uma maior quantidade de agentes com relacionamentos sequenciais aumenta a escalabilidade da arquitetura no atendimento das requisições.

Dos testes específicos para o cenário de sensores pode-se concluir que:

- A utilização da fronteira tem como consequência a diminuição da quantidade de informações enviadas pelos dispositivos que compõem o grupo para o agente responsável por ele. Essa diminuição é importante nesse cenário tanto para evitar o consumo da energia dos dispositivos quanto para aumentar a escalabilidade do agente que os gerencia. Os testes do uso da fronteira nos permitem concluir que a escalabilidade da arquitetura aumenta dado que o agente recebe menos requisições. Ao receber menos requisições, o agente aumenta o desempenho em atendê-las dado que a carga diminui.

- Por outro lado, a utilização da fronteira não é útil quando os dispositivos que a compõem se movimentam de tal forma que constantemente estão entrando e saindo da fronteira. Nesse sentido, o agente (que é um dispositivo agentificado) deverá calcular a borda cada certo tempo, consumindo sua energia.

Dos testes específicos para o cenário de vídeo sob demanda pode-se concluir que:

- O uso de relacionamentos sequenciais (MATe) permite que um vídeo seja baixado de forma mais eficiente se comparado com a alternativa do uso da DHT para conectar somente os segmentos consecutivos (VMesh).

- O uso relacionamentos sequenciais (MATe) não melhora a eficiência para baixar o vídeo se comparado com a estratégia para conectar cenas consecutivas, cada cena composta por vários segmentos consecutivos (Híbrida).

- A arquitetura MATe não elimina a utilização do servidor de streaming caso um segmento, próximo de ser reproduzido, não tenha sido baixado a tempo por um dispositivo (baixado de outro dispositivo do grupo ao qual pertence). 


\section{CONCLUSÃO E TRABALHOS FUTUROS}

Com a popularização da Internet, houve uma produção exponencial de informação como fotos, áudios, vídeos, entre outros. Dentre essas informações, existem algumas delas que podem ser divididas e relacionadas entre si de acordo a uma ordem total. Neste trabalho discutimos, como exemplo de uma informação com relação de ordem total, um vídeo que foi dividido em dez segmentos, cada um identificado com um número único de 1 a 10. Nesse contexto, para reproduzir o vídeo original, a partir dos segmentos, é necessário ordená-los de acordo ao identificador.

Para gerenciar essa imensa quantidade de informações, foi necessário criar sistemas computacionais que permitissem recuperá-las de forma eficiente e escalável. Uma das estruturas distribuídas mais utilizadas por diversos sistemas que gerenciam informações dependentes da ordem total é a tabela de hash distribuída (DHT).

Entretanto, nesses sistemas, existem alguns problemas que impedem que a estrutura se mantenha escalável durante sua execução. No caso do vídeo, o problema surge quando o nó responsável por um segmento do vídeo não consegue atender às requisições dos usuários. Isso acontece, por exemplo, quando todos os usuários requisitam um segmento muito popular ou o primeiro segmento do vídeo.

Este trabalho apresentou uma arquitetura de duas camadas que aumentou a escalabilidade da tabela de hash distribuída, mantendo sua eficiência na localização de informações dependentes de ordem total.

$\mathrm{Na}$ arquitetura, a camada multiagentes é composta por agentes de software, onde cada um é responsável pelo armazenamento de um conjunto de informações, pela criação de novos agentes (para distribuir as requisições e aumentar a escalabilidade da arquitetura) e pelo gerenciamento de um grupo de dispositivos que requisitam as informações.

Já a camada de dispositivos é composta por grupos de dispositivos que realizam requisições por uma determinada informação. Nessa camada, os dispositivos são organizados de tal forma que somente os que pertencem à fronteira do grupo sejam responsáveis por enviar as requisições ao agente que gerencia o grupo. Com isso, o 
agente recebe menos requisições, aumentando a escalabilidade da arquitetura.

De acordo com os resultados experimentais obtidos nas simulações dos cenários de monitoramento de sensores e vídeo sob demanda, a adição de responsabilidades no nó da DHT não afetou a eficiência na recuperação das informações. Por outro lado, a escalabilidade aumentou tanto com a criação de novos agentes quanto com a utilização da fronteira. No primeiro caso, a criação de novos agentes permitiu distribuir as requisições vindas do grupo. No segundo caso, o uso da fronteira permitiu diminuir a quantidade de requisições destinadas ao agente.

\subsection{Contribuições}

Como contribuições científicas e tecnológicas deste trabalho citamos:

- Definição de uma arquitetura de atualização, recuperação e armazenamento escalável de informações com relação de ordem total que permite ser utilizada em diversos domínios de aplicação.

- Extensão da DHT para controlar o problema da escalabilidade. Essa extensão permite que os diversos domínios, que já utilizam a estrutura, se aproveitem da escalabilidade na localização e atualização de informações da arquitetura.

- Extensão dos protocolos que fazem uso do conceito de grupos. Essa extensão permite que somente alguns membros, especificamente os da fronteira, sejam responsáveis por enviar informações ao responsável pelo grupo, diminuindo as informações transferidas, aumentando a escalabilidade da arquitetura.

\subsection{Publicações}

A disseminação das contribuições citadas concretizou-se através das publicações científicas listadas abaixo.

1. (ROCHA; BRANDãO, 2015).

Esse artigo apresenta a arquitetura de duas camadas para o cenário de vídeo sob demanda. Na camada multiagentes, os nós da DHT são transformados em 
agentes de software. Cada agente é responsável por analisar o comportamento do grupo e criar relacionamentos entre si para diminuir o tempo para baixar um vídeo. Na camada de nós, os nós (denominados peers) que representam os usuários assistindo um vídeo, atuam de acordo às políticas de compartilhamento do protocolo BitTorrent para streaming.

2. (ROCHA; BRANDãO, 2016).

Esse artigo apresenta a arquitetura de duas camadas para o cenário de monitoramento de biodiversidade, específicamente o comportamento das aves conhecido como flocking. Assim como no artigo anterior, na camada multiagentes os nós da DHT também são transformados em agentes. Na camada de dispositivos, os nós (denominados dispositivos), que representam as aves, utilizam o conceito de borda do grupo, diminuindo as mensagens enviadas à camada multiagentes, aumentando a escalabilidade da arquitetura.

3. (ROCHA; BRANDãO, 2017).

Esse resumo estendido apresenta a arquitetura de duas camadas para o cenário de monitoramento de sensores em geral (e.g., biodiversidade, pessoas, etc.) definindo brevemente as atividades a serem realizadas pelos agentes e pelos dispositivos. No caso dos agentes, apresenta-se a atividade de criação de novos agentes, que permite distribuir as requisições entre eles caso a escalabilidade esteja sendo afetada.

4. (ROCHA; BRANDãO, 2018).

Esse artigo, ainda em fase de avaliação, define conceitualmente a arquitetura e especifica os algoritmos necessários para executar as atividades mencionadas no resumo estendido. Além disso, descreve a arquitetura de uma forma geral, para que possa ser reutilizada em outros domínios.

\subsection{Trabalhos futuros}

Como desdobramentos desse trabalho propomos alguns tópicos com diversos níveis de dificuldade: 
- Desenvolver um algoritmo distribuído, executado pelos dispositivos, que permita gerar a fronteira de um grupo, evitando que essa geração seja realizada pelo agente.

- Estender o protocolo de roteamento da DHT para contornar a conexão intermitente dos dispositivos no cenário de sensores.

- Analisar se a utilização da fronteira no cenário de vídeo sob demanda aumenta o tempo para baixar o vídeo. Atualmente, no protocolo utilizado (Bittorrent), todos os membros do grupo enviam as informações ao agente responsável.

- Adicionar no modelo dos agentes o consumo de energia e analisar como isso afeta a execução de suas atividades.

- Reproduzir e analisar o comportamento dos usuários que utilizam sistemas de vídeo sob demanda, baseados em registros de uso (log) obtidos de repositórios públicos. 


\section{REFERÊNCIAS}

ABDELWAHAB, S. et al. Cloud of Things for Sensing as a Service: Sensing Resource Discovery and Virtualization. In: 2015 IEEE Global Communications Conference (GLOBECOM). [S.I.: s.n.], 2015. p. 1-7.

AGUILERA, M. K.; GOLAB, W.; SHAH, M. A. A practical scalable distributed b-tree. Proc. VLDB Endow., VLDB Endowment, v. 1, n. 1, p. 598-609, ago. 2008. ISSN 2150-8097. Disponível em: <http://dx.doi.org/10.14778/1453856.1453922>.

ALI, M.; LANGENDOEN, K. A Case for Peer-to-Peer Network Overlays in Sensor Networks. In: International Workshop on Wireless Sensor Network Architecture. [S.I.: s.n.], 2007. p. 56-61.

ALI, M.; UZMI, Z. CSN: a network protocol for serving dynamic queries in large-scale wireless sensor networks. In: Communication Networks and Services Research, 2004. Proceedings. Second Annual Conference on. [S.I.: s.n.], 2004. p. 165-174.

ALLIANCE, Z. ZigBee Specification 1.1. [S.I.], 2005.

Apache CouchDB. Apache CouchDB. 2017. Acessado em Novembro de 2017. Disponível em: <http://http://couchdb.apache.org>.

ASCHENBRUCK, N. et al. Bonnmotion: A mobility scenario generation and analysis tool. In: Proceedings of the 3rd International ICST Conference on Simulation Tools and Techniques. ICST, Brussels, Belgium, Belgium: ICST (Institute for Computer Sciences, Social-Informatics and Telecommunications Engineering), 2010. (SIMUTools '10), p. 51:1-51:10. ISBN 978-963-9799-87-5.

ASPNES, J.; SHAH, G. Skip graphs. ACM Trans. Algorithms, ACM, New York, NY, USA, v. 3, n. 4, nov. 2007. ISSN 1549-6325.

BADER, M. How to Construct Space-Filling Curves. In: Space-Filling Curves:

An Introduction with Applications in Scientific Computing. Berlin, Heidelberg: Springer Berlin Heidelberg, 2013. p. 15-30. ISBN 978-3-642-31046-1.

BAI, F.; SADAGOPAN, N.; HELMY, A. Important: a framework to systematically analyze the impact of mobility on performance of routing protocols for adhoc networks. In: IEEE INFOCOM 2003. Twenty-second Annual Joint Conference of the IEEE Computer and Communications Societies (IEEE Cat. No.03CH37428). [S.I.: s.n.], 2003. v. 2, p. 825-835 vol.2. ISSN 0743-166X.

BHATTACHARYA, A. et al. Temporal-DHT and Its Application in P2P-VoD Systems. In: Proc. of the IEEE ISM. [S.I.: s.n.], 2010. p. 81-88. ISBN 978-0-7695-4217-1.

BHATTACHARYA, A.; YANG, Z.; PAN, D. Popularity Awareness in Temporal-DHT for P2P-based Media Streaming Applications. In: 2011 IEEE International Symposium on Multimedia. [S.I.: s.n.], 2011. p. 241-248. 
BONDI, A. B. Characteristics of scalability and their impact on performance. In: Proceedings of the 2Nd International Workshop on Software and Performance. New York, NY, USA: ACM, 2000. (WOSP '00), p. 195-203. ISBN 1-58113-195-X. Disponível em: <http://doi.acm.org/10.1145/350391.350432>.

BORGIA, E. The Internet of Things vision: Key features, applications and open issues. Computer Communications, v. 54, p. 1-31, 2014. ISSN 0140-3664.

BRAM, C. Incentives Build Robustness in BitTorrent. [S.I.]: BITTORRENT, 2003.

BUFORD, J.; YU, H.; LUA, E. K. P2P Networking and Applications. San Francisco, CA, USA: Morgan Kaufmann Publishers Inc., 2008. ISBN 9780080921198 , 9780123742148.

CAMPO, C. Directory Facilitator and Service Discovery Agent. [S.I.], 2002.

CASTRO, M. et al. Topology-aware routing in structured peer-to-peer overlay networks. In: SCHIPER, A. et al. (Ed.). Future Directions in Distributed Computing. Springer Berlin Heidelberg, 2003, (Lecture Notes in Computer Science, v. 2584). p. 103-107. ISBN 978-3-540-00912-2. Disponível em: <http://dx.doi.org/10.1007/3-540-37795-6_19>.

CASTRO, P. A. L. de; SICHMAN, J. S. Automated asset management based on partially cooperative agents for a world of risks. Applied Intelligence, v. 38, n. 2, p. 210-225, Mar 2013. ISSN 1573-7497.

CHAWATHE, Y. et al. Making Gnutella-like P2P Systems Scalable. In: Proceedings of the 2003 Conference on Applications, Technologies, Architectures, and Protocols for Computer Communications. New York, NY, USA: ACM, 2003. (SIGCOMM '03), p. 407-418. ISBN 1-58113-735-4.

CHERKASOVA, L.; PHAAL, P. Session-based admission control: A mechanism for improving the performance of an overloaded web server. [S.I.], 1998.

$\mathrm{CHOI}, \mathrm{H}$. et al. TDM: Time-Driven Mesh Overlay Network for Peer-to-Peer Videoon-Demand Services. In: Proc. of CYBERC. [S.I.: s.n.], 2011. p. 100-106. ISBN 978-0-7695-4557-8.

CIANCAGLINI, V. From key-based to content-based routing : system interconnection and video streaming applications. Tese (Theses) - Université Nice Sophia Antipolis, jul. 2013. Disponível em: <https://tel.archives-ouvertes.fr/ tel-00875653>.

CISCO. Cisco Visual Networking Index: Forecast and Methodology, 20142019 White Paper. [S.I.], 2015. Disponível em: <http://www.cisco.com/c/en/us/ solutions/collateral/service-provider/ip-ngn-ip-next-generation-network/white_paper_ c11-481360.html>.

COHEN, B. The BitTorrent protocol specification. [S.I.]: BITTORRENT, 2008.

BitTorrent Protocol Specification 1.0. 2008. Acessado em Novembro de 2017. Disponível em: <https://wiki.theory.org/index.php/BitTorrentSpecification>. 
COULOURIS, G. et al. Distributed Systems: Concepts and Design. 5th. ed. USA: Addison-Wesley Publishing Company, 2011. ISBN 0132143011, 9780132143011.

DEKEL, E. Low-power Internet connectivity over Wi-Fi White Paper. [S.I.], 2016. Disponível em: <http://www.ti.com/lit/wp/swry019/swry019.pdf>.

DEMERS, A. et al. Epidemic Algorithms for Replicated Database Maintenance. In: Proceedings of the Sixth Annual ACM Symposium on Principles of Distributed Computing. New York, NY, USA: ACM, 1987. (PODC '87), p. 1-12. ISBN 0-89791-239-X.

DIJKSTRA, E. W. A Note on Two Problems in Connexion with Graphs. Numer. Math., Springer-Verlag New York, Inc., Secaucus, NJ, USA, v. 1, n. 1, p. 269-271, 1959.

DIMAKOPOULOS, V. V.; PITOURA, E. A Peer-to-Peer Approach to Resource Discovery in Multi-agent Systems. In: CIA. [S.I.]: Springer, 2003. (Lecture Notes in Computer Science, v. 2782), p. 62-77. ISBN 3-540-40798-7.

D'ORO, S. et al. Exploiting Object Group Localization in the Internet of Things: Performance Analysis. IEEE Transactions on Vehicular Technology, v. 64, n. 8, p. 3645-3656, 2015. ISSN 0018-9545.

DRESSLER, F. et al. From radio telemetry to ultra-low-power sensor networks: tracking bats in the wild. IEEE Communications Magazine, v. 54, n. 1, p. 129-135, January 2016.

EDELWEISS, N.; OLIVEIRA, J. de. Modelagem de Aspectos Temporais de Sistemas de Informação. [S.I.]: Recife, UFPE, 1994.

Ernesto Van der Sar. Top BitTorrent Trackers Serve 30 Million Peers Across 4.5 Million Torrents. 2016. Acessado em Novembro de 2016. Disponível em: <https://torrentfreak.com/ top-bittorrent-trackers-serve-30-million-peers-across-4-5-million-torrents-130706/>.

FORTINO, G. et al. Middlewares for Smart Objects and Smart Environments: Overview and Comparison. In: . Internet of Things Based on Smart Objects: Technology, Middleware and Applications. Cham: Springer International Publishing, 2014. p. 1-27. ISBN 978-3-319-00491-4.

A Discovery Service for Smart Objects over an Agent-Based Middleware.

In: Proceedings of 6th International Conference of the Internet and Distributed Computing Systems, IDCS 2013. Berlin, Heidelberg: Springer Berlin Heidelberg, 2013. p. 281-293. ISBN 978-3-642-41428-2.

GALLUCCIO, L. et al. On the potentials of object group localization in the Internet of Things. In: IEEE International Symposium on a World of Wireless, Mobile and Multimedia Networks. [S.I.: s.n.], 2011. p. 1-9.

GANESAN, P.; BAWA, M.; GARCIA-MOLINA, H. Online Balancing of Rangepartitioned Data with Applications to Peer-to-peer Systems. In: Proceedings of the Thirtieth International Conference on Very Large Data Bases - Volume 30. VLDB Endowment, 2004. (VLDB '04), p. 444-455. ISBN 0-12-088469-0. Disponível em: <http://dl.acm.org/citation.cfm?id=1316689.1316729>. 
GARCIA-MOLINA, H. Elections in a distributed computing system. IEEE Trans. Comput., IEEE Computer Society, Washington, DC, USA, v. 31, n. 1, p. 48-59, jan. 1982. ISSN 0018-9340.

GOOGLE. Youtube. 2017. Acessado em Novembro de 2017. Disponível em: <http://www.youtube.com.>

. Youtube Statistics. 2017. Acessado em Novembro de 2017. Disponível em: <http://www.youtube.com/yt/press/statistics.html.>

GRAHAM, R. L. An Efficient Algorithm for Determining the Convex Hull of a Finite Planar Set. Inf. Process. Lett., v. 1, n. 4, p. 132-133, 1972.

GUMMADI, K. P.; SAROIU, S.; GRIBBLE, S. D. King: Estimating Latency Between Arbitrary Internet End Hosts. In: Proc. of the Second ACM SIGCOMM Workshop on Internet measurment. [S.I.: s.n.], 2002. p. 5-18. ISBN 1-58113-603-X.

GUSELLA, R.; ZATTI, S. An Election Algorithm for a Distributed Clock Synchronization Program. [S.I.], 1985. Disponível em: <http://www2.eecs.berkeley. edu/Pubs/TechRpts/1985/6117.html>.

HARJULA, E. et al. ADHT: Agent-based DHT architecture for constrained devices. In: 2014 IEEE Global Communications Conference. [S.I.: s.n.], 2014. p. 2763-2769. ISSN 1930-529X.

HERNáNDEZ, M. E. P.; REIFF-MARGANIEC, S. Autonomous and Self Controlling Smart Objects for the Future Internet. In: 2015 3rd International Conference on Future Internet of Things and Cloud. [S.I.: s.n.], 2015. p. 301-308.

HUANG, L. Constructing Large Scale Cooperative Multi-Agent Systems from Semantic P2P Networks. In: Internet of Things and Inter-cooperative Computational Technologies for Collective Intelligence. Berlin, Heidelberg: Springer Berlin Heidelberg, 2013. p. 257-277. ISBN 978-3-642-34952-2.

IANCU, V.; STEGARU, S. C.; TUDOSE, D. S. A Smart City Fighting Pollution, by Efficiently Managing and Processing Big Data from Sensor Networks. In:

Resource Management for Big Data Platforms: Algorithms, Modelling, and High-Performance Computing Techniques. [S.I.]: Springer International Publishing, 2016. p. 489-513. ISBN 978-3-319-44881-7.

IEEE. 5.9 GHz Dedicated Short Range Communication (DSRC) Standards Development Update. 2017. Acessado em Setembro de 2017. Disponível em:


_03-10-02.ppt>.

JIMENEZ, R.; OSMANI, F.; KNUTSSON, B. Sub-Second lookups on a Large-Scale Kademlia-Based overlay. In: 11th IEEE Conference on Peer-to-Peer Computing. [S.I.: s.n.], 2011.

KAMBAYASHI, Y.; HARADA, Y. A Resource Discovery Method Based on Multi-agents in P2P Systems. In: Agent and Multi-Agent Systems: Technologies and Applications. [S.I.]: Springer, 2007, (Lecture Notes in Computer Science, v. 4496). p. 364-374. ISBN 978-3-540-72829-0. 
KAUR, N.; SOOD, S. K. An Energy-Efficient Architecture for the Internet of Things (IoT). IEEE Systems Journal, PP, n. 99, p. 1-10, 2015. ISSN 1932-8184.

KRISHNAMACHARI, B.; ESTRIN, D.; WICKER, S. B. The Impact of Data Aggregation in Wireless Sensor Networks. In: Proceedings of the 22Nd International Conference on Distributed Computing Systems. Washington, DC, USA: IEEE Computer Society, 2002. (ICDCSW '02), p. 575-578. ISBN 0-7695-1588-6.

Lalena. Flocking Behavior Simulator. 2016. Acessado em Novembro de 2016. Disponível em: <https://www.lalena.com/Al/Flock/>.

LEUF, B. Peer to Peer: Collaboration and Sharing over the Internet. Boston, MA, USA: Addison-Wesley Longman Publishing Co., Inc., 2002. ISBN 0201767325.

LIM, H.-K. C. P.-U. Clustered Segment Index Scheme for P2P VOD Service on Virtual Mesh Overlay Network. The transactions of The Korean Institute of Electrical Engineers, The Korean Institute of Electrical Engineers, 65, p. 1052-1059, 2016.

MANZANARES-LOPEZ, P. et al. An Efficient Distributed Discovery Service for EPCglobal Network in Nested Package Scenarios. J. Netw. Comput. Appl., Academic Press Ltd., London, UK, UK, v. 34, n. 3, p. 925-937, maio 2011. ISSN 1084-8045.

MEI, A.; STEFA, J. SWIM: A simple model to generate small mobile worlds. In: Proceedings of The 28th IEEE Conference on Computer Communications (INFOCOM 2009). Rio de Janeiro, Brazil: [s.n.], 2009. p. 2106-2113.

MONTRESOR, A.; JELASITY, M. PeerSim: A scalable P2P simulator. In: Proc. of the 9th Int. Conference on Peer-to-Peer (P2P'09). Seattle, WA: [s.n.], 2009. p. 99-100.

ORAM, A. (Ed.). Peer-to-Peer: Harnessing the Power of Disruptive Technologies. Sebastopol, CA, USA: O'Reilly \& Associates, Inc., 2001. ISBN 059600110X.

ORYńCZAK, G.; KOTULSKI, Z. Agent based infrastructure for real-time applications. Ann. UMCS, Inf., v. 11, n. 4, p. 33-47, jan. 2011. ISSN 1732-1360.

PAGANELLI, F.; PARLANTI, D. A DHT-Based Discovery Service for the Internet of Things. Journal Comp. Netw. and Communic., v. 2012, p. 107041:1-107041:11, 2012.

PAL, S. K. 21st century information technology revolution. Ubiquity, ACM, New York, NY, USA, v. 2008, n. June, p. 9:3-9:3, jun. 2008. ISSN 1530-2180. Disponível em: <http://doi.acm.org/10.1145/1399616.1399619>.

PARK, K. et al. Waterfall: Video distribution by cascading multiple swarms. Selected Areas in Communications, IEEE Journal on, v. 31, n. 9, p. 165-174, September 2013. ISSN 0733-8716.

RAJAGOPALAN, R.; VARSHNEY, P. K. Data-aggregation techniques in sensor networks: A survey. IEEE Communications Surveys Tutorials, v. 8, n. 4, p. 48-63, Fourth 2006. ISSN 1553-877X. 
REYNOLDS, C. W. Flocks, Herds and Schools: A Distributed Behavioral Model. SIGGRAPH Comput. Graph., ACM, New York, NY, USA, v. 21, n. 4, p. 25-34, ago. 1987. ISSN 0097-8930. Disponível em: <http://doi.acm.org/10.1145/37402.37406>.

RIPEANU, M.; IAMNITCHI, A.; FOSTER, I. Mapping the gnutella network. IEEE Internet Computing, IEEE Educational Activities Department, Piscataway, NJ, USA, v. 6, n. 1, p. 50-57, jan. 2002. ISSN 1089-7801. Disponível em: <http://dx.doi.org/10.1109/4236.978369>.

ROCHA, V.; BRANDãO, A. A. F. Towards conscientious peers: Combining agents and peers for efficient and scalable video segment retrieval for VoD services. EAAI, v. 45, p. $180-191,2015$.

. A Scalable Multiagent Architecture for Monitoring Biodiversity Scenarios. In: ADAMATTI, D. (Ed.). Multi-Agent Based Simulations Applied to Biological and Environmental Systems. Hershey, PA: IGI Global, 2016. cap. 4.

. MATe: Multiagent Architecture for Taming e-Devices. In: Proceedings of the 16th Conference on Autonomous Agents and MultiAgent Systems. Richland, SC: International Foundation for Autonomous Agents and Multiagent Systems, 2017. (AAMAS '17), p. 1716-1718.

Scalable Multiagent Architecture for monitoring IoT devices. EAAI (Em avaliação), 2018.

$\mathrm{ROCHA}$, V. et al. A hybrid cloud-P2P architecture for multimedia information retrieval on VoD services. Computing, v. 98, n. 1, p. 73-92, Jan 2016. ISSN 1436-5057.

RUSSELL, S.; NORVIG, P. Artificial Intelligence: A Modern Approach. 3rd. ed. Upper Saddle River, NJ, USA: Prentice Hall Press, 2009. ISBN 0136042597, 9780136042594.

SABLE, A. Comparative Study on IEEE Standard of WPAN 802.15.1/ 3/ 4. International Journal for Research in Emerging Science and Technology (IJREST), v. 1, n. 1, p. 25-27, 2014.

SCHMIDT, C.; PARASHAR, M. Flexible information discovery in decentralized distributed systems. In: High Performance Distributed Computing, 2003.

Proceedings. 12th IEEE International Symposium on. [S.I.: s.n.], 2003. p. 226-235. ISSN 1082-8907.

SCHROEDER, B.; HARCHOL-BALTER, M. Web Servers Under Overload: How Scheduling Can Help. ACM Trans. Internet Technol., ACM, New York, NY, USA, v. 6, n. 1, p. 20-52, fev. 2006. ISSN 1533-5399.

SEGHROUCHNI, A. E. F. et al. Ambient Intelligence Applications: Introducing the Campus Framework. In: 13th IEEE International Conference on Engineering of Complex Computer Systems (iceccs 2008). [S.I.: s.n.], 2008. p. 165-174.

SHEN, H. et al. A DHT-Aided Chunk-Driven Overlay for Scalable and Efficient Peer-to-Peer Live Streaming. In: 2010 39th International Conference on Parallel Processing. [S.I.: s.n.], 2010. p. 248-257. ISSN 0190-3918. 
SINGH, K.; SCHULZRINNE, H. Peer-to-peer internet telephony using sip. In: Proceedings of the International Workshop on Network and Operating Systems Support for Digital Audio and Video. New York, NY, USA: ACM, 2005. (NOSSDAV '05), p. 63-68. ISBN 1-58113-987-X. Disponível em: <http: //doi.acm.org/10.1145/1065983.1065999>.

SINHA, A. Client-server computing. Commun. ACM, ACM, New York, NY, USA, v. 35, n. 7, p. 77-98, jul. 1992. ISSN 0001-0782. Disponível em: <http: //doi.acm.org/10.1145/129902.129908>.

STOICA, I. et al. Chord: A Scalable Peer-to-peer Lookup Service for Internet Applications. In: Proceedings of the 2001 Conference on Applications, Technologies, Architectures, and Protocols for Computer Communications. New York, NY, USA: ACM, 2001. (SIGCOMM '01), p. 149-160. ISBN 1-58113-411-8. Disponível em: <http://doi.acm.org/10.1145/383059.383071>.

TANENBAUM, A. S.; STEEN, M. v. Distributed Systems: Principles and Paradigms (2Nd Edition). Upper Saddle River, NJ, USA: Prentice-Hall, Inc., 2006. ISBN 0132392275.

TANENBAUM, A. S.; WETHERALL, D. J. Computer Networks. 5th. ed. Upper Saddle River, NJ, USA: Prentice Hall Press, 2010. ISBN 0132126958, 9780132126953.

TANG, J. et al. An energy efficient hierarchical clustering index tree for facilitating time-correlated region queries in the Internet of Things. Journal of Network and Computer Applications, v. 40, p. 1-11, 2014. ISSN 1084-8045.

TANIN, E.; HARWOOD, A.; SAMET, H. Using a Distributed Quadtree Index in Peer-to-peer Networks. The VLDB Journal, Springer-Verlag New York, Inc., Secaucus, NJ, USA, v. 16, n. 2, p. 165-178, abr. 2007. ISSN 1066-8888. Disponível em: <http://dx.doi.org/10.1007/s00778-005-0001-y>.

TEKET, K.; SAYIT, M.; KARDAS, G. Software agents for peer-to-peer video streaming. Software, IET, v. 8, n. 4, p. 184-192, August 2014. ISSN 1751-8806.

THAALBI, M. et al. An enhanced chord-based P2P lookup protocol for mobile Ad hoc networks. In: 2011 IFIP Wireless Days (WD). [S.I.: s.n.], 2011. p. 1-5. ISSN 2156-9711.

. Enhanced Backtracking Chord protocol for mobile Ad hoc networks. In: Communications and Information Technology (ICCIT), 2012 International Conference on. [S.I.: s.n.], 2012. p. 191-195.

VU, Q. H.; LUPU, M.; OOI, B. C. Architecture of Peer-to-Peer Systems. In:

Peer-to-Peer Computing: Principles and Applications. Berlin, Heidelberg: Springer Berlin Heidelberg, 2010. p. 11-37. ISBN 978-3-642-03514-2.

WANG, J.; ZHU, Q.; MA, Y. An agent-based hybrid service delivery for coordinating internet of things and 3rd party service providers. Journal of Network and Computer Applications, v. 36, n. 6, p. $1684-1695$, 2013. ISSN 1084-8045. 
WANG, L.; KANGASHARJU, J. Measuring large-scale distributed systems: case of bittorrent mainline dht. In: Peer-to-Peer Computing (P2P), 2013 IEEE Thirteenth International Conference on. [S.I.: s.n.], 2013. p. 1-10.

Waze. About Waze. 2017. Acessado em Novembro de 2017. Disponível em: <https://support.google.com/waze/answer/6071177>.

WEISS, G. Multiagent Systems: A Modern Approach to Distributed Artificial Intelligence. 1st. ed. Cambridge, MA, USA: MIT Press, 2000. ISBN 0262731312.

WIRTH, N. Algorithms and Data Structures. Upper Saddle River, NJ, USA: Prentice-Hall, Inc., 1985. ISBN 0-13-022005-1.

WOOLDRIDGE, M. An Introduction to MultiAgent Systems. 2nd. ed. [S.I.]: Wiley Publishing, 2009. ISBN 0470519460, 9780470519462.

WOUNGANG, I. et al. MR-Chord: Improved Chord Lookup Performance in Structured Mobile P2P Networks. IEEE Systems Journal, v. 9, n. 3, p. 743-751, Sept 2015. ISSN 1932-8184.

WU, Y. et al. PeerTrack: A Platform for Tracking and Tracing Objects in Large-scale Traceability Networks. In: Proceedings of the 15th International Conference on Extending Database Technology. New York, NY, USA: ACM, 2012. (EDBT '12), p. 586-589. ISBN 978-1-4503-0790-1.

XU, H. et al. Peer Selection Strategy Using Mobile Agent and Trust in Peer-to-Peer Streaming Media System. International Journal of Distributed Sensor Networks, v. 9, n. 11, p. 791560, 2013.

YANG, D. et al. MPSS: A multi-agents based P2P-SIP real time stream sharing system. In: PRIMA. [S.I.]: Springer, 2006. (Lecture Notes in Computer Science, v. 4088$)$, p. $398-408$.

YILDIRIM, S.; SAYIT, M.; KARDAS, G. A belief-desire-intention agent architecture for partner selection in peer-to-peer live video streaming applications. Expert Systems, v. 32, n. 3, p. 327-343, 2015. ISSN 1468-0394.

YIU, W. P.; JIN, X.; CHAN, S. H. VMesh: Distributed Segment Storage for Peer-to-Peer Interactive Video Streaming. IEEE J.Sel. A. Commun., IEEE Press, Piscataway, NJ, USA, v. 25, n. 9, p. 1717-1731, dez. 2007. ISSN 0733-8716.

YU, J.; LIU, W.; SONG, J. C2WSN: A Two-Tier Chord Overlay Serving for Efficient Queries in Large-Scale Wireless Sensor Networks. In: Advanced Computing and Communications, 2007. ADCOM 2007. International Conference on. [S.I.: s.n.], 2007. p. 237-242.

YUJI, Y.; FUJITA, S. Hierarchical Architecture for Peer-to-Peer Video on Demand Systems with the Notion of Dynamic Swarms. IEICE Transactions on Information and Systems, E97.D, n. 12, p. 3025-3032, 2014.

ZAVE, P. How to make chord correct (using a stable base). CoRR, abs/1502.06461, 2015. 
ZHANG, C. et al. P2P-based Multidimensional Indexing Methods: A Survey. J. Syst. Softw., Elsevier Science Inc., v. 84, n. 12, p. 2348-2362, 2011. ISSN 0164-1212.

ZHAO, W. et al. A Distributed RFID Discovery System: Architecture, Component and Application. In: Computational Science and Engineering (CSE), 2011 IEEE 14th International Conference on. [S.I.: s.n.], 2011. p. 518-525.

ZHENG, C.; SHEN, G.; LI, S. Distributed prefetching scheme for random seek support in p2p streaming applications. In: Proc. of ACM P2PMMS Workshop. [S.I.: s.n.], 2005. p. 29-38. ISBN 1-59593-248-8.

ZHUO, C.; GANG, F.; YI, L. Improving the Video Data Lookup Efficiency in Peerto-Peer Live Streaming Network,. Journal of Advances in Computer Networks, IACSIT, Singapore, v. 1, n. 3, p. 157-161, dez. 2013. ISSN 1793-8244.

ZHUO, C. et al. Improving playback quality of peer-to-peer live streaming systems by joint scheduling and distributed hash table based compensation. China

Communications, v. 10, n. 6, p. 127-145, June 2013. ISSN 1673-5447. 


\section{APÊNDICE A - CONSTRUÇÃO DA ARQUITETURA}

A seguir veremos a construção das camadas, que se dá a partir da construção das responsabilidades da fronteira (camada de dispositivos) e das responsabilidades dos agentes (camada de agentes). Nas subseções seguintes detalhamos essa construção.

\section{A.1 Construção das responsabilidades do dispositivo}

Nesta subseção serão apresentados os algoritmos para cada uma das atividades executadas pelos dispositivos da fronteira descritas na seção 5.4.3. Vamos adotar que todos os algoritmos são executados pelo dispositivo $d_{i}$.

D1 O algoritmo da atualização da fronteira pode ser observado na Figura 44. No primeiro passo, o dispositivo $d_{i}$ requisita a cada um dos seus vizinhos suas respectivas localizações (Linhas 2-4) e as envia para o agente responsável pelo grupo (Linha 5). Considerando o nível de utilidade entregue pelo módulo de serviços (Linha 6) é realizada a rotação. Na rotação, o dispositivo se comunica com seus vizinhos $d_{f}$ que pertencem à fronteira, para saber qual deles aceitaria substituílo (Linhas 7-11). Cada vizinho verifica, através da sua função de utilidade, se pode ser responsável pela agregação, respondendo ao dispositivo $d_{i}$ se aceita ou não a substituição (Linha 8). O dispositivo $d_{i}$ escolhe dentre os que aceitaram e, a partir desse momento, deixa de executar a atividade de atualização, mesmo sendo parte da fronteira (Linhas 9-11).

D2 O algoritmo de divisão da borda pode ser observado na Figura 45. No primeiro passo, o dispositivo $d_{i}$ que pertence à borda verifica que seu vizinho mais próximo $d_{i+1}$, que também pertence à borda, deixou de ser seu vizinho, gerando uma 
Figura 44: Algoritmo de atualização da fronteira.

\section{1: DispositivoAtualizaFronteira()}

2: meus_vizinhos $\leftarrow$ obterVizinhos $\left(d_{i}\right)$

3: para cada dispositivo viz em meus_vizinhos

4: listaDispositivos.adiciona(viz, viz.loc)

5: enviaAtualização(agente, $d_{i}$ listaDispositivos)

6: se ModuloServico.analisaEstado() eh baixo

7: $\quad$ para cada $d_{f}$ em meus_vizinhos da fronteira

8: $\quad$ aceita $\leftarrow$ enviaSubstituição $\left(d_{f}\right)$

9: $\quad$ se aceita

10: $\quad$ notificaRotação $\left(d_{f}\right)$

11: $\quad$ pararAtualizações()

Fonte: Autor.

abertura (Linhas 2-4). Para preencher essa separação, $d_{i}$ inicia um procedimento guloso e recursivo que procura, dentre seus vizinhos, aquele dispositivo $d_{\min }$ cuja localização é a mais próxima de $d_{i+1}$ (Linha 5) e lhe envia uma requisição de preenchimento, com uma referência a $d_{i+1}$ (Linha 6). Em seguida, $d_{\min }$ executará o mesmo procedimento, até que o caminho entre $d_{i}$ e $d_{i+1}$ (ou algum dispositivo da borda) seja encontrado, notificando o agente desse novo caminho (Linhas 7-8). Como a estratégia é gulosa, caso não seja encontrado um caminho, o agente precisará ser notificado disto pelo dispositivo que iniciou o procedimento, isto é, por $d_{i}$ (Linhas 9-10).

Figura 45: Algoritmo de divisão da borda.

\section{1: DispositivoDivideBorda()}

2: se estouLocalizadoNaBorda

3: $\quad d_{i+1} \leftarrow$ obterVizinhoDaBorda $\left(d_{i}\right)$

4: $\quad$ se não existeConexão $\left(d_{i}, d_{i+1}\right)$

5: $\quad d_{\min } \leftarrow$ obterVizinhoMaisPróximo $\left(d_{i+1}\right)$

6: $\quad$ preencheu $\leftarrow$ preencheSeparação $\left(d_{\min }, d_{i+1}\right)$

7: $\quad$ se preencheu

8: $\quad$ enviaNovoCaminho(agente, $d_{i}, d_{i+1}$ )

9: $\quad$ senão

10: $\quad$ enviaSeparação(agente, $d_{i}, d_{i+1}$ )

Fonte: Autor.

D3 O algoritmo da atualização de vizinhos pode ser observado na Figura 46 . No primeiro passo, como entrada do algoritmo, o dispositivo $d_{i}$ recebe uma lista $L$ 
de dispositivos passíveis de serem seus vizinhos (Linha 1). Em seguida, acrescentamos aos vizinhos de $d_{i}$ cada $d_{L} \in L$ tal que exista uma conexão entre eles (Linhas 3-4). Depois disso, obtemos todos os vizinhos de $d_{L}$ (Linha 5) e os adicionamos à $L$ (Linha 6). Finalmente, a atualização acaba quando a quantidade de vizinhos em $d_{i}$ atinja um valor predeterminado (Linhas 7-8).

Figura 46: Algoritmo de atualização de conexões.

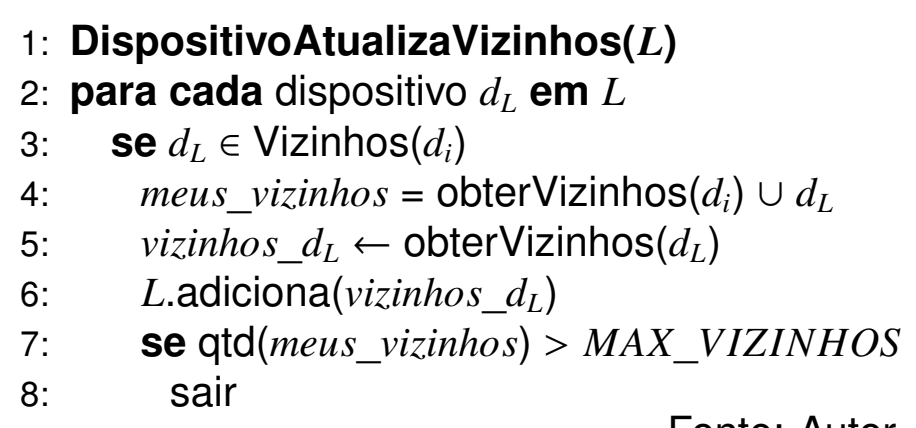

Fonte: Autor.

D4 O algoritmo de agentificação pode ser observado na Figura 47. No primeiro passo, como entrada do algoritmo, o dispositivo $d_{i}$ recebe: uma lista de dispositivos grupo da qual será encarregado de gerenciar quando for agentificado; uma lista de agentes que serão seus relacionamentos sequenciais seqs e o agente $a_{r}$ que fez o pedido de agentificação (Linha 1). Caso o nível de utilidade entregue a $d_{i}$ pelo módulo de serviço indique que pode atuar como agente, cria o agente utilizando os parâmetros recebidos (Linhas 2-4). Cabe destacar que a criação do agente (Linha 4) constrói e inicializa os módulos de bordas, sequencial e de saltos do agente. Depois disso, como $d_{i}$ já terá responsabilidade de agente, o dispositivo tenta ser rotacionado por um vizinho da fronteira (Linhas 5-8). Finalmente, o dispositivo deve parar de executar a atividade de atualização, mesmo sendo parte da fronteira, para evitar que seu nível de utilidade diminua (Linhas 9).

\section{A.2 Construção das responsabilidades do agente}

Nesta subseção serão apresentados os algoritmos para cada um das atividades executadas pelos agentes descritas na seção 5.5.3. Vamos adotar que todos os algoritmos são executados pelo agente $a$. 
Figura 47: Algoritmo de agentificação.

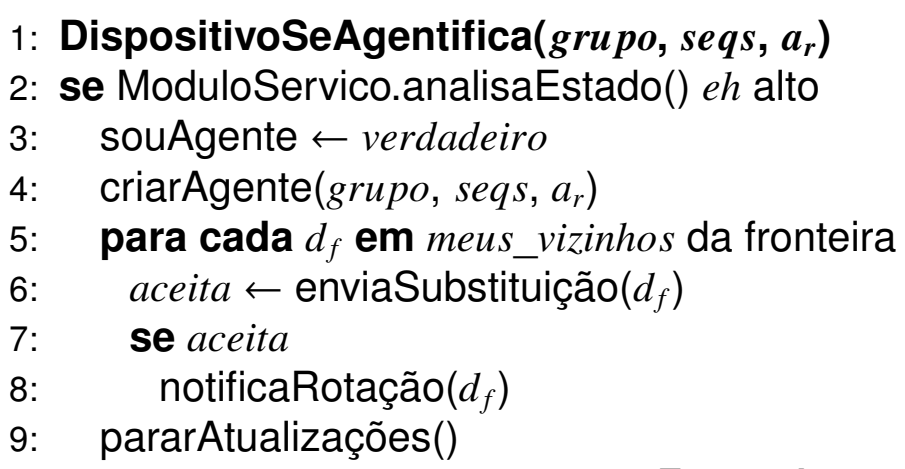

Fonte: Autor.

A1 O algoritmo de busca por uma localização pode ser observado na Figura 48. No primeiro passo, como entrada do algoritmo, o agente $a$ recebe tanto a localização procurada loc quanto o dispositivo $d_{i}$ que solicita a busca e o agente $a_{r}$ que iniciou a busca $^{1}$ (Linha 1). Caso essa localização esteja no interior das bordas gerenciadas pelo agente $a$ ou dos setores onde elas estão localizadas, a notifica ao dispositivo $d_{i}$ que será responsável por gerenciar essa localização (Linhas 2-4). Caso contrário, o agente obtém da sua tabela de roteamento aquele agente $a_{c}$, cujo setor esteja mais próximo à localização procurada, reenviando-lhe o pedido de busca. O agente $a_{c}$, por sua vez, repetirá o algoritmo até encontrar o agente $a_{i}$ responsável pelo setor (Linhas 5-7). Finalmente, caso o número de buscas pela localização loc tenha atingido uma quantidade limite de vezes, o agente $a$ altera o registro do agente $a_{c}$ por aquele responsável pela localização, isto é, $a_{i}$ (Linhas 8-9).

A2 O algoritmo de monitoramento de dispositivos pode ser observado na Figura 49. No primeiro passo, o agente verifica se a quantidade de dispositivos que fazem parte da fronteira é maior que um determinado valor, que poderia comprometer sua escalabilidade (Linhas 2-3). Se for maior, i.e., se o estado do agente analisado pela função de utilidade do Módulo de Bordas for baixo, o agente escolhe alguns desses dispositivos e lhes notifica para que não enviem as informações da fronteira (Linhas 4-6). Cabe destacar que a escolha será baseada na distância que tenham os dispositivos entre si. Nesse sentido, se dois dispositivos estiverem muito próximos (Linha 5), as informações coletadas poderiam ter va-

\footnotetext{
${ }^{1}$ Se a busca for a primeira a ser executada, então $a=a_{r}$.
} 
Figura 48: Algoritmo de busca por uma localização.



Fonte: Autor.

lores semelhantes, o que permitirá eliminar um deles visando a escalabilidade (Linha 6). Finalmente, o agente elimina os dispositivos que fazem parte da fronteira, mas que não estão enviando as informações coletadas (Linhas 7-9).

Figura 49: Algoritmo de monitoramento do grupo.

\section{1: AgenteMonitoraGrupo()}

2: fronteira $\leftarrow$ obterDispositivosFronteira

3: se ModuloBordas.analisaEstado(fronteira) eh baixo

4: $\quad$ para cada par $d_{i}, d_{i+1}$ tal que $d_{i} \in$ fronteira e $d_{i+1} \in$ fronteira

5: $\quad$ se Distância $\left(d_{i}, d_{i+1}\right)<\delta$

6: $\quad$ eliminarFronteira $\left(d_{i+1}\right)$

7: para cada dispositivo $d$ na fronteira

8: $\quad$ se $d$ não enviou informações

9: $\quad$ eliminarDoGrupo $(d)$

Fonte: Autor.

A3 O algoritmo de atualização da fronteira pode ser observado na Figura 50 . No primeiro passo, como entrada do algoritmo, o agente recebe as localizações agregadas por um dispositivo da fronteira, oriundas da Linha 5 da atividade D1 (Linha 1). Com essas informações, o agente obtém a localização do dispositivo $d_{i}$ (Linha 3), atualiza a fronteira com essa nova localização (Linha 4) e notifica seus relacionamentos sequenciais sobre a nova fronteira coberta (Linhas 5-6).

A4 $\mathrm{O}$ algoritmo de junção de grupos pode ser observado na Figura 51. No primeiro passo, como entrada do algoritmo, o agente a recebe uma lista de bordas bordas e o agente $a_{r}$ responsável por elas (Linha 1). Caso uma das bordas dessa lista 
Figura 50: Algoritmo de atualização da fronteira.

\section{1: AgenteAtualizaFronteira(listaDispositivos) \\ 2: para cada $d_{i}$ em listaDispositivos \\ 3: $\quad l o c_{i} \leftarrow d_{i}$.loc \\ 4: $\quad$ fronteira $\leftarrow$ atualizarFronteira $\left(l o c_{i}\right)$ \\ 5: sequenciais $\leftarrow$ obterRelSequenciais \\ 6: notificarNovaFronteira(sequenciais, fronteira)}

Fonte: Autor.

intersecte uma das bordas gerenciadas pelo agente $a$, essa borda será denominada $B$ (Linhas 3-4). O agente $a$ troca com $a_{r}$ a quantidade de dispositivos existentes na fronteira e analisa a possibilidade de juntar as bordas. Isto é feito verificando se a soma dos dispositivos da fronteira é maior que um valor que comprometeria a escalabilidade do agente (Linhas 5-7). Se a junção é possível e pode ser gerenciada por ambos agentes, escolhe-se um deles (vamos supor que seja o mesmo $a$ ), que será responsável por atualizar a nova fronteira formada pela junção (Linhas 8-9) e notificar seus relacionamentos sequenciais dessa informação (Linha 10). Por outro lado, o agente $a_{r}$ que não foi escolhido deverá notificar seus relacionamentos sequenciais que devem apontar para $a_{i}$, para finalmente sair do repositório global (Linha 11).

Figura 51: Algoritmo de junção de grupos.

\section{1: AgenteUneGrupos(bordas, $\left.\boldsymbol{a}_{r}\right)$}

2: minhas_bordas $\leftarrow$ obterMinhasBordas()

3: se existelntersecção(bordas, minhas_bordas)

4: $\quad B \leftarrow$ obterlntersecção(bordas, minhas_bordas)

5: $\quad f_{r} \leftarrow$ obterDispositivosFronteira $\left(a_{r}, B\right)$

6: $\quad f_{a} \leftarrow$ obterDispositivosFronteira $(a, B)$

7: $\quad$ se ModuloBordas.analisaEstado $\left(f_{r}, f_{a}\right)$ eh alto

8: $\quad$ grupo $\leftarrow$ obterTodosDispositivos $\left(a_{r}, B\right)$

9: $\quad$ fronteira $\leftarrow$ AgenteAtualizaFronteira(grupo)

10: $\quad$ notificarNovaFronteira(sequenciais, fronteira)

11: $\quad$ atualizarGrupoEliminarAgente $\left(a, a_{r}\right)$

Fonte: Autor.

A5 O algoritmo de separação do grupo pode ser observado na Figura 52. No primeiro passo, como entrada do algoritmo, o agente recebe, de um dos dispositivos da borda, os dois dispositivos $d_{1}$ e $d_{2}$ que estão gerando a possível separação, 
oriundo da Linha 10 da atividade D2 (Linha 1). De posse das localizações dos dispositivos, o agente verifica se outros dispositivos, também notificaram sobre essa separação (Linhas 2-4). Se assim for, o agente verifica se existe um caminho alternativo entre $d_{1}$ e $d_{2}$ (cabe destacar que, como o agente conhece todos os dispositivos da fronteira, pode ser que exista um caminho que não foi encontrado pela execução da atividade D2 (de percepção de abertura da borda) (Linha 5). Se existir, o agente notifica os dispositivos do caminho que fazem parte da borda e atualiza a fronteira (Linhas 6-9). Caso contrário, o agente deve dividir o grupo em dois (Linhas 10-11).

Figura 52: Algoritmo de separação do grupo (verificação).

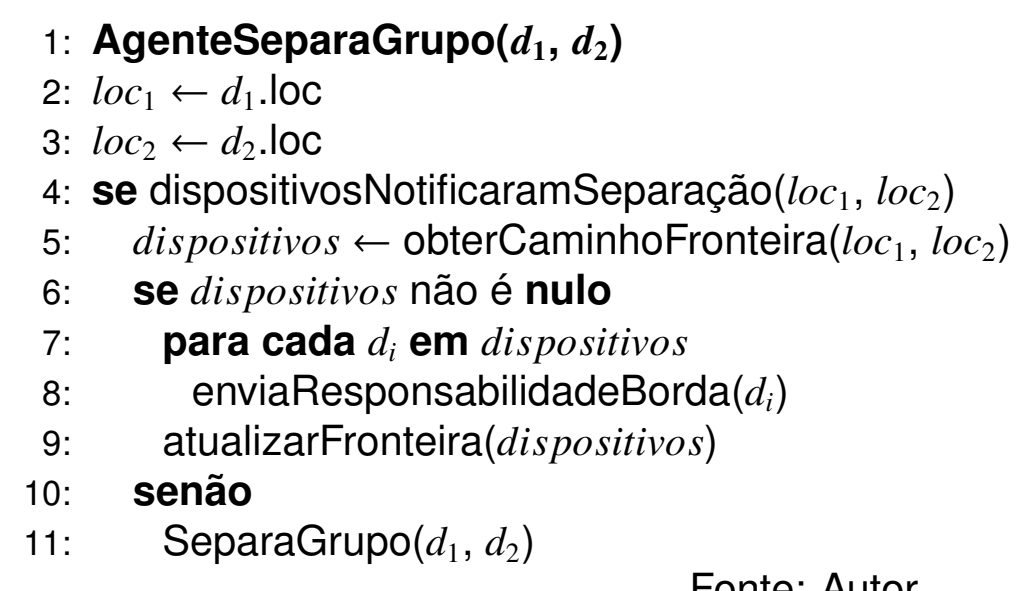

Fonte: Autor.

Como o método SeparaGrupo da linha 11 é completamente dependente do cenário onde será implantada a arquitetura, será implementado na Seção B.1 e B.2 para os cenários de monitoração de sensores e de vídeo sob demanda, respectivamente.

A6 O algoritmo de divisão do grupo pode ser observado na Figura 53. No primeiro passo, assim como na atividade A2, o agente verifica se a quantidade de dispositivos da fronteira (com suas respectivas quantidades de requisições) é maior que um determinado valor (Linhas 2-3). Se for maior, i.e., se o estado do agente analisado pela função de utilidade do Módulo de Bordas for baixo, o agente pode encontrar os dois dispositivos $d_{1}$ e $d_{2}$ cuja atividade de separação divida aproximadamente na metade a quantidade de dispositivos do grupo (Linha 4), utilizando o mesmo algoritmo de divisão da atividade A5 (Linha 5). 
Figura 53: Algoritmo de divisão do grupo.

\section{1: AgenteDivideGrupo()}

2: fronteira $\leftarrow$ obterDispositivosFronteira

3: se ModuloBordas.analisaEstado(fronteira) eh baixo

4: $\quad d_{1}, d_{2} \leftarrow$ obterDispositivosParaSeparação

5: $\quad$ SeparaGrupo $\left(d_{1}, d_{2}\right)$

Fonte: Autor. 


\section{APÊNDICE B - CONSTRUÇÃO DA SEPARAÇẪO DE UM GRUPO}

A seguir veremos o algoritmo que permite separar um grupo no cenário de monitoramento de sensores e no de vídeo sob demanda.

\section{B.1 Cenário de monitoramento de sensores}

A implementação do algoritmo que permite separar um grupo em dois para o cenário de monitoramento de sensores é mostrada na Figura 54. No primeiro passo, o agente $a_{i}$ recebe os dois dispositivos $d_{1}$ e $d_{2}$ que estão gerando a separação (Linha 1). Em seguida, o agente deve encontrar um dispositivo que pertence à borda (chamemos ele de $d_{p}$ ) cuja localização está aproximadamente na perpendicular do segmento de reta formado por $d_{1}$ e $d_{2}$, como mostrado na linha vermelha do exemplo da Figura 55(a) (Linhas 2-4). Em posse de $d_{p}$ o agente tenta encontrar o caminho $c_{a m}$ que existe entre $d_{1}$ e $d_{p}$ (denotemos $d_{a}$ o último dispositivo de $c a m_{1}$ ) e o caminho cam $_{2}$ entre $d_{2}$ e $d_{p}$ (denotemos $d_{b}$ o último dispositivo de $\operatorname{cam}_{2}$ ) (Linhas 5-7) e analisar se esses caminhos se intersectaram em algum dispositivo antes de chegar a $d_{p}$ (Linha 8). Se os caminhos se intersectam antes, significa que não será necessária uma divisão do grupo, como o exemplo mostrado na Figura 55(b). Assim, o agente notifica aos dispositivos do caminho, que eles fazem parte da borda, atualizando a fronteira (Linhas 9-12). Caso contrário, existem quatro situações a serem analisadas:

a) os dispositivos $d_{a}$ e $d_{b}$ pertencem à borda (Linha 14); b) o dispositivo $d_{a}$ pertence à borda e $d_{b}$ não (Linha 20); c) o dispositivo $d_{a}$ não pertence à borda e $d_{b}$ sim (Linha 23); d) ambos dispositivos não pertecem à borda (Linha 26). Em a), o grupo será dividido em dois, um cuja borda compreende $d_{1}, d_{a}$ e $d_{1}$ e a outra que compreende $d_{2}, d_{b}$ e $d_{2}$, como mostra a Figura 56(a) (Linhas 15-16). A seguir, o agente deve criar 
um novo agente (responsável por gerenciar um dos grupos) e eliminar os dispositivos da borda que se encontram localizados entre $d_{a}$ e $d_{b}$ (Linhas 17-19). Finalmente, o agente deve atualizar a fronteira coberta pelas novas bordas, notificar os dispositivos das novas fronteiras formadas pela divisão e notificar os relacionamentos sequenciais (Linhas 28-31). Em b), o grupo somente será restringido à borda que compreende $d_{1}, d_{a}$ e $d_{1}$, como mostra a Figura 56(b) (Linha 21) e eliminar os dispositivos da borda que se encontram localizados entre $d_{a}$ e $d_{2}$ (Linha 22) Note que, como os dispositivos no caminho entre $d_{2}$ e $d_{b}$ não foram notificados como sendo parte da borda, não será necessário eliminá-los da mesma. Em seguida, ao igual que no caso anterior, o agente deve atualizar a fronteira coberta pelas nova borda, notificar os dispositivos da nova fronteira e notificar os relacionamentos sequenciais (Linhas 28-31). Em c), os passos são similares ao caso b), mas para a borda que compreende $d_{2}, d_{b}$ e $d_{2}$, como mostra a Figura 56(c) (Linha 24-25). Finalmente, em d), a borda entre $d_{1}$ e $d_{2}$ deverá ser eliminada completamente, dado que não existem nenhum caminho que feche a borda, como mostra a Figura 56(d) (Linha 27). Nesse caso, a borda deverá ser gerada novamente.

\section{B.2 Cenário de vídeo sob demanda}

A implementação do algoritmo que permite separar um grupo em dois para o cenário de vídeo sob demanda é mostrada na Figura 57. No primeiro passo, o agente $a_{i}$ recebe os dois dispositivos $d_{1}$ e $d_{2}$ que estão gerando a separação (Linha 1). A seguir, o agente deve encontrar o segmento $s_{i}$ que está gerando a separação da borda, dada as localizações dos dispositivos (Linhas 2-4). Após descoberto o segmento, o agente obtém qual é o intervalo $\left[s_{i n i}, s_{\text {fim }}\right]$ de segmentos gerenciados, isto é, qual é o identificador do menor e do maior segmento que foram baixados pelos dispositivos que gerencia (Linha 5). Em posse disso, o agente divide o grupo em duas partes, uma cuja borda compreende $s_{i n i}$ até $s_{i-1}$ (Linha 6) e a outra borda que compreende $s_{i+1}$ até $s_{\text {fim }}$ (Linha 7). Finalmente, o agente deve criar um novo agente (responsável por gerenciar um dos grupos), atualizar a fronteira coberta pelas novas bordas, notificar os dispositivos das novas fronteiras formadas pela divisão e notificar os relacionamentos sequenciais (Linhas 8-12). 
Figura 54: Algoritmo de separação do grupo.

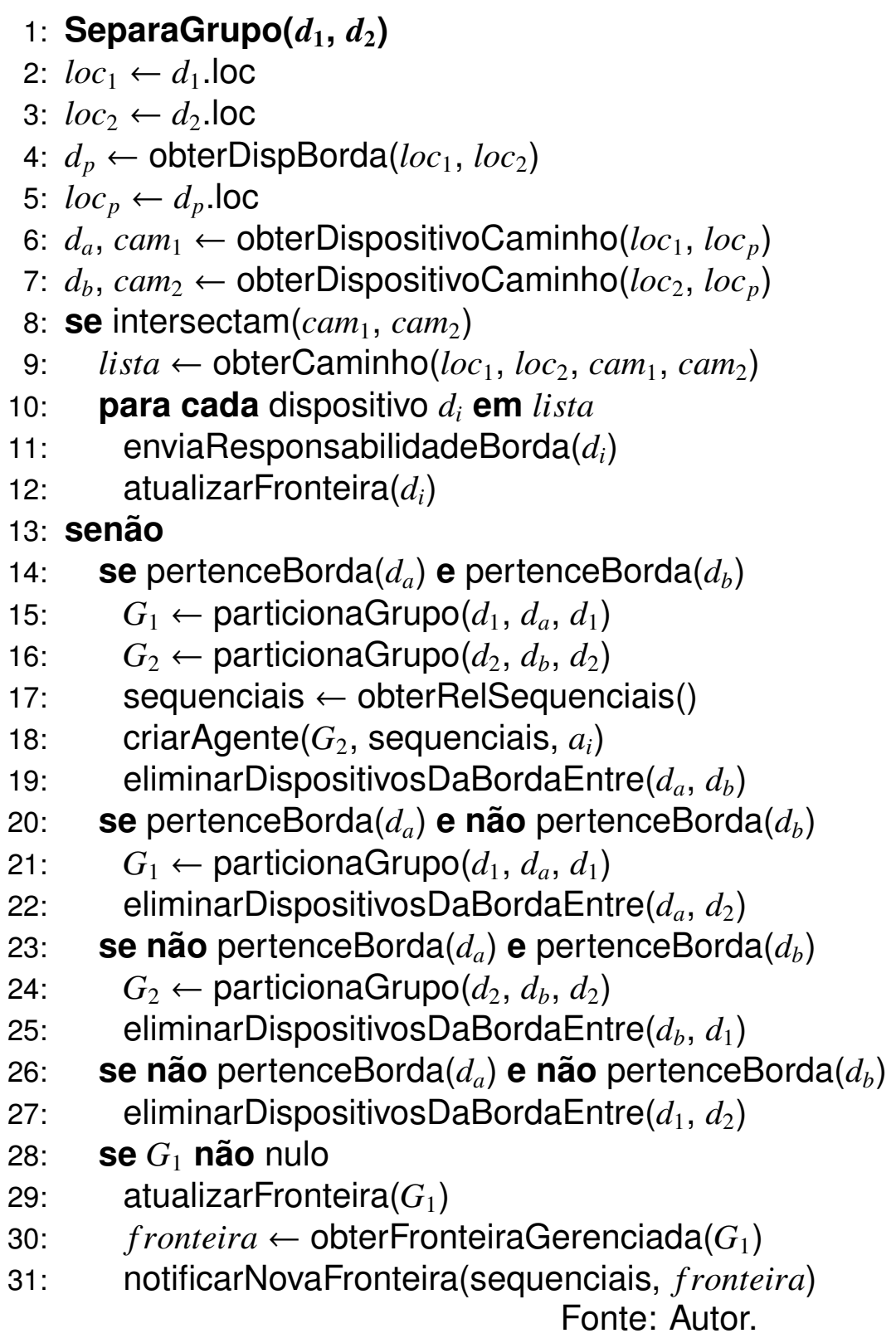

Na Figura 58(a) pode-se observar que o segmento $s_{i}$ com valor 5 gera uma separação no intervalo [1,7] (inicialmente, a borda possuia todos os segmentos, como mostrado na Figura 29). Após a aplicação do método SeparaGrupo, serão formados os grupos $G_{1}$, com o intervalo [1,4], e $G_{2}$ com o intervalo [6,7], como mostrado na Figura 58(b). 
Figura 55: Divisão do grupo.

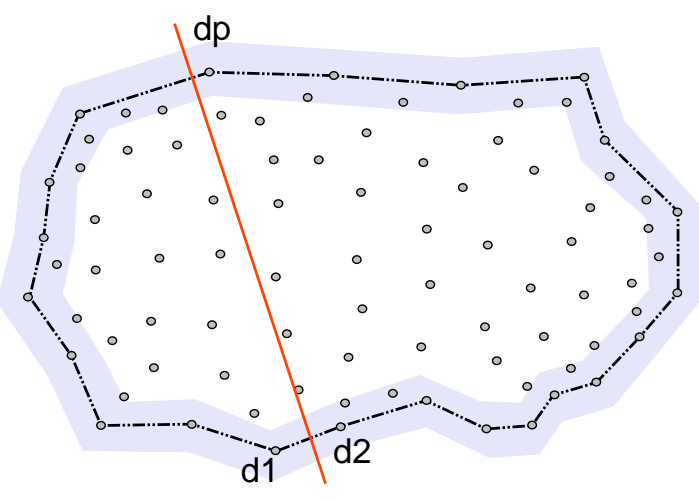

(a) Encontrando o nó $d_{p}$.

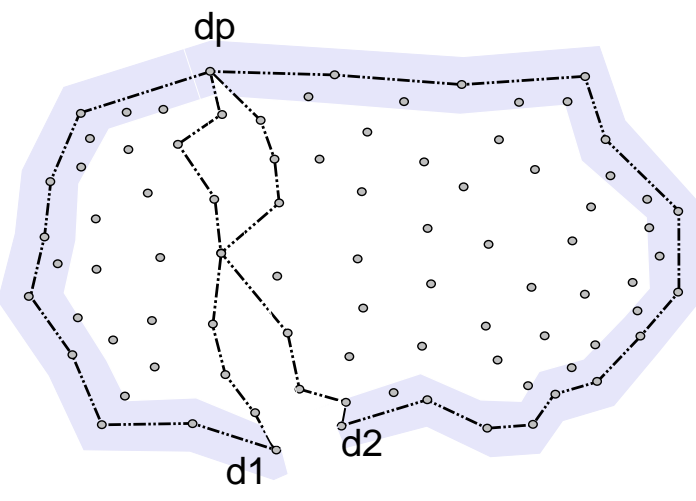

(b) Intersecção de caminhos.

Fonte: Autor.

Figura 56: Casos a-d na divisão do grupo.



(a) $d_{a} \in$ Borda e $d_{b} \in$ Borda.

$\mathrm{dp} \quad \mathrm{db}$

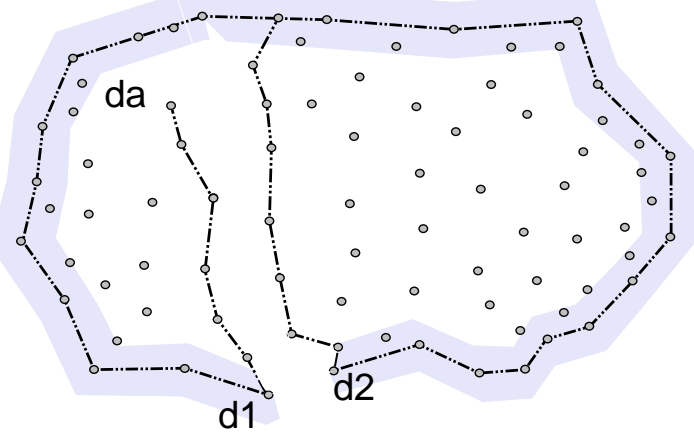

(c) $d_{a} \notin$ Borda e $d_{b} \in$ Borda.

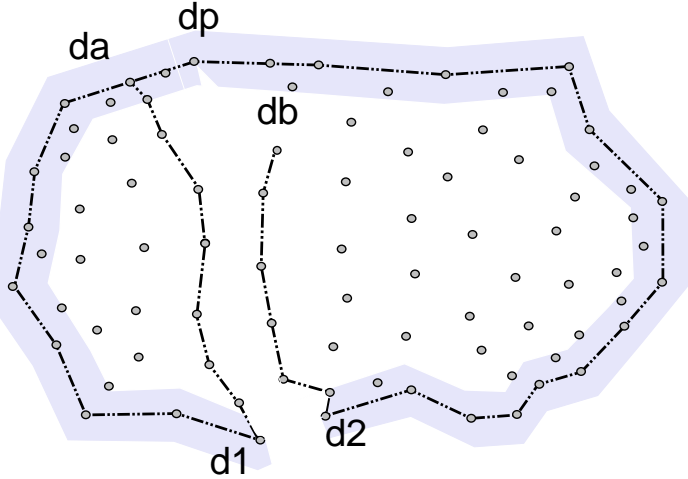

(b) $d_{a} \in$ Borda e $d_{b} \notin$ Borda. $\mathrm{dp}$

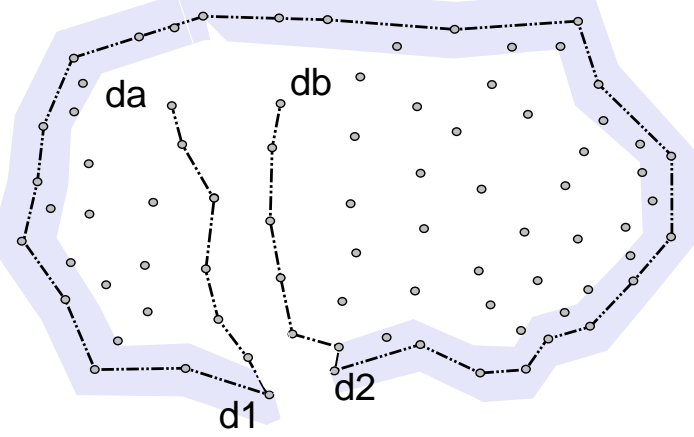

(d) $d_{a} \notin$ Borda e $d_{b} \notin$ Borda.

Fonte: Autor. 
Figura 57: Algoritmo de separação do grupo.

1: SeparaGrupo $\left(d_{1}, d_{2}\right)$

2: $l o c_{1} \leftarrow d_{1}$.loc

3: $l o c_{2} \leftarrow d_{2}$.loc

4: $s_{i} \leftarrow$ obterSegmentoSeparação $\left(l o c_{1}, l o c_{2}\right)$

5: $s_{i n i}, s_{\text {fim }} \leftarrow$ obterIntervaloGerenciado()

6: $G_{1} \leftarrow$ particionaGrupo $\left(s_{i n i}, s_{i-1}\right)$

7: $G_{2} \leftarrow$ particionaGrupo $\left(s_{i+1}, s_{f i m}\right)$

8: sequenciais $\leftarrow$ obterRelSequenciais()

9: criarAgente $\left(G_{2}\right.$, sequenciais, $\left.a_{i}\right)$

10: atualizarFronteira $\left(G_{1}\right)$

11: fronteira $\leftarrow$ obterFronteiraGerenciada $\left(G_{1}\right)$

12: notificarNovaFronteira(sequenciais, fronteira)

Fonte: Autor. 
Figura 58: Divisão do grupo.

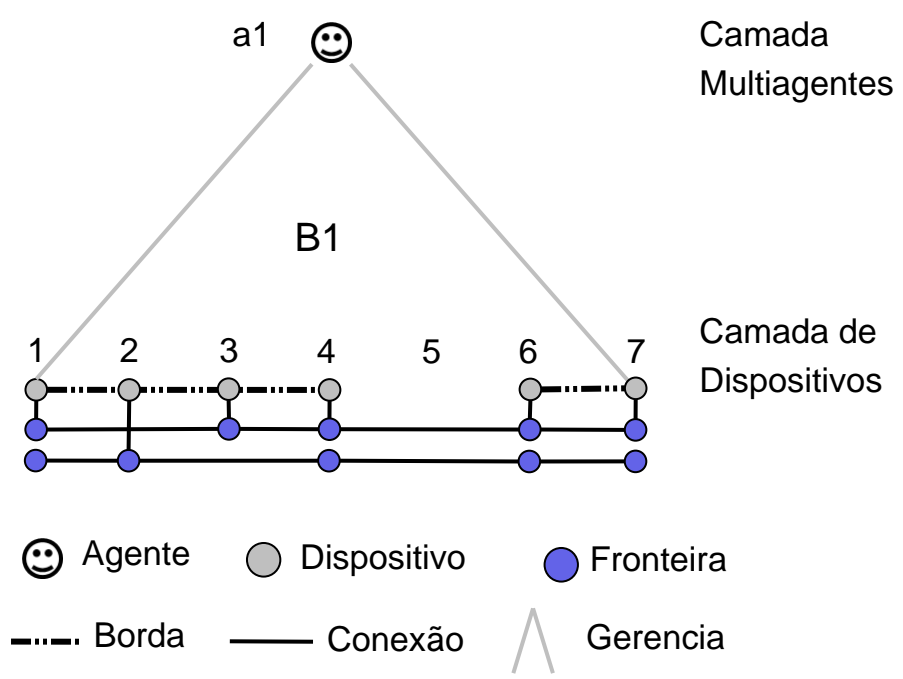

(a) Segmento 5 gerando a divisão.

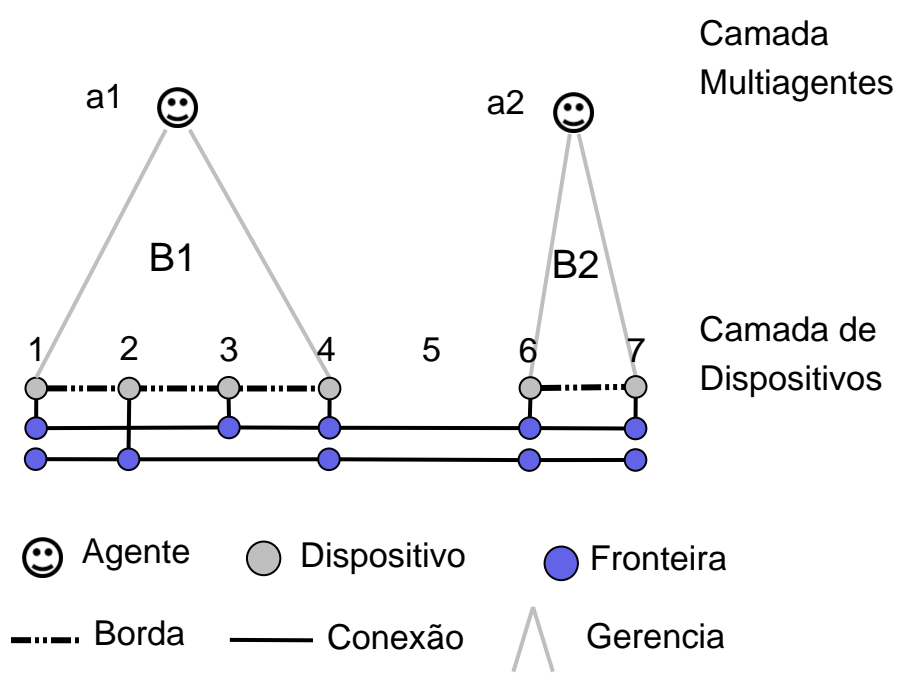

(b) Dividindo o grupo em dois.

Fonte: Autor. 